\title{
LA FORMACIÓN PROFESIONAL INTEGRAL EN LOS EGRESADOS 2014-2015 DEL CENTRO DE BIOTECNOLOGIA AGROPECUARIA SENA - MOSQUERA
}

CLARA GLADYS CLAVIJO SABOGAL

UNIVERSIDAD SANTO TOMÁS

FACULTAD SOCIOLOGÍA

TRABAJO DE GRADO

BOGOTÁ

2017 


\title{
LA FORMACIÓN PROFESIONAL INTEGRAL EN LOS EGRESADOS 2014-2015 DEL CENTRO DE BIOTECNOLOGIA AGROPECUARIA SENA - MOSQUERA
}

\section{CLARA GLADYS CLAVIJO SABOGAL}

Código: 2176422

\author{
Directora: \\ LUISA NATALIA CARUSO
}

Trabajo de grado para optar el título de Magister en Planeación para el Desarrollo

UNIVERSIDAD SANTO TOMÁS

FACULTAD SOCIOLOGÍA

TRABAJO DE GRADO

BOGOTÁ

2017 
Tabla de contenido

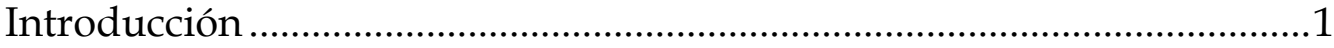

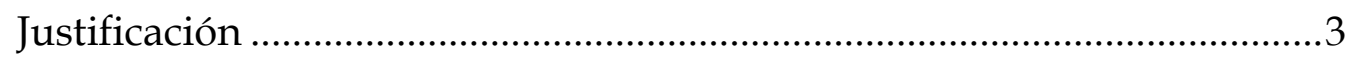

Pregunta de Investigación......................................................................

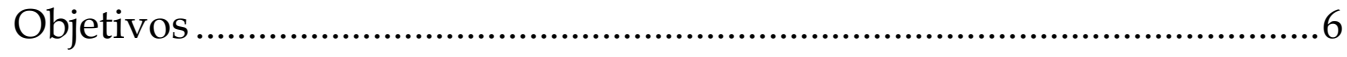

Aspectos Metodológicos.......................................................................

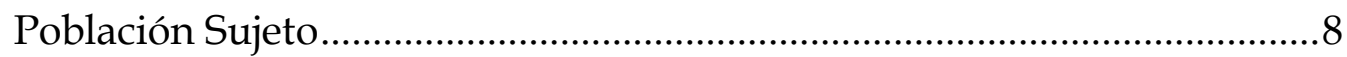

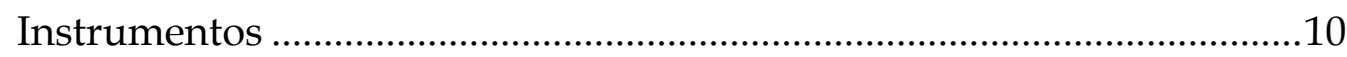

1. LA FORMACIÓN TÉCNICA DEL SENA: PROPUESTA DE CAPITAL HUMANO Y DESARROLLO HUMANO INTEGRAL

1.1. Acercamiento al concepto de Capital Humano y Desarrollo Humano Integral ...........................................................................12

1.1.1. Capital Humano: Ambigüedad y Oportunidad ......................12

1.1.2. Desarrollo Humano Integral un concepto de construcción.21

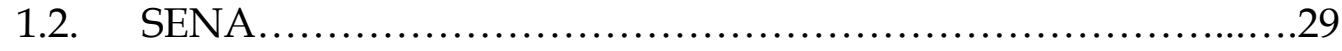

1.2.1. SENA Entidad de Formación para el Trabajo.................32

1.2.2. La propuesta SENA: Formación Profesional Integral .........37

2. EL ENTORNO DE LOS APRENDICES SENA

2.1. Enfoque de la Formación SENA ……………………………….......42

2.2. Caracterización de Aprendices ....................................46

3. CAMBIOS OBSERVADOS EN LA TRANSICIÓN DE APRENDICES A EGRESADOS

3.1. Situación de los Egresados .......................................55

3.2. Variaciones en la Vida de los Aprendices-Egresados ............64

CONCLUSIONES................................................... 70

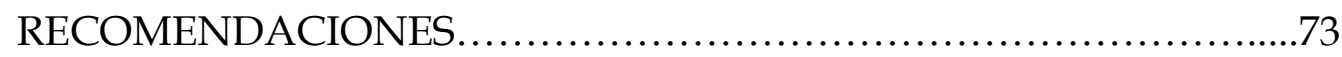


BIBLIOGRAFÍA.................................................74 ANEXOS

Anexo 1 Bases de Datos............................................78

Anexo 2 Encuesta Social de Caracterización ó Ficha de Caracterización Anexo 3 Encuesta de Egresados..................................... 93 
Tabla de gráficos

Gráfico No.1 Sexo-Rango de edad de los aprendices.............................47

Gráfico No.2 Municipio de residencia y procedencia ............................4

Gráfico No.3 Vivienda ..............................................................48

Gráfico No.4 Trabajo y estudio.........................................................49

Gráfico No.5 Afiliación a salud ...........................................................49

Gráfico No.6 Población vulnerable ...........................................................50

Gráfico No.7 Problemática de los aprendices .......................................50

Gráfico No.8 Fuente de ingresos ....................................................51

Gráfico No.9 Nivel de ingresos....................................52

Gráfico No.10 Actividades extra curriculares ........................................52

Gráfico No.11 Sexo-Rango de edad de los egresados .............................55

Gráfico No.12 Municipio de residencia y trabajo ...................................56

Gráfico No.13 Vivienda de egresados .................................................57

Gráfico No.14 Ocupación laboral .......................................................58

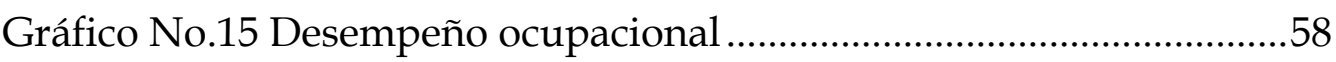

Gráfico No.16 Visión ocupacional y personal ........................................59

Gráfico No.17 Afiliación al sistema de salud .........................................60

Gráfico No.18 Ingresos mensuales ....................................................6 60

Gráfico No.19 Dificultad en usos de las competencias ..........................61

Gráfico No.20 Actividades extra labórales ..........................................61

Gráfico No.21 Afiliación al sistema de salud ........................................65

Gráfico No.22 Municipio de residencia aprendices y egresados ...........65 
Gráfico No.23 Vivienda aprendices y egresados ........................................66

Gráfico No.24 Ocupación de aprendices y egresados.................................67

Gráfico No.25 Nivel de ingresos de aprendices y egresados........... ...67

Gráfico No.26 Actividades extra curriculares y extra laborales.........68 


\section{RESUMEN}

Los aprendices SENA recibieron una formación técnica profesional y ahora son egresados, certificados para un desempeño laboral en el sector productivo, como técnicos profesionales en Recursos Humanos, Seguridad Ocupacional, y Nómina y Prestaciones Sociales, del Centro de Biotecnología Agropecuaria - Mosquera.

La investigación busca conocer los cambios que han tenido los egresados 2014 -2015 después de la terminación del proceso de formación técnica, tiene un enfoque cualitativo de tipo descriptivo.

Así mismo, identifica la formación del recurso humano, como generación de capital humano y la concepción del desarrollo humano integral visualizada en el análisis de la encuesta a egresados.

La identificación de los aprendices se obtuvo de la ficha de caracterización de ingreso y de la encuesta de egresados de la investigación, se deducen las transformaciones de los titulados; se trabajó con la muestra de la población objeto del $95 \%$ de confiabilidad y un margen de error del $5 \%$, con 224 aprendices que ingresaron a la formación y estos salieron como egresados.

Los cambios que se observaron en los egresados, están referenciados en: la afiliación al sistema de salud, la forma subsidiada disminuye significativamente y se incrementa la afiliación por cotización; traslado del lugar de residencia a los municipios con mayor tejido empresarial, algunos tienen casa propia, asoma la ocupación como independiente y los ingresos se incrementan.

Se concluye que la formación dada en la etapa lectiva y productiva, tiene estrecha relación con el concepto de capital humano; en los egresados se 
percibe aspectos relacionados en el Desarrollo Humano Integral, como satisfacción de necesidades humanas, auto dependencia, adquisición de inmuebles propios, cambio del lugar de residencia buscando una ocupación laboral y participación en diferentes organizaciones y brigadas.

El SENA a través de la Formación Profesional Integral propende por el Desarrollo Humano Integral, se basa en el despliegue de las capacidades del aprendiz, que le permitan al egresado actuar en forma crítica y proyectarse en su vida, esto se refleja cuando el titulado anhela tener la ocupación en la que fueron certificados y manifiestan su visión personal y ocupacional.

Palabras claves: capital humano, desarrollo humano integral, formación profesional integral.

\begin{abstract}
ABSTRAC
The SENA trainees received technical and professional training in the productive sector, such as technicians in Human Security, Occupational Safety, and Payroll and Social Benefits, of the Center of Agricultural Biotechnology - Mosquera.

The research seeks to know the changes that have had the graduates 2014 -2015 after the completion of the process of technical training, has a qualitative approach of descriptive type.

Likewise, it identifies the formation of human resources, such as the generation of human capital and the conception of the integral human development visualized in the analysis of the survey of graduates.

The identification of the learnings was obtained from the entry characterization form and from the survey of graduates of the research, the transformations of the graduates are deduced; it worked with the sample of
\end{abstract}


the population subject to $95 \%$ reliability and a margin of error of 5\%, with 224 apprentices who entered the training and these left as graduates.

The changes that were observed in the graduates, are referenced in: the affiliation to the health system, the subsidized form diminishes significantly and the affiliation by quotation increases; Transfer from the place of residence to the municipalities with the mayor weaving business, some have their own house, looks occupation as independent and income are increased.

It is concluded that the training given in the educational and productive stage has a close relationship with the concept of human capital; In Integral Human Development, as satisfaction of human needs, self-dependency, acquisition of own properties, change of place of residence looking for a job occupation and participation in different organizations and brigades.

The SENA through Integral Professional Training, is based on the deployment of the human resources capacities that the graduate permit acts critically and projected in their life, that is it reflects when the graduate desires to have the occupation in which he was certified and manifest his personal and occupational vision. 


\section{INTRODUCCIÓN}

El presente trabajo versa sobre la formación del recurso humano como generación de capital humano, el Servicio Nacional de Aprendizaje SENA ofrece la Formación Profesional Integral, plasmado en el Proyecto Educativo Institucional, para la creación de Capital Humano en los aprendices y propicia el Desarrollo Humano Integral de los egresados.

Con este propósito se escogió como sujeto de la investigación a los egresados 2014 -2015 del Centro de Biotecnología Agropecuaria SENA Mosquera en la formación técnica titulada en Recursos Humanos, Seguridad Ocupacional, y Nómina y Prestaciones Sociales.

"El Servicio Nacional de Aprendizaje, SENA, está encargado de cumplir la función que corresponde al Estado de invertir en el desarrollo social y técnico de los trabajadores colombianos; ofreciendo y ejecutando la formación profesional integral, para la incorporación y el desarrollo de las personas en actividades productivas que contribuyan al desarrollo social, económico y tecnológico del país". ${ }^{1}$

En el departamento de Cundinamarca, el SENA presta sus servicios en los 116 municipios, a través de seis Centros de Formación: Centro de Desarrollo Agroempresarial - Chía, Centro de Desarrollo Agroindustrial y Empresarial - Villeta, Centro de la Tecnología del Diseño y la Productividad Empresarial- Girardot, Centro Industrial y Empresarial de Soacha, Centro Agroecológico y Empresarial - Fusagasugá y Centro de Biotecnología Agropecuaria - Mosquera.

${ }^{1}$ SENA Proyecto Educativo Institucional 2013. 
El Centro de Formación Biotecnología Agropecuaria SENA Mosquera tiene cobertura de 19 municipios de Cundinamarca, a saber: Bojacá, Cachipay, Cota, El Rosal, Facatativá, Funza, Gachetá, Gachalá, Gama, Guasca, Junín, La Calera, Madrid, Mosquera, Subachoque, Tenjo, Tabio, Ubalá y Zipacón. La formación técnica se realiza en la Sede principal municipio de Mosquera y en Subsedes en los otros municipios.

El trabajo se estructura en la siguiente forma: un primer capítulo en que se realiza una aproximación teórica sobre los conceptos de capital humano y desarrollo humano integral en de la Formación Profesional Integral del SENA.

En el segundo capítulo se presenta las características de los aprendices al ingresar al SENA, corresponde a los resultados de la ficha de caracterización diligenciada en el momento de la matricula por las personas aceptadas para ingreso a la entidad.

En el tercer capítulo se identifican los cambios manifestados por los egresados, luego de haber pasado por un proceso de formación técnica y las manifestaciones de sus expectativas ocupacionales y profesionales hacia el futuro.

La secuencia de los tres capítulos del presente trabajo nos lleva a presentar algunas reflexiones y expresar algunas recomendaciones objeto de la investigación. 


\section{i) Justificación}

El SENA es la entidad del Estado que aporta al país la Formación Profesional Integral de forma gratuita a la población colombiana y está presente en todo el territorio nacional por medio de las 33 regionales que corresponden a los departamentos del país.

Bajo esta perspectiva y en trabajo directo con los aprendices en el programa bienestar al aprendiz, como funcionaria de la entidad y de la Regional Cundinamarca, se hizo un recorrido por algunos municipios del departamento, donde encontramos egresados SENA, algunos manifestaron: haber tenido un desempeño ocupacional en la formación técnica recibida y otros no tuvieron esa oportunidad, porque en su entorno no requerían esta mano de obra calificada.

De esta experiencia nace la inquietud de conocer la situación de los egresados, después de adelantar el proceso de formación técnica por un año, partiendo de la caracterización de los aprendices cuando ingresan a la entidad.

El sujeto de la investigación, corresponde a los egresados del Centro de Biotecnología Agropecuaria SENA - Mosquera que tiene una cobertura de 19 municipios del departamento de Cundinamarca, cercanos a la municipalidad de Mosquera, donde se tienen subsedes de formación SENA; como se observa en el siguiente mapa. 


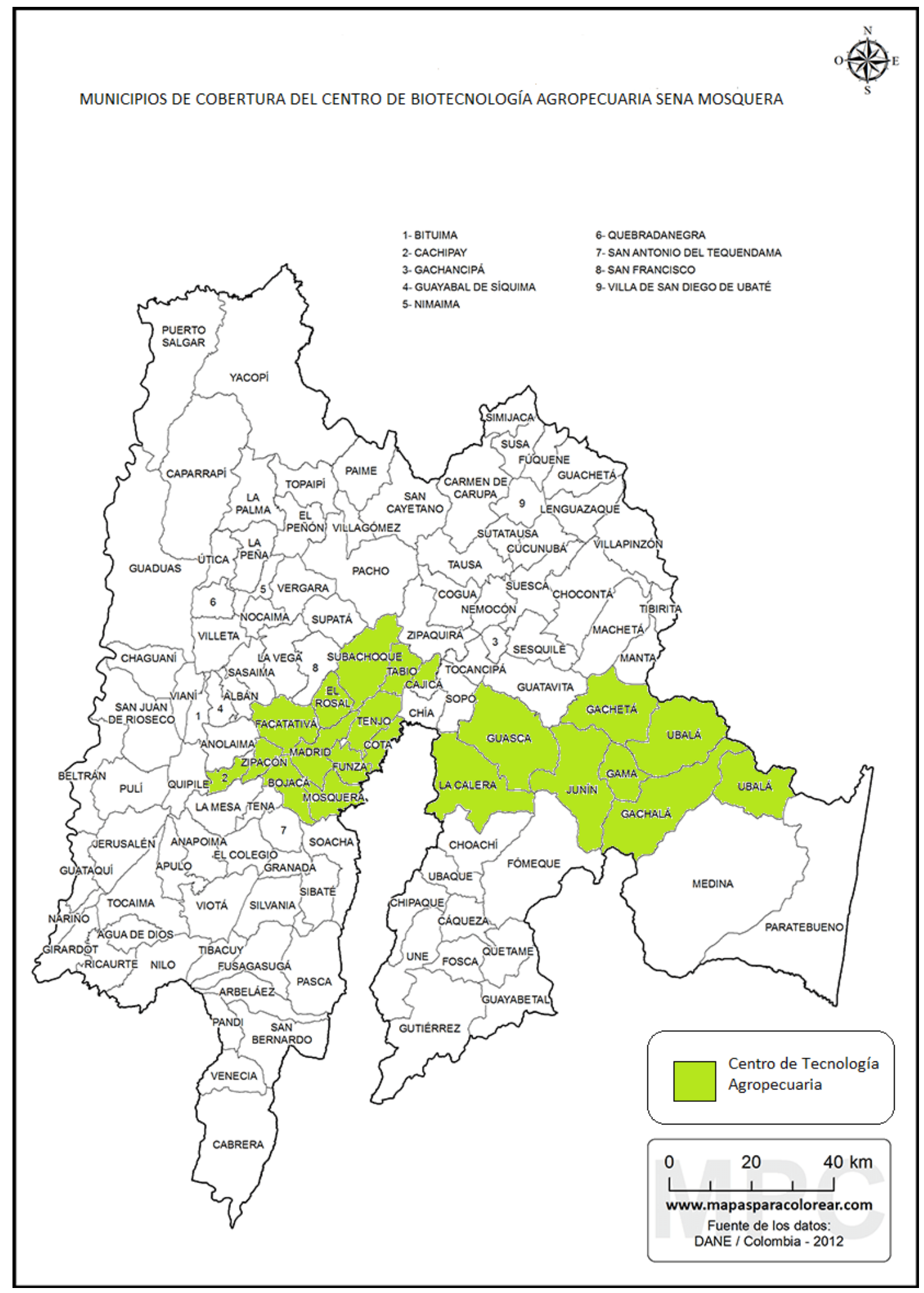


La vocación inicial del Centro de Formación, es la tecnología aplicada a los procesos biológicos y agropecuarios, con la disposición de los ambientes de formación para capacitar en las técnicas agropecuarias, dada la producción agropecuaria de la región y la abundancia de los cultivos de flores.

Sin embargo, la vocación productiva del territorio ha venido cambiando, y ello implica la disminución significativa de los cultivos de flores, y la actividad agropecuaria, teniendo en cuenta que son pocos los terrenos dedicados a la agricultura y la oferta de formación técnica para el sector agropecuario no tiene mucha demanda.

Dados los procesos de ocupación territorial de las grandes infraestructuras industriales y de actividades logísticas, por la expansión de las industrias de la capital o continuidad periférica occidental, formando el corredor occidental, de los municipios de Funza, Mosquera y Madrid. ${ }^{2}$

La extensión industrial, partiendo de la zona franca de Fontibón, y al establecerse la zona franca de Mosquera e interzona de Funza, favorecidas por los bajos precios de la tierra, respecto a la capital; exenciones tributarias municipales; menor congestión de vías y la ventaja de estar cerca a los mercados. (Gaitán, 2009, p.29).

Por ende, el Centro de Formación de Mosquera ofrece otras tituladas, mencionamos algunas: Producción Pecuaria, Asistencia Administrativa, Mantenimiento de Equipos de Cómputo, Cocina, Venta de Productos y Servicios, entre otros.

Se escoge este Centro de Formación por el permiso y apoyo de las directivas para tener acceso a las fuentes de información. Así mismo, se

\footnotetext{
2 Gaitán Rincón, S. Y. (2009). Lineamientos para la localización de grandes infraestructuras industriales y de actividades logísticas en el corredor occidente de la sabana de Bogotá: caso Funza, Mosquera, Madrid (Master's thesis, Facultad de Arquitectura y Diseño).
} 
definen las tituladas de Recursos Humanos, Seguridad Ocupacional y, Nómina y Prestaciones Sociales, por ser ocupaciones requeridas por todas las empresas.

\section{ii) Pregunta de Investigación}

En el SENA los aprendices han recibido una formación técnica y han recibido la titulación o certificación, como Técnico Profesional en Recursos Humanos, Seguridad Ocupacional, y Nómina y Prestaciones Sociales, por consiguiente, se busca analizar los cambios que han tenido los egresados, iniciaron como aprendices en el 2013 y 2014 y salieron como egresados en el 2014 y 2015; teniendo en cuenta que fueron preparados para un desempeño laboral en el sector productivo en el marco de una Formación Profesional Integral del SENA.

Por lo tanto, el problema de investigación es identificar los cambios que han tenido los egresados que lograron las competencias y si realmente, tienen un desempeño laboral en el sector productivo en la ocupación para la que se formaron. La pregunta de investigación es:

¿Cuál es el cambio que se evidencia en los egresados del 2014- 2015, por la formación recibida en el SENA en los programas técnicos del Centro de Biotecnología Agropecuaria - Mosquera?

\section{iii) Objetivos}

\section{Objetivo General}

Analizar los cambios que evidencian los egresados del 2014- 2015, por la formación recibida en el SENA en los programas técnicos del Centro de Biotecnología Agropecuaria - Mosquera. 


\section{Objetivos Específicos}

- Relacionar la propuesta de Formación Profesional Integral del SENA con la concepción de Capital Humano y el Desarrollo Humano Integral

- Caracterizar el estado actual de los aprendices de la técnica profesional en Recursos Humanos, Seguridad Ocupacional y Nómina y Prestaciones Sociales en los años 2014-2015 del Centro de Biotecnología Agropecuaria SENA - Mosquera

- Describir las condiciones de los egresados 2014-2015, después de la formación por competencias, como capital humano, en los programas de formación técnica en Recursos Humanos, Seguridad Ocupacional, y Nómina y Prestaciones Sociales del Centro de Biotecnología Agropecuaria del SENA Mosquera.

\section{iv) Aspectos Metodológicos}

El presente trabajo se plantea como una investigación con un enfoque cualitativo $^{3}$ de tipo descriptivo, busca identificar los elementos del capital humano y del desarrollo humano integral de los egresados del SENA en el marco de la Formación Profesional Integral, en los programa de formación técnica profesional en Recursos Humanos, Seguridad Ocupacional y Nómina y Prestaciones Sociales.

\footnotetext{
3 Torres, C. A. B. (2006). Metodología de la investigación: para administración, economía,
} humanidades y ciencias sociales. Pearson educación. 
La investigación es de tipo descriptivo, ${ }^{4}$ donde se identifican los elementos claves que inciden en un fenómeno, es de carácter cualitativo, dado que partimos de los conceptos teóricos de capital humano y desarrollo humano integral, y en un paso heurístico se identifican las variables en el proceso de formación técnica del capital humano.

Mediante la comunicación con los egresados, se busca describir el desarrollo humano integral, identificando las características que nos llevan a la reflexión de la concordancia o disonancia con la formación profesional integral del SENA.

Como fuentes de información primaria, tenemos: encuestas a egresados, con preguntas cerradas y una pregunta abierta; ficha de caracterización nos da la línea base de la investigación, se obtiene de la información suministrada por el aprendiz, al ingresar al ciclo de formación SENA; Bases de Datos de los matriculados, Currículos de los programas de Formación Técnica Profesional de los programas de Recursos Humanos, Seguridad Ocupacional, y Nómina y prestaciones Sociales; Documentos SENA, Diario de Campo de la investigadora, es la observación participante.

Por otro lado, las fuentes secundarias, son: documentos, libros, artículos, revistas.

\section{v) Población Sujeto}

La población propuesta para esta investigación está conformada por 537 egresados de enero de 2014 a septiembre de 2015 de la Formación Técnico Profesional en los Programas de: Recursos Humanos con 193; Nómina y

\footnotetext{
4 Gross, M. (2010). Conozca 3 tipos de investigación: Descriptiva, Exploratoria y
} Explicativa. Obtenido de Pensamiento Imaginagtivo: http://manuelgross. bligoo. com. 
Prestaciones Sociales con 127; y Seguridad Ocupacional con 217 del Centro de Biotecnología Agropecuaria del SENA Mosquera.

El uso de la información de las Bases de Datos de Egresados y ficha de caracterización de aprendices se realiza con permiso consentido de la entidad. Base de datos - Ver Anexo 1.

Para el presente trabajo se ha definido una muestra sobre la población sujeto con el 95\% de confiabilidad y margen de error del 5\%, como resultado del diseño de la muestra se tiene 224 aprendices que ingresaron a la formación y estos -224- salieron como egresados.

Al tomar los datos de la ficha de caracterización, se recogió en forma aleatoria, la información de los aprendices que salieron egresados, definidos en la base de datos, de los programas de formación definidos para el presente trabajo.

Con la base de datos de los egresados se envían en forma aleatoria, las encuestas al correo electrónico a los certificados en los programas técnicos definidos, solicitando su diligenciamiento.

Para definir el tamaño de la muestra de la ficha de caracterización y de la encuesta, y determinar el grado credibilidad a los resultados que se obtengan, se aplicará la fórmula para determinar la muestra que oriente el cálculo del tamaño de la muestra para datos globales ${ }^{5}$, a saber:

$$
n=\frac{k^{\wedge 2 *} p * q * N}{\left(e^{\wedge 2 *}(N-1)\right)+k^{\wedge} 2 * p^{*} q}
$$

\footnotetext{
5 Devore, J. L. (2015). Probability and Statistics for Engineering and the Sciences. Cengage Learning. Traducido Jorge Humberto Roma. México 2008.
} 
$\mathrm{N}$ : tamaño de la población o universo - número total de posibles encuestados-

K: es una constante que depende del nivel de confianza que definamos, este indica la probabilidad de que los resultados sean ciertos. Los valores $\mathrm{k}$ más utilizados y sus niveles de confianza son:

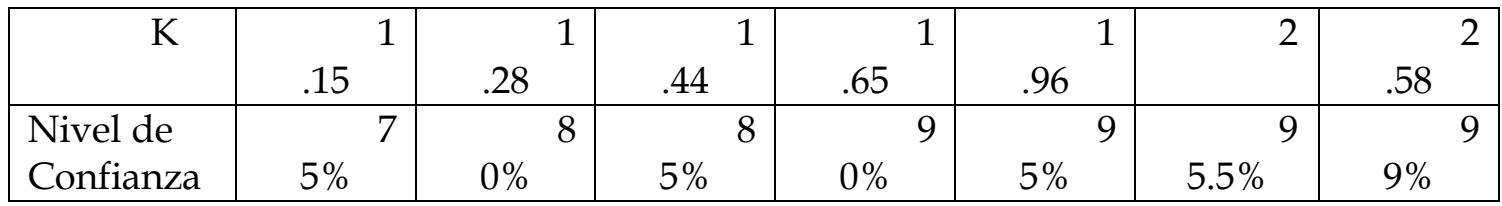

e: el error muestral, es la diferencia que puede haber entre los resultados que obtenemos preguntando a una muestra de la población y el que tendríamos si preguntamos al total de la población

p: es la proporción de individuos que poseen en la población la característica del estudio. Este dato es generalmente desconocido y se suele suponer que $\mathrm{p}=\mathrm{q}=0.5$ que es la opción más segura

q: es la proporción de individuos que no poseen la característica del estudio, es 1-p

n: es el tamaño de la muestra

Para nuestro caso:

\begin{tabular}{|c|c|c|c|c|c|}
\hline Población & $\begin{array}{l}\text { Nivel de } \\
\text { Confianza } \\
95 \%\end{array}$ & Error & $\begin{array}{l}\text { Proporción } \\
\text { conocedora }\end{array}$ & $\begin{array}{l}\text { Proporción } \\
\text { desconocedora }\end{array}$ & Muestra \\
\hline $\mathrm{N}$ & $\mathrm{k}$ & e & $\mathrm{P}$ & $q$ & $\mathrm{~N}$ \\
\hline 537 & 1.96 & $5 \%$ & 0.5 & 0.5 & 224 \\
\hline
\end{tabular}

Cálculos propios

De acuerdo a lo planteado nuestra población sujeto corresponde a 537 egresados de los tres programas de Formación Técnica Profesional: Recursos Humanos, Seguridad Ocupacional y Nómina y Prestaciones Sociales, la muestra es de 224 fichas de caracterización y 224 encuestas a los egresados con un grado de confiabilidad del 95\% y margen de error del 5\%. 


\section{vi) Instrumentos}

- La Ficha de Caracterización de los aprendices: es una fuente primaria, este documento del SENA, es diligenciado por las personas que han logrado la vinculación a la entidad y se matriculan como aprendices y constituyen la línea de base, ingreso de los aprendices. Ver Anexo 2.

- Encuesta a egresados: es una fuente de información primaria, de autoría propia, para el presente trabajo, nos muestran la situación de los egresados al año 2016. Ver Anexo 3.

- El trabajo está estructurado en la siguiente forma: un primer capítulo en que se realiza una aproximación teórica sobre los conceptos de capital humano y desarrollo humano integral en de la Formación Profesional Integral del SENA.

En el segundo capítulo se presenta las características de los aprendices al ingresar al SENA, corresponde a los resultados de la ficha de caracterización diligenciada en el momento de la matricula por las personas aceptadas para ingreso a la entidad.

En el tercer capítulo se identifican los cambios manifestados por los egresados, luego de haber pasado por un proceso de formación técnica y las

manifestaciones de sus expectativas ocupacionales y profesionales hacia el futuro. 


\section{LA FORMACIÓN TÉCNICA DEL SENA: PROPUESTA DE CAPITAL HUMANO Y DESARROLLO HUMANO INTEGRAL}

El Servicio Nacional de Aprendizaje SENA es una entidad pública del orden nacional, en acuerdo a la ley 119 de 1994, adscrita al Ministerio del Trabajo, según el Decreto 4108 de 2011; en atención a esta normatividad, le corresponde al SENA invertir en el desarrollo social y técnico de los trabajadores colombianos, ofreciendo y ejecutando la formación profesional integral para la incorporación de las personas en actividades productivas que contribuyan al crecimiento social, económico y tecnológico del país, a través de programas de formación técnica profesional y tecnológica.

\subsection{Acercamiento al concepto de Capital Humano y Desarrollo Humano Integral}

El resultado complejo y diverso proceso de fortalecimiento de las capacidades de los individuos a través de la educación y formación, hoy es conocido como capital humano, término que se empezó a gestar en 1950, en la conferencia pronunciada por Theodore W. Schultz en la American Economic Association, acuñado como sinónimo de educación y formación. "al invertir en sí mismos, los seres humanos aumentan el campo de sus posibilidades. Es un camino por el cual los hombres pueden aumentar su bienestar" (Schultz, 1961, p.17).

\subsubsection{Capital Humano: Ambigüedad y Oportunidad}

Lo que hoy es conocido como capital humano se cimienta en dos importantes factores: la educación y la experiencia, aunque no denominado 
bajo este término, su análisis más básico surgió con los economistas clásicos, por una parte Adam Smith en $1776^{6}$, se interesó por analizar la forma en que actividades como la enseñanza académica, la medicina y las artes incrementan la producción interna de una economía determinada, y Thomas Malthus ${ }^{7}$ más adelante en 1806, analizó la educación en un contexto social y la propuso como un factor importante para hacer a las personas del común más realizadas y menos hostiles.

Lo anterior esboza cómo se inició el estudio de las potencialidades y capacidades humanas fomentadas a partir de la educación. "Se observa, por tanto, que ya desde los inicios se resalta la importancia que tiene la formación sobre la productividad individual" (Pons, 2004, p.17).

Hoy en día, las instituciones internacionales afirman que el capital humano es el recurso principal del sistema de un país para su desarrollo social y económico, y su valoración es entendida como "el conjunto de conocimientos y de las capacidades de cada individuo, puede indudablemente traer beneficios desde el punto de vista de la calidad de vida, del trabajo, de la cohesión social y de la competitividad" (AVSI, 2008, p.20)

El término capital humano designa la cantidad de conocimientos útiles y valiosos acumulados por los individuos en el proceso de educación y formación. Incluye la capacidad y el talento innatos, así como la educación y las cualificaciones adquiridas, y suele estar fuertemente condicionado por el entorno familiar.

Así las cosas, del concepto en mención se diferencia de la siguiente manera: (i) el capital humano innato y (ii) el capital humano adquirido, el

\footnotetext{
6 Smith, Adam. Riqueza de las naciones (1776).

7 Malthus, Thomas. Ensayo sobre el principio de la población (1798) tercera edición 1806. Piketty, T. (2014). El capital en el siglo XXI. Fondo de Cultura Económica.
} 
primero, estaría formado por las aptitudes físicas e intelectuales de los individuos y el segundo, por la educación formal e informal. (Giménez, 2005)

La relación del capital humano y el crecimiento de la economía se miran desde las perspectivas de la educación y el conocimiento, como estas dos se relacionan directamente sobre las habilidades desarrolladas por los individuos. (de Urbina Criado, M. O., \& López, 2002. p.163)

El concepto a lo largo de la historia ha evolucionado e inicio desde la antigüedad cuando Platón, planteó que los hombres son diferentes según razas y etnias, mientras que Aristóteles, con su teoría de la esclavitud natural o teoría aristocrática, afirmó que los hombres no son iguales, ni físicamente, ni intelectualmente: mandar y obedecer es un hecho natural. Darwin afirmó que la diversidad entre los individuos se debe a la selección natural. Marx en su momento hizo el análisis sobre las clases y su teoría de la eliminación de las diferencias entre las clases.

Los anteriores autores manifestaron que las diferencias entre los hombres dependen de factores externos como el clima, las creencias religiosas, morales y filosóficas, y que esta diversidad, generalmente contribuye a la formación de patrimonios sociológicos y la construcción de un hombre situado en una cultura que expresa todo el potencial social y lo limita desde lo económico.

Por consiguiente, el capital cultural busca explicar las diferencias en los resultados escolares que presentan niños de diferentes clases sociales respecto del éxito "escolar", es decir, los beneficios específicos que los niños de distintas clases pueden obtener del mercado escolar, en relación a la distribución del capital cultural entre clases y fracciones de clase. (Bourdieu, 1987) 
"El capital cultural puede existir bajo tres formas: en el estado incorporado, es decir, bajo la forma de disposiciones duraderas del organismo; en el estado objetivado, bajo la forma de bienes culturales, cuadros, libros, diccionarios, instrumentos, maquinaria, los cuales son la huella o la realización de teorías o de críticas a dichas teorías, y de problemáticas, etc., y finalmente en el estado institucionalizado, como forma de objetivación muy particular, porque tal como se puede ver con el título El escolar, confiere al capital cultural -que supuestamente debe de garantizar - las propiedades totalmente originales." (Boudier, 1987, p.17)

Por otro lado, los autores Edvinsson y Malone (1997), mencionan que "el Capital Intelectual hace referencia al valor resultante del conjunto de intangibles creados por la empresa. Se define así como un Capital Intangible por su naturaleza, basado en el conocimiento o en el intelecto humano y desarrollado en la organización" (Edvinsson \& Malone, 1999).

De otra parte, Kendrick (1961), afirma que el concepto de Capital Intelectual fue introducido por primera vez en el siglo XIX por el economista alemán F. List (1841), quien lo define como aquél referido a las naciones, o a la humanidad, por la acumulación de los descubrimientos, invenciones, esfuerzos, etc..., de las generaciones precedentes (Kendrick, 1961) .

Los fundamentos del capital humano, y otros factores relativos al conocimiento como factor de producción, se relacionan y se explican bajo la visión de los principales aportes teóricos sobre la educación y la experiencia laboral hasta la década de 1960, teniendo en cuenta los principales aportes teóricos del capital humano, hechos por Robert Solow (1957) ${ }^{9}$, Theodore W. \&

\footnotetext{
8 Bueno, E., Salmador, M. P., \& Merino, C. (2008). Génesis, concepto y desarrollo del capital intelectual en la economía del conocimiento: Una reflexión sobre el Modelo Intellectus y sus aplicaciones. Estudios de economía aplicada, 26(2), 43-63.

9 Solow Robert. "Technical Change and the Aggregate Production Function"; 1957. Review of Economics and Statistics 39: 312-20.
} 
Schultz (1961)10, Denisson. E. F. (1962)11, Gary Becker (1964)12, y Jacob Mincer $(1974)^{13}$.

En este punto, es necesario entender que el ser humano no es un factor más de la producción, es el trabajo humano lo que hace conmensurable a bienes y servicios muy distintos. Los modelos de Becker (1993) y Lev (2001) ${ }^{14}$ ofrecen estructuras analíticas para comprender el nuevo rol del trabajo, en las organizaciones empresariales y en las economías (Bernal \& Mantilla, 2011),

De esta manera, el capital humano en la nueva economía es el motor del desarrollo organizacional, constituyendo la principal ventaja de las compañías para desenvolverse en sus entornos.

La teoría del capital humano desarrollada por Becker (1964), citado en Gleizes (s/f), definida como el: "conjunto de las capacidades productivas que un individuo adquiere por acumulación de conocimientos generales o específicos" (p. 1). Lo anterior, es una noción de inventario inmaterial asociado a la persona que lo posee, no solo implica la educación y formación recibida, sino la capacidad humana de llevar a cabo acciones productivas en función de las habilidades adquiridas Becker (1993) (Gleizes, 2000) .

Hay que mencionar además, el propósito de analizar el factor humano en las organizaciones es la clarificación de las condiciones bajo las cuales el trabajo se convierte en capital, pues sin una correcta identificación no es

10 Schultz, T. W. (1961). Investment in human capital. The American economic review.

${ }^{11}$ Edward Fulton Denison. The Residual Factor and Economic Growth (Paris, 1962)

${ }^{12}$ Gary Becker (1993). The economic way of looking. at behabior. Volumen 101, numero 3.

13 Jacob Mincer (marzo-abril de 1974). "Inversiones familiares en capital humano: los ingresos de las mujeres" . Revista de Economía Política, edición especial: el matrimonio, la familia de Capital Humano, y Fertilidad (parte 2) . Revistas Chicago . 82

14 Baruch Lev. Management, Measurement, and Reporting, Washington, DC,Brookings Institution Press, 2001, pp. viii+216 
posible lograr una valoración objetiva. En este sentido, resultar pertinente diferenciar y caracterizar niveles de trabajo en la organización, así como visibilizar la forma en que cada nivel se articula con la estructura organizacional general. El nuevo rol de tal factor en las firmas depende de los nuevos medios de que se dispone para el trabajo (Ferro, 2000).

La formación académica en instituciones especializadas ofrece la base de conocimientos y las capacidades a partir del reconocimiento de teorías y síntesis de casos críticos (análisis de coyuntura) en contextos similares (Becker, 1993), mientras que los aprendizajes en el hacer, en la especialización y la profesionalización refieren a la dimensión empírica de los saberes, aspectos que convergen en la productividad (Becker, 1993).

De la misma manera, para poder desarrollarse, ambos aspectos requieren un ambiente propicio, dado por la cultura organizacional eficaz y un entorno de oportunidades. El paso de un nivel básico de funcionalidad en el factor trabajo a la condición de capital humano exige una transformación cualitativa de las condiciones personales y ambientales (Becker, 1993).

El capital humano es un concepto que remite a la productividad de los trabajadores en función de su formación y experiencia de trabajo. El mismo busca dar cuenta de distintas ventajas en términos de generación de valor considerando al aporte humano que se realiza en un mercado determinado (Bernal \& Mantilla, 2011).

Dentro los aportes de los autores, indican que la educación y formación son generadoras del capital humano y son una inversión que debe hacer el Estado; las personas cuando participan del proceso productivo aportan todas sus capacidades, potencialidades inherentes, los conocimientos y competencias adquiridas en los diferentes procesos educativos y de formación. 
De parte, según Díaz (2009), permite identificar una relación de universidad empresa: "La gestión compartida Universidad-Empresa en la formación del Capital Humano, Su relación con la promoción de la Competitividad y el Desarrollo Sostenible" ( Diaz, 2009, p.50)

Por otro lado, el Estado y el aparato productivo, buscan lograr unos mayores índices de competitividad, posicionar y fortalecer el país, esto bajo un enfoque economicista en un entorno de productividad.

Por lo tanto, considera que la academia debe acceder a las tecnologías que utiliza el sector productivo con el fin de fortalecer la capacitación y formación de los individuos que buscan la universidad, de tal forma que al vincularse en el sector productivo, se constituyen agentes que propician y generan la competitividad en el sector productivo.

De otra parte Aronson (2007), realiza consideraciones significativas al respecto, como son la devaluación del capital humano en el tiempo, dados los acelerados avances del conocimiento, cambio tecnológico y organizacional, hecho que con lleva a la capacitación permanente del recurso humano, abarca un análisis sobre los aportes teóricos y empíricos de la primera versión de la teoría del capital humano, enfatizando en la necesidad de tomar un concepto claro sobre la educación para configurarla dentro de la estructura social. Contemplando la organización laboral y el papel que el Estado desempeña en este proceso. (Aronson, 2007, p.26).

El concepto sobre el Capital Humano, está relacionado en forma directa con la educación, y los individuos al logar diferentes niveles de educación alcanzan una mejor remuneración y mejorar las condiciones de vida propia y de sus familias, y manifiesta: "El desarrollo del concepto de educación se consolidó en la teoría del capital humano, destacando la inversión en la gente como un factor fundamental para el crecimiento y el bienestar de los países. El capital humano se 
consolida entonces como un segmento en el análisis económico, que ha demostrado ser contribuyente en el crecimiento económico, al tener en cuenta que la educación le da la posibilidad al trabajador de acceder a puestos de trabajo mejor remunerados y de aumentar su calidad de vida, Mincer (1974), Thurow (1978), Becker (1983), entre otros." (Acevedo., Montes., Vásquez., Villegas., \& Brito., 2007)

En la teoría de las capacidades de Amartya Sen, y su relevancia pedagógica, más allá del ámbito socio-económico, resalta el haber puesto de manifiesto la importancia de la educación en un mundo globalizado y así estimular las inversiones en este campo (Córdoba, 2010).

Inicialmente explica el enfoque de las capacidades de Amartya Sen a través de sus principales elementos: capacidades, funcionamientos y circunstancias de la conversión de recursos en funcionamientos, teoría que pretende ser un marco conceptual donde el nivel de vida no es un sentido únicamente material, sino en general el bienestar entendido como libertad para llevar una vida valiosa. (Córdoba, 2010).

El capital humano según Amartya Sen (1999), lo define como un concepto que se concentra en el carácter de agentes [agency] de los seres humanos, que por medio de sus habilidades, conocimientos y esfuerzos, aumentan las posibilidades de producción (Sen A. , 1999). Así mismo, expresa una diferencia sobre la Capacidad Humana la cual define como aquella habilidad para llevar el tipo de vida que consideran valiosa e incrementar sus posibilidades reales de elección (Sen A. , 1999). Ambas perspectivas están relacionadas porque se ocupan del papel de los seres humanos $\mathrm{y}$, en particular, de las habilidades efectivas que éstos logran y adquieren.

En algunas teorías económicas sobre el crecimiento económico se designa el capital humano como un factor de producción que depende de la cantidad, calidad, grado de formación y la productividad de las personas o 
recurso humano vinculado en el proceso productivo. En las instituciones educativas se considera el capital humano al conjunto de conocimientos, habilidades, destrezas, experiencias y talentos, que tiene una persona y la hacen apta para desarrollar unas actividades específicas.

En este contexto es importante presentar una definición sobre el capital humano, a saber: es un concepto que remite a la productividad de los trabajadores en función de su formación y experiencia de trabajo. El mismo busca dar cuenta de distintas ventajas en términos de generación de valor considerando al aporte humano que se realiza en un mercado determinado.

Por extensión, muchas veces se utiliza el término "capital humano" para dar cuenta de los recursos humanos que tiene una empresa, de sus competencias conjugadas que derivan en una mejora general en la producción. De alguna manera puede decirse que el concepto de capital humano remite al viejo concepto del trabajo como factor productivo, poniendo esta vez el énfasis en la formación de ese factor productivo." (Las ciencias sociales, 2010)

Esta definición permite tener un concepto general sobre capital humano, por medio del cual se genera la productividad laboral, con base en la educación y competencias del recurso humano de las unidades productivas.

Con este análisis y desglose acerca de los principales autores de la teoría de capital humano y su aporte, para el trabajo investigativo en cuestión será acogida como apropiada la definición de Bustamante. (Bustamante, 2003, p. 231)15, quien especifica el capital humano "como el conjunto de conocimientos, capacidades y habilidades de la fuerza laboral, ya sea por

15 de Maldonado, I. P., Pérez, M. M., \& Uzcátegui, S. B. (2015). Clima organizacional y gerencia: inductores del cambio organizacional. Investigación y postgrado, 21(2), 231248. 
inversiones en educación, salud, seguridad y cultura o por aquellas destrezas adquiridas por la experiencia"

Concluimos que el capital humano, está dado en las personas que han adquirido conocimientos y avanzado en sus capacidades, para un desempeño laboral, a través de procesos de educación y formación, logrado por la inversiones realizadas por los individuos, familia, gobierno en educación y formación, salud y el entorno cultural, y obtenido una acreditación o certificación que les permite presentarse, para una vinculación al mundo del trabajo.

Bajo esta concepción podríamos decir que el capital humano se constituye en una oportunidad para las personas porque establece un fuerza laboral certificada para el desempeño en el sector productivo, debidamente acreditada, sin embargo, esto no es suficiente para logar la vinculación en el mundo del trabajo, dado que el sector productivo no demanda este recurso humano, o la oferta laboral esta desborda. Por ende, la generación de capital humano, parece una ambigüedad es improductivo y no cumple con las expectivas dadas al iniciar los procesos de educación y formación del recurso humano, es decir, es proceso equivoco, al llevarse a cabo sin tener en cuenta los requerimientos de las actividades económicas.

\subsubsection{Desarrollo Humano Integral un concepto en construcción}

Con relación a la educación y el desarrollo humano, se ven los individuos como un activo más o un factor productivo que genera renta, por el contrario Amartya Sen, concibe el desarrollo como una expansión de la libertad humana mediante la capacidad para llevar la vida que cada uno tenga razones de elegir y según la libertad como capacidad, la educación sirve para aumentar las capacidades de vivir una vida valiosa. 
Dadas sus características personales, sus antecedentes sociales, sus circunstancias, económicas, entre otras, los individuos tienen la habilidad para hacer ciertas cosas que consideran valiosas; la importancia de esta calificación puede ser directa, como: enriquecer su vida en forma directa, como estar bien nutrido o estar saludable, o indirecta, contribuir a la producción futura o alcanzar un precio en el mercado.

Esta perspectiva del capital humano puede cubrir ambos tipos de valoración, pero se suele definir en términos de valor indirecto: las cualidades humanas que se pueden emplear como capital en la producción, tal como se emplea el capital físico, en este sentido, la concepción de capital humano, es restringida y en un sentido más amplio, la capacidad humana que incluye las habilidades humanas. (Sen, 2000, p. 70).

La educación hace que la persona sea más eficiente en la producción de bienes, hay un mejoramiento del capital humano, que agrega valor a la producción de la economía y aumenta el ingreso de la persona que ha sido educada. Pero aún con el mismo nivel de ingreso, esa persona puede beneficiarse de la educación por la posibilidad de leer, argumentar, comunicar, elegir con mayor información, ser tenida en cuenta más seriamente por otros y así sucesivamente. “De modo que los beneficios de la educación son mayores que su función de capital humano en la producción de bienes. La perspectiva más amplia de capacidad humana puede abarcar -y valorar- estas funciones adicionales. Las dos perspectivas están, entonces, Íntimamente relacionadas aunque sean distintas." . (Sen, 2000, p. 72).

Por otra parte, las capacidades tienen varios cometidos en el desarrollo humano: ser el objetivo mismo de tal desarrollo, promover el progreso social que conduce a él y, finalmente, influir indirectamente en el aumento de la producción económica. Debido a ello, desde esa perspectiva no se repara en 
las consecuencias de las políticas educativas para la justicia social: se atiende a cuánto mejora la economía nacional, pero no a quién se beneficia de la educación, ni a cuánto lo hace, ni a cómo la educación contribuye a la igualdad social y al respeto de las libertades (Córdoba, 2010).

Según S. Fukuda- Parr, ex-directora de los Informes sobre el Desarrollo Humano del Programa de las Naciones Unidas para el Desarrollo (P.N.U.D.), "el enfoque de las capacidades ha proporcionado el fundamento conceptual más sólido de este nuevo paradigma" (PNUD, 2003).

El Programa de las Naciones Unidas para el Desarrollo -PNUD, define el desarrollo humano como... «el proceso de expandir las opciones de las personas» (P.N.U.D., 1990, 2), elaborando bajo este criterio desde 1990 los índices de desarrollo humano como una idea que surge del economista paquistaní Mahbub ul Haq. ..."la verdadera riqueza de una nación está en su gente. Sin lugar a dudas, el objetivo básico del desarrollo es aumentar las libertades humanas en un proceso que puede expandir las capacidades personales toda vez que amplía las alternativas disponibles para que la gente viva una vida plena y creativa"... (P.N.U.D., 2004, 127).

Con esta definición y sus orígenes, se considera el inicio de este discutido concepto, con el aporte de Amartya Sen "el desarrollo puede verse como un proceso de expansión de las libertades reales de las personas" (Sen, 1999, p.3).

Pero su propósito no es limitado solo a elaborar el $\mathrm{IDH}^{16}$ o evaluar el desarrollo, busca con su teoría crear un amplio marco conceptual para ver la vida no solo en un sentido material, sino como un bienestar generado por llevar una vida valiosa en libertad y con funcionamientos definidos como esa situación que se alcanza gracias a los recursos y el uso que se les puede dar.

16 Índices de Desarrollo Humano 
En el enfoque de las capacidades, la educación es más importante que en otras teorías del desarrollo para citar un ejemplo Sunkel y Paz (1988) definieron el desarrollo como "proceso de cambio social, se refiere a un proceso deliberado que persigue como finalidad última la igualación de las oportunidades sociales, políticas y económicas, tanto en el plano nacional como en relación con sociedades que poseen patrones más elevados de bienestar social" (Sunkel y Paz, 1988, p. 39) y otras definiciones de perspectivas economicistas en las cuales los individuos se consideran un activo más que genera renta "un modelo de desarrollo o patrón de acumulación es una modalidad del proceso de reproducción del capital, históricamente determinada" (Valenzuela, 1990).

Bajo la óptica de Amartya Sen, el desarrollo es un medio para el crecimiento económico, y la educación aumenta las capacidades productivas del individuo, sino que aumenta los talentos para llevar una vida valiosa; el objetivo de la educación, como piensa otra teórica del enfoque de las capacidades, "es cultivar la humanidad, y eso implica dotar al ciudadano de los instrumentos que le permitan una elección autónoma de su modo de vida" (Nussbaum, 1997, p.205).

El desarrollo humano ha inyectado un elemento de competencia en el mercado de las ideas y ha conseguido romper el monopolio del Fondo Monetario Internacional FMI y del Banco Mundial en materia de orientación de estrategias de desarrollo. (Griffin, 2001, p. 35).

El Banco Mundial merece un cierto crédito por el hecho de haber reconocido que el desarrollo tiene que ver con las personas y no solo con el Producto Nacional Bruto PNB. En la publicación de los Indicadores del Desarrollo Mundial de 1998, el Banco presenta por primera vez una "Visión Mundial" con indicadores de desarrollo tanto económicos como humanos; a 
continuación se incluyen varios conjuntos de tablas sobre "personas" y "medioambiente". (Griffin, 2001, p. 38).

Cejudo aborda la concepción de la educación implícita en el desarrollo humano, y compara la misma con otra teoría del desarrollo, la del capital humano, que también ha concedido a la educación un papel relevante. La crítica de la función instrumental asignada a la educación por esta última permite contextualizar la vinculación entre capacidad, libertad y educación.

Considera que la concepción de la libertad como capacidad propuesta tiene aplicaciones pedagógicas más amplias no exploradas por Sen, en la reflexión habitual sobre la educación en las sociedades avanzadas se repite la idea de que la institución escolar corre el riesgo de perder su función educadora ante las exigencias del mercado, desde su aplicación a los problemas educativos de las sociedades avanzadas; como denuncia A. Pérez Gómez, actualmente "el criterio para medir la calidad de la educación es la eficacia de la institución escolar como subsistema social para producir y reproducir el conocimiento experto que el sistema económico y social necesita para su mantenimiento y expansión". Ante esto no parece haber ninguna dinámica compensadora, si no es que..." ". El concepto de educación se disuelve en el omnipotente proceso de socialización" (Pérez Gómez, 1988, 137).

Cuando se habla de capital humano no sólo se tiene en cuenta la educación; también otros dos pilares: la salud y la experiencia, que se constituyen también en factores que se considera fundamentales para el desarrollo y libertad de la población, bajo el enfoque de las capacidades que vincula la calidad de vida y el bienestar con la libertad, y teniendo en cuenta 
este análisis se ha ido forjando el concepto de desarrollo humano (Sen A. K., 2010) .

En este sentido, el concepto mismo de desarrollo humano, debe ser entendido como despliegue o desenvolvimiento en múltiples posibilidades, entre las cuales se deberá escoger, basándose en criterios u opciones y alternativas, unas veces de naturaleza ideológicay otras, incluso, con trasfondo ético. En los tiempos actuales se enfatizó tanto la necesidad de la armonía y convivencia cívicas, como lo hace la Psicología Humanista (Martínez, 2004).

El ser humano es un suprasistema altamente complejo, pero más o menos integrado. El nivel de integración armónica determina el grado de desarrollo y madurez de su personalidad. Todo esto impone a la educación una tarea o misión sumamente ardua y difícil, en la cual frecuentemente fracasan muchos educadores y otros profesionales que trabajan en el desarrollo humano. La superación de dichas dificultades estriba en un conocimiento teórico-práctico de los diferentes niveles de las áreas a desarrollar en las profesiones de ayuda. (Martínez, 2009, p. 121).

Durante los últimos 20 años, la UNESCO, como Organización de las Naciones Unidas para la Educación, la Ciencia y la Cultura, viene insistiendo en una serie de ideas de máxima relevancia (Ciret-UNESCO 1997, 2000, UNESCO 1979,1998a, 1998b). Entre esas ideas están las siguientes afirmaciones:

La UNESCO, plantea entre sus aspectos que el desarrollo de un país, sólo lo alcanzará con una calificada y competente preparación de sus profesionales. Ello implica que los países tomen conciencia de la importancia de la formación de sus conciudadanos de manera seria y comprometida en pro 
de un mejoramiento continuo de las condiciones de vida de su población, teniendo en cuenta que la universidad es la llamada a trasformar las relaciones y la manera de asumir el mundo cambiante y el ritmo cambiante que impone la ciencia y la tecnología.

Hoy el mundo reclama a la universidad un protagónico papel en las nuevas condiciones de dialogo inter, intra y multidisciplinar en pro de un protagónico desempeño de los profesionales para un nuevo país.

Ahora bien, esta línea de reflexión desemboca por su propia naturaleza en la exigencia de un cambio de paradigma epistémico, en la necesidad de adoptar un paradigma sistémico (UNESCO, 1979) para enfrentar la alta complejidad con que se nos presentan las realidades del mundo actual y, especialmente en el proceso educativo, pues, como dice Ludwig von Bertalanffy, "desde el átomo hasta la galaxia vivimos en un mundo de sistemas" (1981. Pág. 47).

Por esto, llevar a un ser humano a su pleno desarrollo y madurez, en su realidad integral, constituye la empresa más difícil y ambiciosa que pueda proponerse una persona, una institución e, incluso, una sociedad completa.

Sin embargo, caminar en esa dirección, abriendo horizontes e iluminando caminos, es la meta que se propone, en general, la educación y desarrollo pleno del ser humano. (Martínez, 2009, p. 119).

A manera de conclusión, expresamos que en la revisión bibliográfica, hemos pasado por la consideración del desarrollo, asimilándolo desde el punto de vista económico, de las capacidades y libertades para tener una vida plena y creativa.

La consideración del desarrollo humano integral: como el proceso de expandir las opciones de las personas y el objetivo es aumentar las libertades humanas, en el transcurso se pude expandir las capacidades personales, 
ampliando las alternativas para que las personas tengan una vida plena $\mathrm{y}$ creativa.

Así mismo, el debate, sobre el desarrollo humano integral, ha permeado el Banco Mundial, al plantear inversión social, para propiciarlo; en consecuencia, podemos concluir que el concepto, está en construcción. No obstante, la búsqueda del pleno desarrollo y madurez en la realidad integral del ser humano es la meta de la educación y la formación del desarrollo pleno del hombre o desarrollo humano integral del individuo.

Para efectos del presente trabajo de investigación, el cual está enmarcado en la Formación Técnica del SENA, se acoge la propuesta de Desarrollo Humano Integral, de Socorro del Pilar Morales Arámburo17, Universidad de León: el Desarrollo Humano Integral, "se orienta a fortalecer las capacidades del individuo, formándolos con herramientas de conocimiento, y una conciencia para desarrollar actitudes y aptitudes personales que les permitan convertirse en personas que practiquen su profesión, autónomas, seguras y confiadas para insertarse al mundo con un sentido de vida propio, con ética para la construcción de una sociedad mejor, donde el valor humano es el punto de partida, desde donde todo cobra sentido" .

\subsection{SENA}

La Formación Profesional en Colombia se remonta al año 1890 cuando los Padres Salesianos fundaron en Bogotá el Colegio León XIII de Artes y Oficios para la formación técnica de la juventud. Luego vino la creación de

\footnotetext{
17 Arámburo, S. D. P. M. DESARROLLO HUMANO INTEGRAL. Diversidades, 33, 2013 Universidad de León. España.
} 
doce escuelas técnicas y varios institutos agrícolas para la capacitación de los trabajadores.

La primera iniciativa sobre la creación de un instituto de formación profesional surgió durante el V Congreso de la Unión de Trabajadores de Colombia celebrado en Medellín en febrero de 1954. La idea era crear un conjunto de escuelas industriales al estilo de las que en ese entonces existían en Brasil con el nombre de Servicio Nacional de Aprendizaje Industrial SENAI. Fue así, como mediante el Decreto 2920 de 1954 se creó el Instituto Nacional de Capacitación Obrera y como director fue nombrado Rodolfo Martínez Tono.

El Servicio Nacional de Aprendizaje, nace en 1957, mediante el DecretoLey 118 del 21 de junio de 1957, como resultado de la iniciativa conjunta de los trabajadores organizados, los empresarios, la iglesia católica y la Organización Internacional del Trabajo. Es un establecimiento público del orden nacional, con personería jurídica, patrimonio propio e independiente y autonomía administrativa, adscrito al Ministerio de Trabajo y Seguridad Social de la República de Colombia.

El SENA está encargado de cumplir la función que le corresponde al Estado de invertir en el ámbito social y técnico de los trabajadores colombianos, ofreciendo y ejecutando la formación profesional integral, para el desarrollo de las personas y la incorporación en actividades productivas que contribuyan al desarrollo social, económico y tecnológico del país.

En la década de los 90 la internacionalización de la economía incrementó la competencia empresarial, de ahí nace la necesidad de expedir la entidad y en la Ley 119 de 1994, por medio de la cual la institución se 
reestructuró para brindar programas de formación profesional integral en todas las áreas económicas. El objetivo: aumentar la productividad y el desarrollo social y económico.

El SENA es un Establecimiento Público del orden nacional con personería Jurídica, patrimonio propio e independiente y autonomía administrativa, adscrita al Ministerio del Trabajo, según el Decreto 4108 de 2011; su misión, funciones y términos en que deben cumplirse, están señaladas en la Ley 119 de 1994, le corresponde al SENA invertir en el desarrollo social y técnico de los trabajadores colombianos, ofreciendo y ejecutando la formación profesional integral para la incorporación de las personas en actividades productivas que contribuyan al crecimiento social, económico y tecnológico del país.

La formación técnica profesional y tecnológica, es impartida en los 116 Centros de Formación que dan cobertura a todo el país; así mismo, brinda servicios de formación continua del recurso humano vinculado a las empresas; información; orientación y capacitación para el empleo; apoyo al desarrollo empresarial; servicios tecnológicos para el sector productivo, y apoyo a proyectos de innovación, desarrollo tecnológico y competitividad.

La Ley 119 mantiene la unidad jurídica y organizativa de la Entidad; su carácter estatal de interés público; su dirección y administración tripartita (gobierno, trabajadores y empresarios) en los niveles nacional y regional; su adscripción al Ministerio de Trabajo con carácter descentralizado, es decir, con administración independiente y establece el manejo autónomo de su 
presupuesto y el carácter redistributivo de la asignación de los recursos entre regiones, sectores económicos y niveles de la producción. ${ }^{18}$

Las condiciones objetivas que hicieron posible la creación y estructuración del Servicio Nacional de Aprendizaje, SENA, pueden fundamentalmente reducirse a dos: una hace referencia a aspectos socioeconómicos y la otra a elementos de orden institucional.

Por una parte, el SENA es una respuesta al empuje del desarrollo económico y social que el país estaba experimentando en la década de los años 50: proceso de industrialización con base en la sustitución de importaciones, proceso de urbanización por la expansión industrial y la emigración hacia las ciudades de la población rural y expansión del movimiento sindical.

Por otra parte, el SENA surge como producto de una necesidad sentida respecto de una mayor y mejor mano de obra calificada, de la cual fueron conscientes tanto los empresarios como los obreros organizados. (Estrada, 2009, p.85)

Desde sus raíces el SENA tiene una estrecha relación con los empresarios, son coformadores de los aprendices en la etapa práctica de la formación, a través del contrato de aprendizaje; así mismo, las empresas participan de la formación especializada que requiere su entorno productivo, con las nuevas tecnologías que tienen otros países, los egresados constituyen la mano de obra calificada; de esta forma, la formación técnica llega a las empresas.

Sin embargo, como parte del proceso de Contrato de aprendizaje ${ }^{19}$, he observado ${ }^{20}$ que para algunas empresas esta labor de coformadores, la sienten

\footnotetext{
18 http:/ / biblioteca.sena.edu.co/
} 
como una pérdida de tiempo y desgaste institucional, prefieren monetizar el valor de los contratos de aprendices y minimizar el afianzamiento de las competencias de los aprendices en la etapa práctica, dejando de lado una de las premisas en la creación de la entidad "una necesidad sentida respecto de una mayor y mejor mano de obra calificada" para el sector productivo del país.

\subsubsection{SENA entidad de Formación para el Trabajo}

El Servicio Nacional de Aprendizaje es la entidad del Estado en cargada de la formación para el trabajo, y la línea de política está dada, con base a los planes de desarrollo del gobierno.

Durante el periodo 2002-2006 con el lema: "SENA: Conocimiento para todos los colombianos", la entidad se trazó como metas: situarse a tono con la globalización y entrar renovada en la era digital; utilización intensiva de su capacidad instalada; la reorientación decidida de las inversiones hacia los procesos de aprendizaje y del talento humano, que constituyen la razón de ser del SENA; la dedicación exclusiva de los instructores a los procesos de aprendizaje; la supresión de burocracia innecesaria; el control a la construcción de edificios nuevos y la adquisición de equipos industriales innecesarios; fueron parte de las estrategias de la entidad celebrar, completamente rediseñada, sus primeros 50 años.

${ }^{19}$ Con esto se ofrece a los empresarios acceder a personal calificado y a los aprendices, realizar prácticas empresariales en ambientes reales. La contratación de aprendices se encuentra regulada por la Ley 789 de 2002,

${ }^{20}$ Diario de campo de la autora, 2017. 
La apertura de alianzas nacionales e internacionales y la disposición de nuevos ambientes de aprendizaje, le permitieron generar calidad, pertinencia y eficiencia en el cumpliendo de su misión en las diferentes regiones del país ${ }^{21}$.

A partir del 2003, el SENA implementa el aprendizaje virtual, con ventajas como la alta cobertura, en 2004, se lanza el programa SENA 24 horas, que incrementa la cobertura de formación profesional y la utilización de los Centros de Formación, entre las 9 de la noche y las 6 de la mañana.

La reestructuración de la entidad, adoptada mediante el Decreto 249 del 28 de enero de 2004, estableció que los instructores deben dedicar 32 horas a la semana para los procesos directos de formación, decisión contrasta con las 26 horas semanales por instructor, que venían rigiendo desde 1997.

Los ambientes virtuales de aprendizaje, constituyen uno de los pilares estratégicos que le permitieron al SENA crecer 263\% en los últimos cuatro años, pasando de ofrecer en sus diversos programas de aprendizaje un total de 1.142.798 cupos en el 2002, a 4.148.809 cupos en el 2006.

La formación virtual ha beneficiado con módulos de especialización a 772.635 colombianos en 1.045 municipios y a otros 2.200 colombianos residentes en 71 diferentes países.

El plan estratégico de la entidad, 2007-2010, busca dar respuesta a los retos que enfrentará Colombia, derivados de la profundización en la globalización de la economía, a la necesidad de una transformación a fondo del aparato productivo nacional en términos de su diversificación, especialización y modernización, y a la búsqueda de un desarrollo social y económico.

\footnotetext{
${ }^{21}$ http://www.sena.edu.co/Portal/Direcci\%C3\%B3n+General/Historia+del+SENA/
} 
Las universidades han abierto las puertas a los técnicos y tecnólogos para que continúen su cadena de formación y alcancen su título profesional, lo cual constituye un estímulo adicional para nuestros egresados.

El SENA está al día en conocimiento, desarrollo tecnológico e innovación, pero mantiene su dinámica de cambio, a fin de seguir proporcionando la herramienta fundamental para que un país salga de la pobreza y las empresas sean más competitivas. ${ }^{22}$

En el 2002 la entidad ofreció 1.141 .000 cupos de formación, esa meta ha ido incrementándose y a 2006 atenderá 4.066 .000 cupos, tiene cobertura a nivel nacional, actualmente atiende a los 1.098 municipios del país, la formación que ofrece el SENA, de cada 100 alumnos que atiende, 74 pertenecen a los estratos 1 y $2 .{ }^{23}$

El SENA debe tener en cuenta más la atención a clientes, "se encuentra en un $0,5 \%$ " lo que demuestra que son una de las debilidades que se deben reforzar ya que existen muchos planes y programas pero los usuarios en si no los conocen y no saben cómo acceder a ellos. (Castro, 2012, p.47)).

En el año 2011 el SENA presentó su Plan de Desarrollo Estratégico 2011-2014, donde indica el quehacer institucional para ese período, con referentes de orden nacional e internacional como los Objetivos de Desarrollo del Milenio, el Plan Nacional de Desarrollo, los Planes Sectoriales y varios planes y programas institucionales, y la intención del gobierno respecto a la estabilidad funcional del SENA: la formulación estratégica del SENA establece

\footnotetext{
22 http://www.sena.edu.co/Portal/Direcci\%C3\%B3n+General/Direcci\%C3\%B3n+de+F ormaci \%C3 \% B3n+Profesional/Formacion+en+TICs/Generalidades.htm 23

http://www.sena.edu.co/Portal/Direcci\%C3\%B3n+General/Direcci\%C3\%B3n+de+F ormaci $\%$ C3\%B3n+Profesional/Separata/
} 
una visión al 2020 la cual proyecta al SENA como una institución de clase mundial para beneficio de los colombianos.

El modelo estratégico concibe al SENA como una Entidad que contribuye a la competitividad del país, a través de dos grandes propósitos: el incremento de la productividad de las empresas y las regiones y la inclusión social de personas y comunidades vulnerables ${ }^{24}$.

Con frecuencia, los estudiantes optan por carreras de "formación profesional" solo cuando no han encontrado una plaza en las carreras generales de estudios superiores. Por esta razón, "es necesario orientar estrechamente las ofertas de formación y educación profesional hacia la necesidad del mercado laboral y de las empresas"; es necesario diseñarlas con mayor relevancia para el empleo y simultáneamente más transparentes para el sistema educativo de formación general, tornándolas más atractivas para todos los interesados. ${ }^{25}$

En un estudio realizado por el Ministerio de Educación en 2011, se muestra el comportamiento de la matrícula en los distintos programas educativos. Allí, se evidencia que el estrato 1 es el que tuvo mayor aceptación del programa Técnico laboral de SENA; además, existió mayor participación por parte de los estratos bajos en estudiar programas de educación para el trabajo y desarrollo humano como programas técnicos y tecnólogos (García, 2016, p.35).

24 SENA, Plan estratégico 2011- 2014 con visión 2020 (2011) ,1, <http://www.sena.edu.co/acercadel- sena/planeacion-estrategica/Documents/informesgestion/ PE\%20SENA\%202011\%E2\%80\%932014.pdf >.

25 Natalia Ariza Ramírez, Sistema de Educación Terciaria (Ministerio de Educación, 2013), $\langle$ http://www.mineducacion.gov.co/1621/articles-323714_presentacion_1.pdf〉. ${ }_{61} \mathrm{Ib}$ íd. 
Con base en el actual Plan Nacional de Desarrollo del Gobierno Nacional, el SENA ha definido su plan estratégico para el 2015 - 2018, asume la formación del capital humano, con calidad y pertinencia; generación de las normas de competencia laboral en concordancia con las características del trabajo decente, respondan a las particularidades definidas por las Mesas Sectoriales que lidera el Servicio Nacional de Aprendizaje en articulación con el sector productivo, gubernamental y académico.

De igual forma, contribuirá con la certificación de competencias laborales que reconocen saberes previamente adquiridos, mejorando la empleabilidad de las personas para su vinculación al mundo del trabajo.

Siendo el capital humano una variable relevante en la productividad, y de acuerdo con los resultados de los estudios de diagnóstico y de participación ciudadana previos a la construcción de este plan, se evidencia que persiste en el país disparidad entre las competencias laborales de los trabajadores frente a aquellas que requieren los empleadores, situación que se traduce en disminución de la productividad laboral y del crecimiento económico. Aún existe un alto déficit de oferta laboral en los niveles técnico y tecnológico y además los empresarios encuentran insuficiencia de habilidades laborales tanto técnicas como blandas. (Plan Estratégico SENA 2015- 2018)

De esta manera, concluimos que el SENA cumple su misión de formación para el trabajo de acuerdo a Plan de Desarrollo del Gobierno de turno y lo plantea en el Plan de Estratégico Institucional.

Así las cosas, en el periodo 2002 - 2010 el SENA amplió su cobertura, atendiendo los municipios del país, incrementa su capacidad en cupos de formación, maximizando el uso de sus muebles e inmuebles, a través de la formación virtual, estableciendo nuevas y modificando jornadas, la formación 
técnica se adelanta en un año: seis meses de etapa lectiva y seis meses de etapa práctica.

En atención al diario de campo, ${ }^{26}$ los empresarios han planteado que los aprendices en la etapa práctica y los egresados presentan inhabilidades laborales en su desempeño ocupacional.

El SENA reconoce en el Plan Estratégico 2015-2018 que persiste en el país disparidad entre las competencias laborales de los trabajadores frente a aquellas que requieren los empleadores, y los empresarios encuentran insuficiencia de habilidades laborales tanto técnicas como blandas de los egresados.

\subsubsection{La propuesta SENA: Formación Profesional Integral}

El SENA como una entidad de formación y en cumplimiento de la normatividad ha elaborado el Proyecto Educativo Institucional PEI y lo ha venido actualizando para hacerlo pertinente a los lineamientos de política dados por los planes de desarrollo, para el presente trabajo, expondremos la propuesta de Formación Integral del Servicio Nacional de aprendizaje SENA, está definida en Proyecto Educativo Institucional SENA 2013.

\section{Formación Profesional Integral}

Es el proceso mediante el cual los aprendices adquieren y desarrollan: conocimientos, destrezas, y aptitudes; identifican, generan y asumen: valores y actitudes; participan activamente en: el trabajo productivo y en la toma de

${ }^{26}$ Clavijo, C.G.. (2015) Diario de Campo 
decisiones. ${ }^{27}$ Dada la naturaleza de la Formación Profesional Integral, el eje de la misma es el Aprender a Hacer.

\section{Principios de la Formación Profesional Integral28}

- El Trabajo Productivo: La aceptación de que el desarrollo de las facultades humanas se logra fundamentalmente a través del trabajo, esto es, mediante la transformación intencional que el hombre hace de su entorno físico y social.

- La Formación Permanente: El reconocimiento del derecho y el deber del sujeto de formación de ser gestor de su propio desarrollo en todas las dimensiones, a través de toda la vida, en razón a su cotidiana interacción con los demás y con el medio productivo.

- La Equidad Social: Ofrece una gama de opciones formativas en condiciones adecuadas de acceso, permanencia o tránsito, según las posibilidades, inclinaciones y conveniencia de las personas de manera gratuita y oportuna.

- La Integralidad: Concibe la formación como un equilibrio entre lo tecnológico y lo social; comprende el obrar tecnológico en armonía con el entendimiento de la realidad social económica, política, cultural, estética, ambiental y del actuar práctico moral.

\section{Objetivos de la Formación Profesional Integral29}

\footnotetext{
${ }^{27}$ sistemaintegradodegestionceet.blogspot.com/.../proyecto-educativo-institucionalsena..

${ }^{28}$ Idem

${ }^{29}$ Idem
} 
- El Aprender a Aprender, que se orienta hacia el desarrollo de la originalidad, la creatividad, la capacidad crítica, el aprendizaje por procesos y la formación permanente.

- El Aprender a Hacer, en e1 cual se involucra ciencia, tecnología y técnica, en función de un adecuado desempeño en el mundo de la producción.

- El Aprender a Ser, que se orienta al desarrollo de actitudes acordes con la dignidad de la persona y con su proyección solidaria hacia los demás y hacia el mundo.

\section{Componentes de la Propuesta de la Formación Profesional Integral ${ }^{30}$}

- Componente antropológico: la persona que participe en el Proceso de Formación Profesional Integral desarrolla competencias específicas, transversales y básicas, que le posibilitan el desempeño pertinente y de calidad en el mundo de la vida y del trabajo; lo cual implica la comprensión crítica de los procesos sociales y económicos; así como la generación de actitudes y valores que fortalezcan su compromiso de responsabilidad frente a sí mismo, a la comunidad, al trabajo y a la naturaleza.

- Componente Axiológico: El proceso de formación procurara la apropiación y el desarrollo de competencias cognitivas, operativas y actitudinales del Aprendiz, es decir, buscará una capacitación técnica de calidad y la madurez humana del Aprendiz, para que logre alcanzar la coherencia entre lo que piensa, lo que dice y lo que hace.(Manual Diseño Curricular, SENA, 2002, p.62).

\footnotetext{
30 Servicio Nacional de Aprendizaje SENA. Lineamientos plan de acción 2013

"Aprendiz SENA Siglo XXI". 2012. Dirección de Planeación y Direccionamiento Corporativo. Bogotá.
} 
- Componente Epistemológico: los proyectos de formación la aplicación del conocimiento, el desarrollo de habilidades de pensamiento, síntesis, análisis, deducción, inducción, entre otras, propias del saber; el desarrollo de habilidades de carácter biofísicas requeridas para el hacer; y por otra parte, el desarrollo de competencias básicas inherentes al ser, como: actitud ética, comunicación asertiva, trabajo en equipo.

\section{Enfoque para el Desarrollo de Competencias ${ }^{31}$}

La Formación Profesional Integral del SENA se realiza por competencias de manera permanente en el proceso de enseñanza, aprendizaje y evaluación, su punto de partida lo constituye el proyecto de vida personal del Aprendiz, se contextualizan en el marco del programa de formación y se evidencian en los entornos sociales y productivos en donde el aprendiz intervenga mediante sus desempeños.

Competencia Laboral es la capacidad del aprendiz en términos de desempeños reales, es la convergencia de conocimientos, habilidades y actitudes necesarias para el desempeño productivo.

Competencias Específicas: son las identificadas en las Normas de Competencias Laboral, propuestas por el sector productivo en las Mesas Sectoriales y se constituyen en el referente para el diseño de los Programas de Formación.

Competencias Básicas es el conjunto dinámico de capacidades para el desempeño en el mundo de la vida que facilitan a la persona su inserción y permanencia en el mundo del trabajo, y le permiten comprender, argumentar

\footnotetext{
${ }^{31}$ Servicio Nacional de Aprendizaje, SENA, Manual de Diseño Curricular para el Desarrollo de Competencias en la Formación Profesional Integral. 2005. Dirección de Formación Profesional. Bogotá.
} 
y resolver problemas tecnológicos, sociales y ambientales, se logran de modo permanente en el proceso de formación profesional.

Competencias Transversales son necesarias para complementar los desempeños sociales y laborales del aprendiz; como su nombre lo indica son de carácter transversal, atraviesan las ocupaciones establecidas en la Clasificación Nacional de Ocupaciones ${ }^{32}$ y por lo tanto, todas y cada una de las estructuras de los programas de formación dado que no están enmarcadas en ninguna disciplina específica. ${ }^{33}$

Ante los planteamientos, que anteceden, podemos responder ¿En qué consiste la propuesta de Formación Profesional Integral del SENA?

Al respecto se concluye que la Formación Profesional Integral del SENA es un proceso de formación del recurso humano que genera capital humano, donde los individuos adquieren y desarrollan conocimientos, destrezas y aptitudes, identifican, generan y asumen valores y actitudes, participan en el mundo del trabajo y tomen decisiones con un sentido de vida propio; es decir, desarrollan sus capacidades y definen su proyectos de vida, en una proyección del Desarrollo Humano Integral.

\footnotetext{
32 la información ocupacional en la Clasificación Nacional de Ocupaciones (C.N.O)., en la cual se presenta la organización sistemática de las Ocupaciones existentes en el mercado laboral colombiano. La contribución de la C.N.O. es importante para el diseño e implementación de servicios SENA http://www.sena.edu.co/esco/trabajo/Documents/instructivo_2016.pdf

33 SENA Clasificación Nacional de Ocupaciones C.N.O. 2013. http://www.sena.edu.co/es-co/trabajo/Documents/instructivo_2016.pdf
} 


\section{EL ENTORNO DE LOS APRENDICES SENA}

La Formación Profesional Integral denominado "PFI" del SENA, se plantea la generación del conocimiento en el argumento de la ciencia, en la investigación, desarrollo e innovación tecnológica que se adelantan en el contexto productivo y son llevados a cabo mediante la metodología general de la formulación y resolución de problemas, a través de la estrategia general del Aprendizaje por Proyectos en cuya esencia subyace la enseñanza y el aprendizaje problémico.

\subsection{Enfoque de la Formación SENA}

El enfoque pedagógico de la Formación Profesional Integral está centrado en el logro de competencias y presenta un carácter problémico, sistémico, integrador e interdisciplinario dentro de un marco socioconstructivista.

Está orientado hacia la comprensión, el aprendizaje significativo, el aprender a aprender, el aprendizaje colaborativo, el desarrollo cognitivo y moral, el desarrollo de la autonomía, del espíritu crítico y de la dimensión praxiológica; es decir, hacia el Desarrollo Humano Integral cuyo fin último es la transformación de la realidad.

Con el propósito de presentar de manera sintética el proyecto educativo del SENA, se enfatiza que este responde a las exigencias y necesidades que el mundo actual exige y es propuesto como un proceso formativo estructurado y con una visión de lo humano para lo humano que está centrado en el aprendiz como sujeto de aprendizaje en y para la vida enmarcado en un sólida formación en valores, actitudes y emociones que se integran para dar 
estructura a las competencias y a la formación cognitiva de un aprendiz para que resuelva problemas por medio de competencias en el saber, hacer y el $\operatorname{ser}^{34}$.

De igual forma asume el aprendizaje por proyectos y este se constituye en la estrategia didáctica activa por excelencia, propiciando las condiciones para la gestión holística sistémica de lo cognitivo y propende por la formación integral, entendida esta como el desarrollo de habilidades de pensamiento, actitudes y comportamiento que convaliden desempeños éticos.

Se pretende un aprendiz integral que dé respuestas desde lo cognitivo a realidades socio-humanísticos con un actuar ético comprometido con su entorno.

Así mismo, el SENA se asume desde el marco de Política Institucional como son: la Ley 119 de 1994, el Acuerdo 12 de 1985, Unidad Técnica y el Acuerdo 00008 de 1997 Estatuto de la Formación profesional Integral. Éste último, estructurado como documento marco para dar respuesta a la Misión asumida en la Ley 119 de 1994.

En el orden nacional el SENA se enmarca dentro del Plan Nacional de Desarrollo 2010-2014 "Prosperidad para todos" y asume que más empleo, menos pobreza y más seguridad. (Proyecto educativo institucional 2013, pág.5).

En la formulación estratégica del SENA 2015-2018, esta le apuesta a un país en paz, equitativo y educado de cara a la nueva realidad económica, tecnológica y a las exigencias laborales del país.

El plan estratégico del SENA, asume unos principios a saber: primero la vida, la dignidad del ser humano, la libertad con responsabilidad, el bien

34 SENA Proyecto Educativo Institucional 2013 ajustado - 2015 
común prevalece sobre los intereses particulares, formación para la vida y el trabajo. De igual forma, unos valores como son: el respeto, el libre pensamiento y actitud crítica, solidaridad, justicia y equidad, la creatividad y la innovación y unos compromisos institucionales como lo son: convivencia pacífica, coherencia entre el pensar y el actuar, disciplina, dedicación y lealtad, promoción del emprendimiento y el empresarismo, responsabilidad con la sociedad y el medio ambiente y la honradez. (Plan estratégico 2015-2018 pág. $11)$.

Los anteriores convierten al SENA en una institución de formación para el trabajo, la productividad, comprometida con la formación integral del aprendiz como sujeto de acciones y decisiones frente a su proyecto de vida personal y social.

La visión del SENA para el año 2018, será reconocida por la efectividad de su gestión, sus aportes al empleo decente y a la generación de ingresos, impactando la productividad de las personas y de las empresas; que incidirán positivamente en el desarrollo de las regiones como contribución a una Colombia educada, equitativa y en paz." (Plan estratégico 2015-2018 pág. 10).

Se pretende en rutar todas sus acciones para el posicionamiento de esta en el contexto colombiano como una institución de talla mundial que se preocupa por el talento humano de manera integral. (Plan estratégico 20152018 pág. 12)

En esta propuesta formativa se componente pedagógico destacan los roles del instructor y del aprendiz, nos conlleva a definir el perfil de aprendiz, instructor y por ende del egresado.

Perfil del aprendiz, se considera una persona activa, proactiva, con actitudes positivas frente al proceso de aprendizaje, abierto y comprometido con sus procesos, autónomo, crítico, responsable, creativo e innovador y con 
un alto nivel de autorregulación de sus procesos y con una alta capacidad de aprender colaborativamente, con sentido de autoevaluarse y evaluar al otro como componente de sus desempeños profesionales ${ }^{35}$.

Perfil del instructor, en el contexto pedagógico descrito al instructor le corresponde el rol de mediador de la cultura y promotor del aprendizaje y el desarrollo de los aprendices. El instructor en el SENA debe ser una persona reflexiva, autónoma, crítica, creativa, rigurosa y flexible. Ser modelo y ejemplo de vida para los aprendices y una persona en permanente proceso de mejoramiento personal y profesional. Debe evidenciar unas competencias comunicativas, pensamiento lógico, crítico y creativo ${ }^{36}$.

Perfil del egresado, se denomina egresado a toda persona que participe en procesos de Formación Profesional Integral desarrollando y evidenciando capacidades técnicas, intelectuales, sociales y cívicas que le permitan desempeñarse productivamente en su trabajo, comprender críticamente los procesos sociales y económicos de que es partícipe y generar actitudes y valores que fortalezcan su compromiso de responsabilidad frente a sí mismo, a la comunidad, al trabajo y a su medio ecológico, dentro de los lineamientos democráticos que consagran la Constitución Nacional y las Leyes de Colombia ${ }^{37}$.

Actualmente, el SENA a través de la oficina pública de empleo atiende la población vulnerable, entendida esta como el grupo de personas que se encuentran en estado de desprotección o incapacidad frente a una amenaza a su condición psicológica, física y mental, entre otras. La discriminación es una forma de violencia pasiva; convirtiéndose, a veces, en una agresión física.

\footnotetext{
35 SENA Plan Estratégico 2015-2018

36 Idem

${ }^{37}$ Idem
} 
El SENA atiende las poblaciones víctimas de la violencia, personas con discapacidad, desplazadas por fenómenos naturales, indígenas, Instituto Nacional Penitenciario y Carcelario, mujeres cabeza de familia, jóvenes vulnerables, adolescentes en conflicto con la ley penal, desplazados de las Farc. De igual forma, atenderá grupos poblacionales como: afrodescendientes, negritudes, palenqueros, raizales, gitanos, población LGBTI. ${ }^{38}$

\subsection{Caracterización de Aprendices}

Al ingresar al SENA los aprendices diligencian la Encuesta Social de Caracterización o Ficha de caracterización, (Anexo 2), donde brindan a la institución información socioeconómica, busca conocer los aprendices y fortalecer la atención oportuna y pertinente a los requerimientos del entorno con el programa de Bienestar al Aprendiz.

A continuación observaremos los resultados obtenidos en la ficha de caracterización de aprendices 2013-2014 del Centro de Biotecnología Agropecuaria - Mosquera, en la Formación Técnica de los programas de Recursos Humanos, Seguridad Ocupacional y Nómina y Prestaciones Sociales, (Bases de Datos: Anexo 1)39, en la muestra de 224 aprendices, muestran la caracterización de los aprendices que ingresaron a estas formaciones técnicas:

\footnotetext{
38 Normatividad: Ley $144 \quad 8$ de 2011. Ley 1618 de 2003. Auto 0004 de 2009. Ley 1151 de 2007. CONPES 3567. Ley 1709 del 2014.

39 SENA aplicativo Sofía Pluss -Bases de datos Egresados 2014-2015
} 


\section{Gráfico No 1. Sexo - Rango de Edad de los Aprendices:}

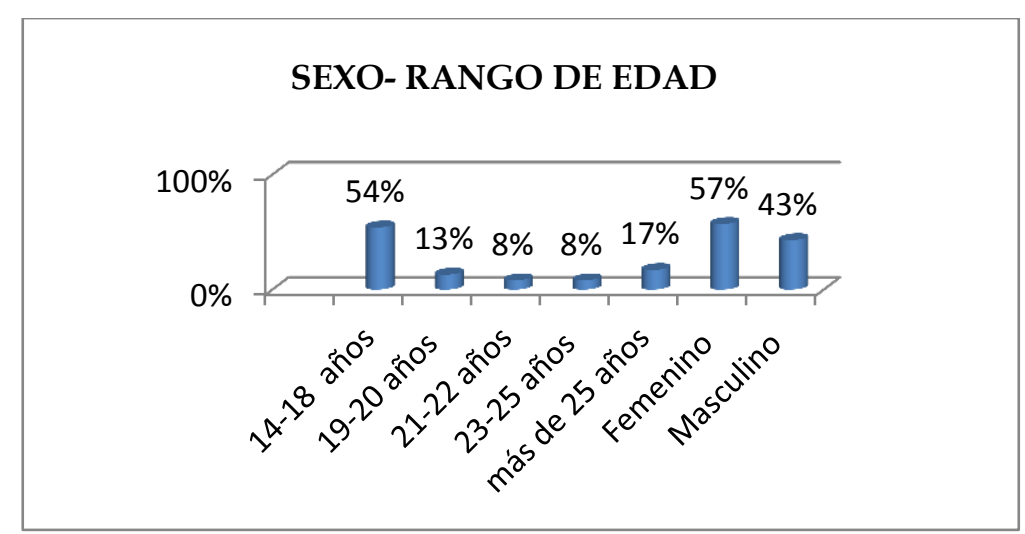

Fuente: cálculos de la investigadora.

A las formaciones técnicas en Recursos Humanos, Seguridad Ocupacional y Nómina y Prestaciones Sociales ingresaron en el período de 2013 - 2014 se vincularon un 54\% de mujeres y un 43\% de hombres; por grupos de edad la mayor participación está dada por lo jóvenes entre los 14 y 18 años, con un porcentaje del $8 \%$ los grupos de edad de 20 a 22 años y 23 a 25 años, seguido del grupo de 19 a 20 años con el 13\% y con un 17\% los mayores de 25 años. Es decir el 83\% son jóvenes menores de 26 años.

\section{Gráfico No 2. Municipio de Residencia y Procedencia}

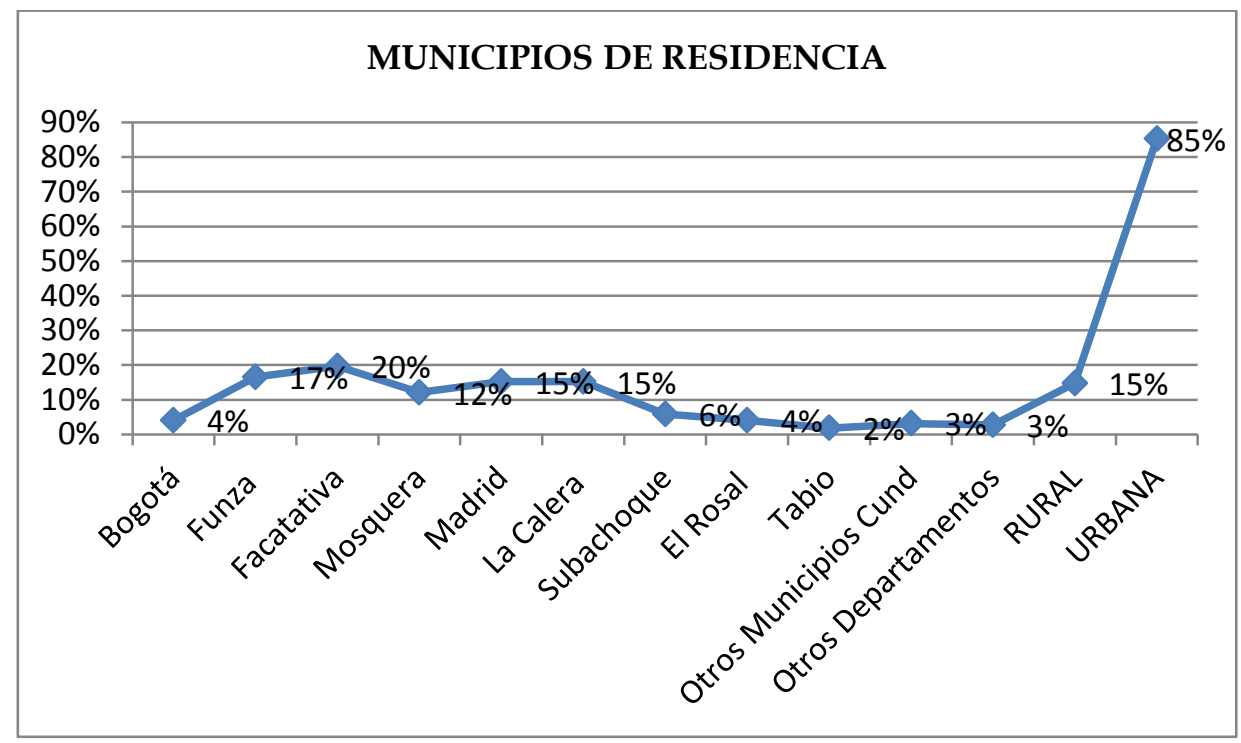

Fuente: cálculos de la investigadora 
El Centro de Formación Biotecnología Agropecuaria SENA Mosquera tiene cobertura de 19 municipios de Cundinamarca a saber: Bojacá, Cachipay, Cota, El Rosal, Facatativá, Funza, Gachetá, Gachalá, Gama, Guasca, Junín, La Calera, Madrid, Mosquera, Subachoque, Tenjo, Tabio, Ubalá y Zipacón. La formación técnica se realiza en la Sede principal municipio de Mosquera y en Subsedes en los otros municipios, por tal razón estas localidades tiene la mayor participación Facatativá 20\%, Funza 17\%, Madrid 15\%, La Calera 15\%, Mosquera 12\%, Subachoque 6\%, El Rosal 4\% y Tabio 2\%; aprendices que viven en Bogotá con un 4\%, de otros municipios de Cundinamarca y otros departamentos presentan un igual porcentaje de participación del 3\%. Es importante mencionar que el $85 \%$ de los aprendices provienen de la zona urbana y un $15 \%$ provienen de la zona rural de los municipios, y en un $90 \%$ provienen de los municipios de cobertura del Centro de Formación de Mosquera.

Gráfico No. 3. Vivienda

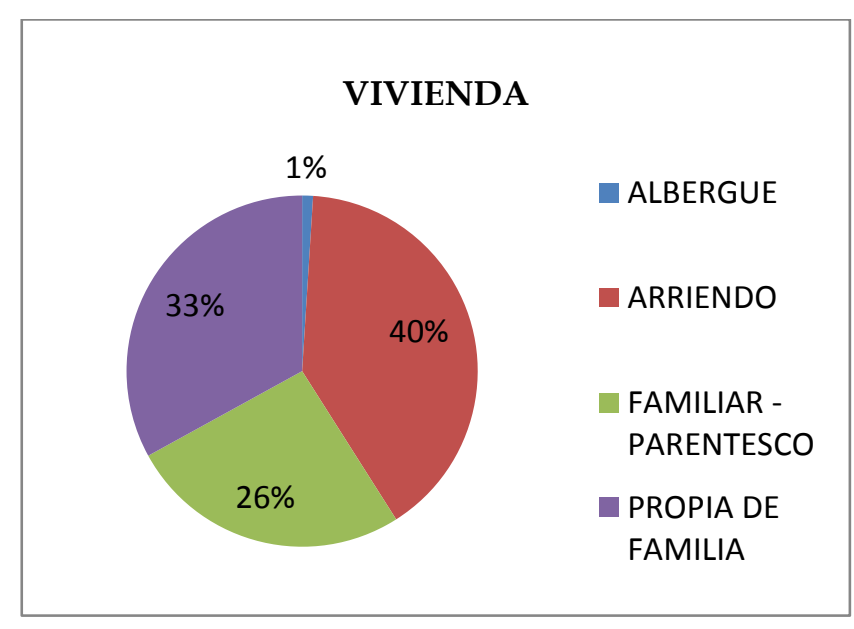

Fuente: cálculos de la investigadora

Los aprendices habitan en inmuebles en arriendo un 40\%, inmueble propia de la familia o núcleo familiar $33 \%$, familia de parentesco un $26 \%$ y en 
albergue un 1\%; significa que ninguno posee vivienda propia, depende de su familia para el lugar de habitación.

\section{Gráfico No. 4. Trabajo y Estudio}

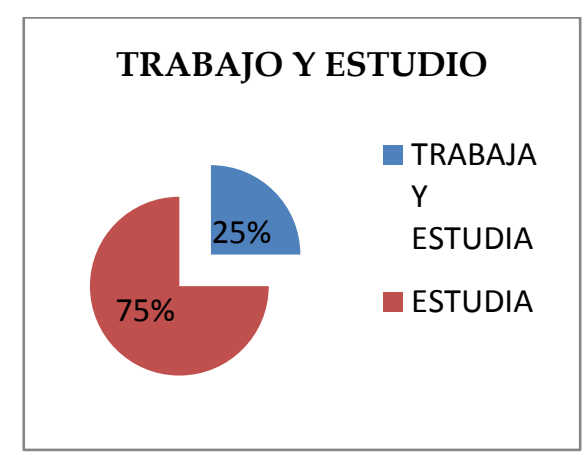

Fuente: cálculos de la investigadora

Los aprendices de las formaciones técnicas de Nómina y Prestaciones Sociales, Recursos Humanos y Seguridad Ocupacional en un 75\% están dedicados a su formación y solamente un $25 \%$ combina el estudio con el trabajo. Por lo tanto en un $75 \%$ los aprendices dependen de sus familias, son jóvenes y $83 \%$ menores de 25años, el 90\% están ubicados en los municipios de cobertura del Centro de Formación SENA Mosquera, y el 85\% provienen de la zona urbana.

\section{Gráfico No 5. Afiliación a Salud}

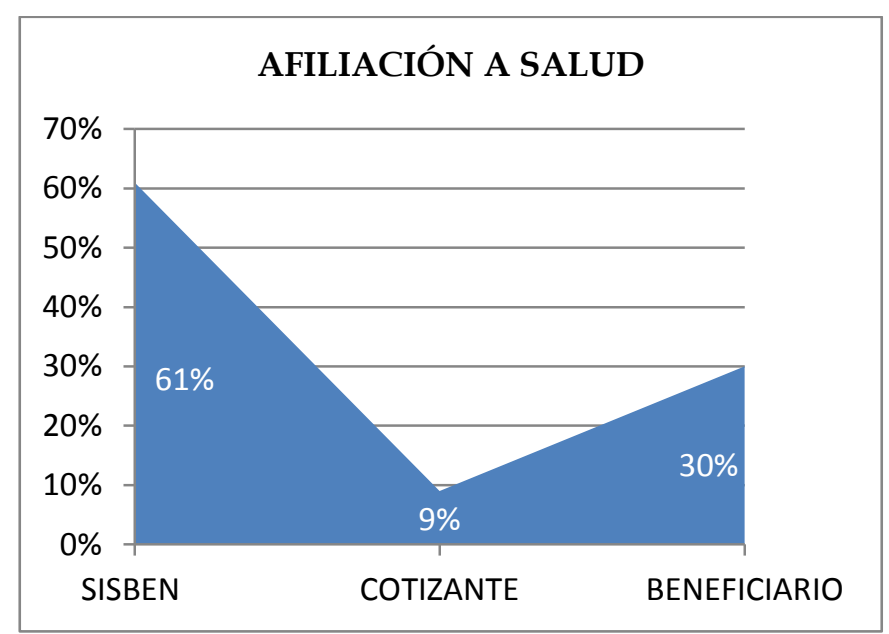

Fuente: cálculos de la investigadora 
Todos los aprendices están vinculados al sistema de salud, el $61 \%$ tiene afiliación al sistema de salud en forma subsidiada, el 30\% como beneficiario y un $9 \%$ como cotizante, es decir el $91 \%$ hace parte del sistema de salud con aportes de terceros.

\section{Gráfico No. 6 Población Vulnerable}

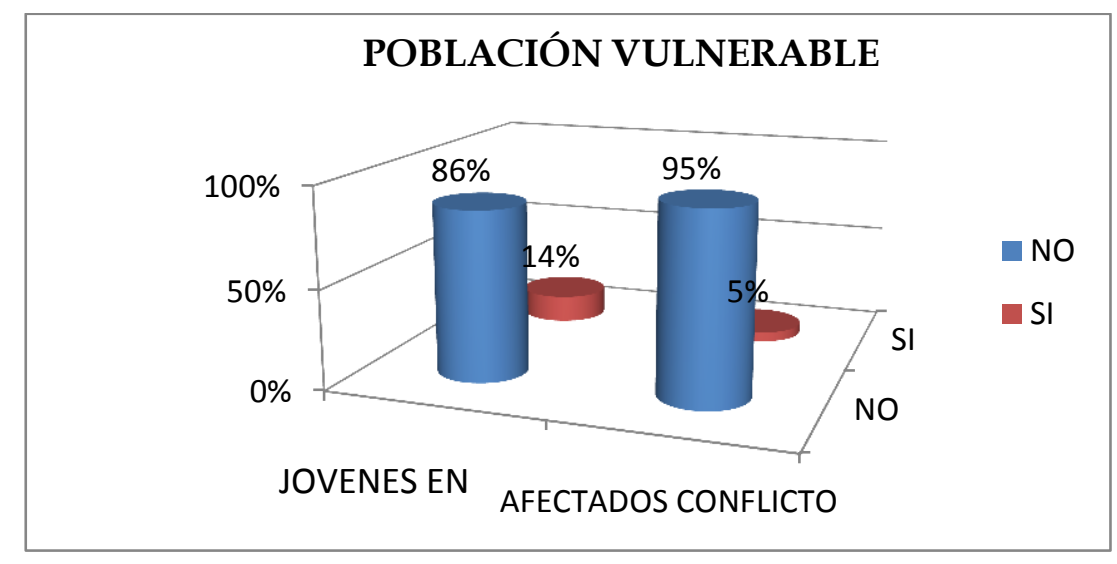

Fuente: cálculos de la investigadora

Los aprendices en un porcentaje del $14 \%$ se manifiestan están en el programa de Jóvenes en Acción del Departamento para la Prosperidad Social que brinda apoyo a los jóvenes que quieren continuar sus estudios superiores y no pueden hacerlo por sus condiciones de vulnerabilidad, en este programa el joven puede recibir hasta $\$ 200.000$ mensuales para apoyar los gastos de manutención, y un 5\% manifiestan ser víctimas del conflicto armado; es decir el 19\% hace parte de población vulnerable. 


\section{Gráfico No 7. Problemáticas de los Aprendices}

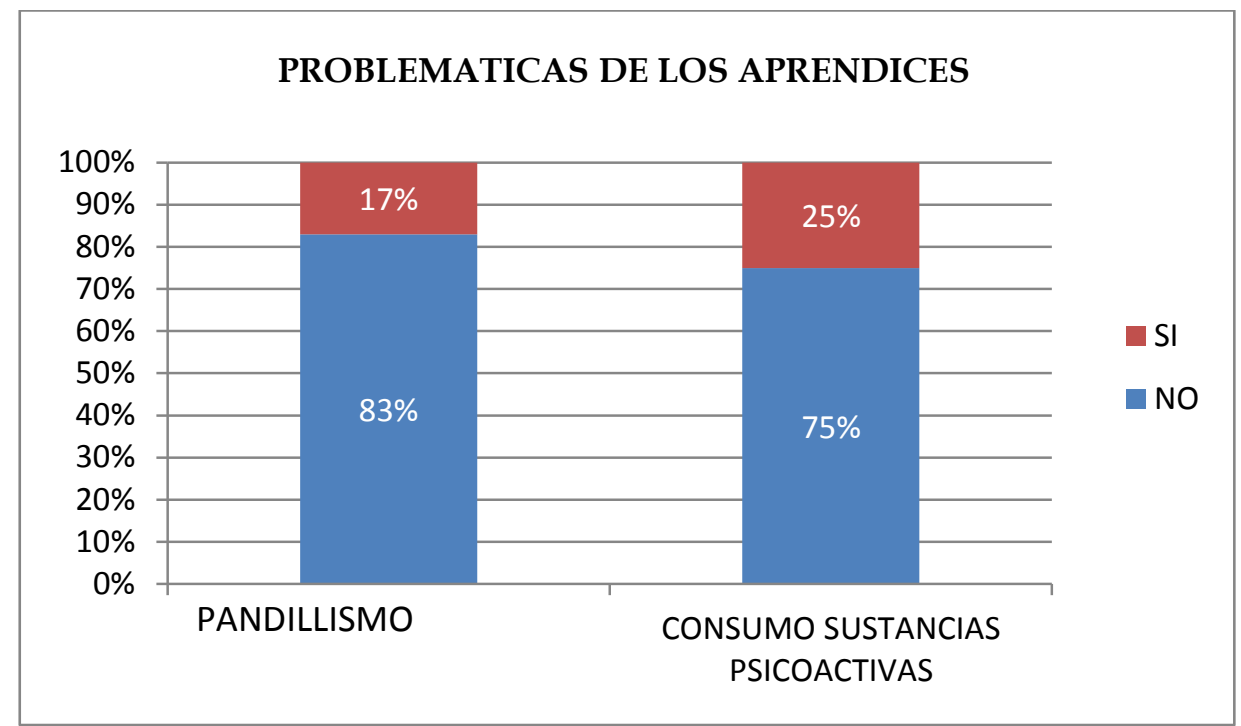

Fuente: cálculos de la investigadora

Algunos aprendices manifiestan al entrar al SENA que pertenecen a pandillas en un $17 \%$ y consumen sustancias psicoactivas en un $25 \%$, es decir el $42 \%$ de los aprendices presenta problemáticas.

Gráfico No. 8. Fuente de Ingresos

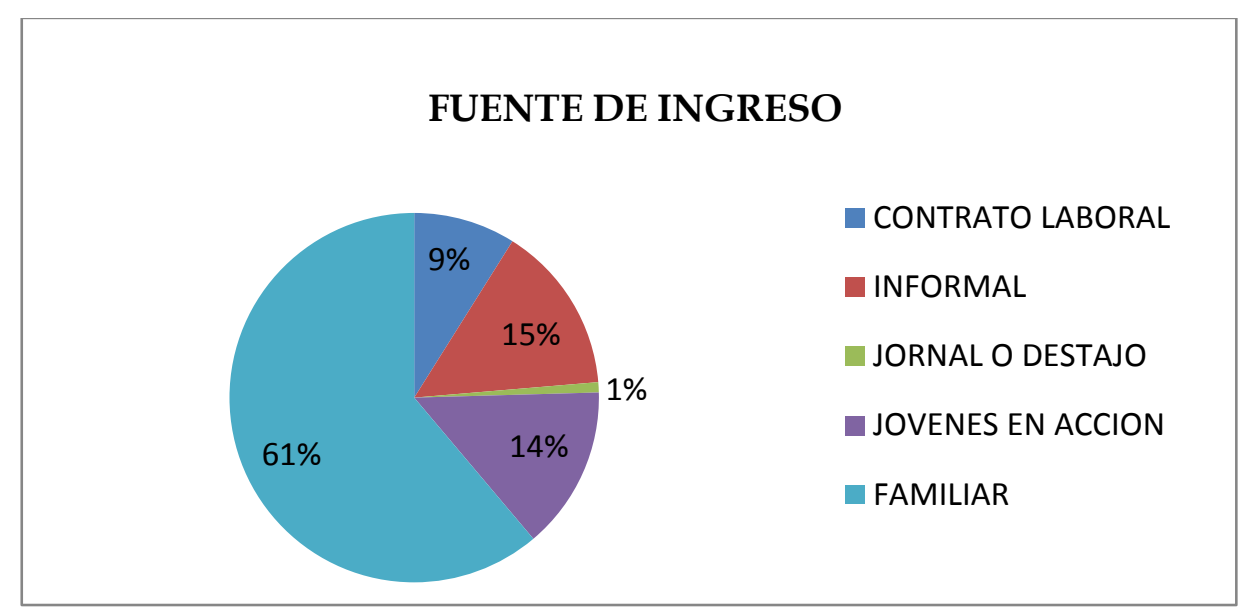

Fuente: cálculos la investigadora 
La fuente de ingresos de los aprendices están dados en un $61 \%$ por ingresos familiares, un $15 \%$ recibe ingresos por trabajo informal, el $14 \%$ perciben ingresos del programa de Jóvenes en Acción, un 9\% por contrato laboral y $1 \%$ por jornal y destajo. Por lo tanto, el $25 \%$ de los ingresos de los aprendices proviene de labores de trabajo y el $75 \%$ procede de terceros: familia y apoyos del gobierno.

\section{Gráfico No 9. Nivel de Ingresos}

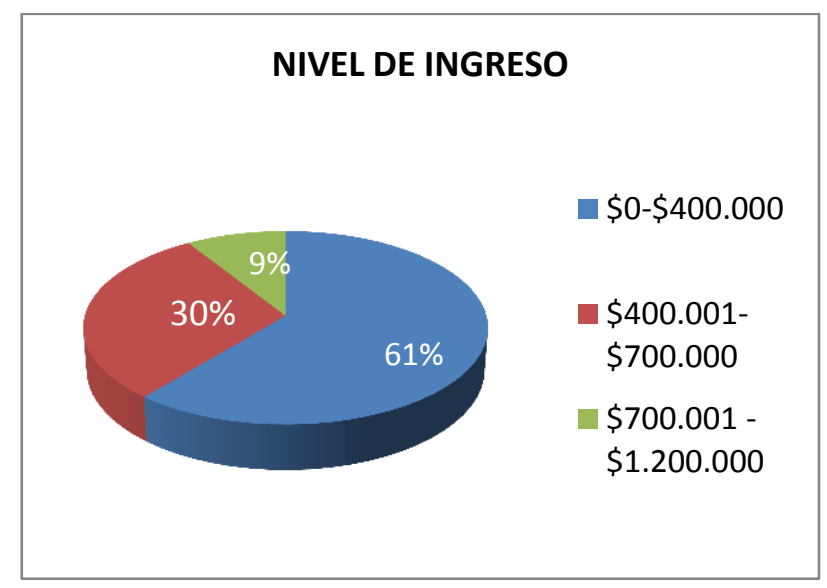

Fuente: cálculos de la investigadora.

El ingresos mensuales que perciben los aprendices en un $61 \%$ corresponde a ingresos son menores de $\$ 400.000$, donde están incluidos los Jóvenes en Acción 14\% que perciben ingresos menores de $\$ 400.000$ como apoyo de manutención, el 9\% presenta ingresos superiores a $\$ 700.000$, corresponde a los aprendices que tienen contrato laboral y devengan un salario y subsidio de transporte, salario mínimo, $\$ 689.454$ y subsidio de transporte $\$ 77.700$ de 2016 , $y$ un $30 \%$ con ingresos entre los $\$ 400.000$ a los $\$ 700.000$. 


\section{Gráfico No 10. Actividades Extra Curriculares}

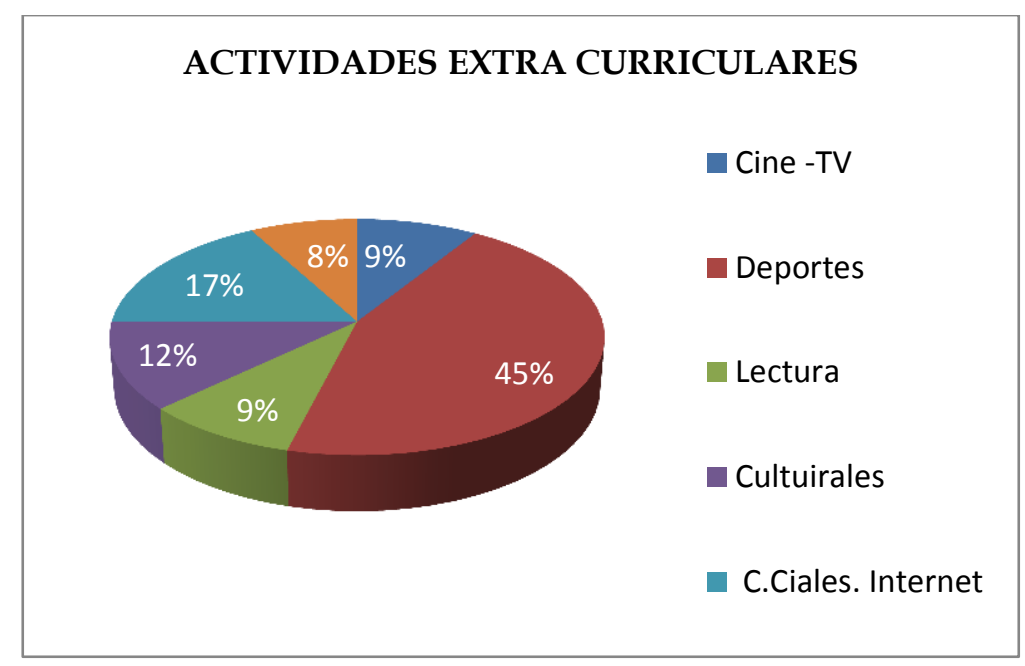

Fuente: cálculos de la investigadora

Los aprendices al iniciar la formación manifiestan que realizan actividades deportivas en un $45 \%$, en un $17 \%$ realizan actividades de entretenimiento en Centros Comerciales e Internet, el 12\% participan en actividades culturales, el 9\% desarrolla actividades de esparcimiento en la lectura y $9 \%$ en Cine - TV., y un 8\% despliega acciones en otras organizaciones.

Podemos manifestar que los aprendices SENA del Centro de Biotecnología Agropecuaria - Mosquera en las formaciones técnicas en Recursos Humanos, Seguridad Ocupacional y Nómina y Prestaciones Sociales ingresaron en el período de 2013 - 2014 presentan las siguientes características: un 57\% son mujeres, el $83 \%$ corresponde a jóvenes menores de 25 años, el $81 \%$ provienen de la zona urbana de los municipios de cobertura del Centro de formación, no poseen vivienda propia y depende de su familia para el lugar de habitación, un 75\% están dedicados a su formación, dependen de sus familias y apoyos de gobierno, el $61 \%$ corresponde a ingresos son 
menores de \$400.000, donde están incluidos los Jóvenes en Acción, el 91\% hace parte del sistema de salud con aportes de terceros,

La problemática de pandillismo y consumo de sustancias psicoactivas se presenta en un $42 \%$ de los aprendices, y presenta un $19 \%$ de aprendices que están declarados con población vulnerable, Jóvenes en Acción y afectados por el conflicto.

Al relacionar este diagnóstico de los aprendices con el perfil del aprendiz propuesto por el SENA en el Plan Educativo Institucional, tenemos aprendices con actitudes positivas frente al proceso de aprendizaje, abierto y comprometido, como se observa, provienen de en $96 \%$ del departamento, un 19\% corresponde a la población vulnerable, se adaptan a las condiciones de vivienda e ingresos para acceder a la formación, no obstante, se presenta el $42 \%$ de aprendices presenta problemáticas que afectan al formación, sin embargo, la entidad es incluyente y esta situación no descalifica al aprendiz, y busca propiciar niveles de autorregulación y desarrollar la capacidad de aprender con sentido de autoevaluarse. 


\section{CAMBIOS OBSERVADOS EN LA TRANSICIÓN DE APRENDICES A EGRESADOS}

El SENA es la entidad del Estado, es la institución de formación para el trabajo, comprometida con la formación integral del aprendiz como sujeto de acciones y decisiones frente a su proyecto de vida personal y social.

\subsection{Situación de los Egresados}

Con el propósito de conocer el estado en que se encuentran los egresados de 2014 -2015, de la técnica profesional en el SENA, se ha aplicado una encuesta a 224 certificados de los programas de Recursos Humanos, Nómina y Prestaciones Sociales y Seguridad Ocupacional del Centro de Biotecnología Agropecuaria SENA - Mosquera.

\section{Gráfico No. 11. Sexo y Rango de Edad de los Egresados}

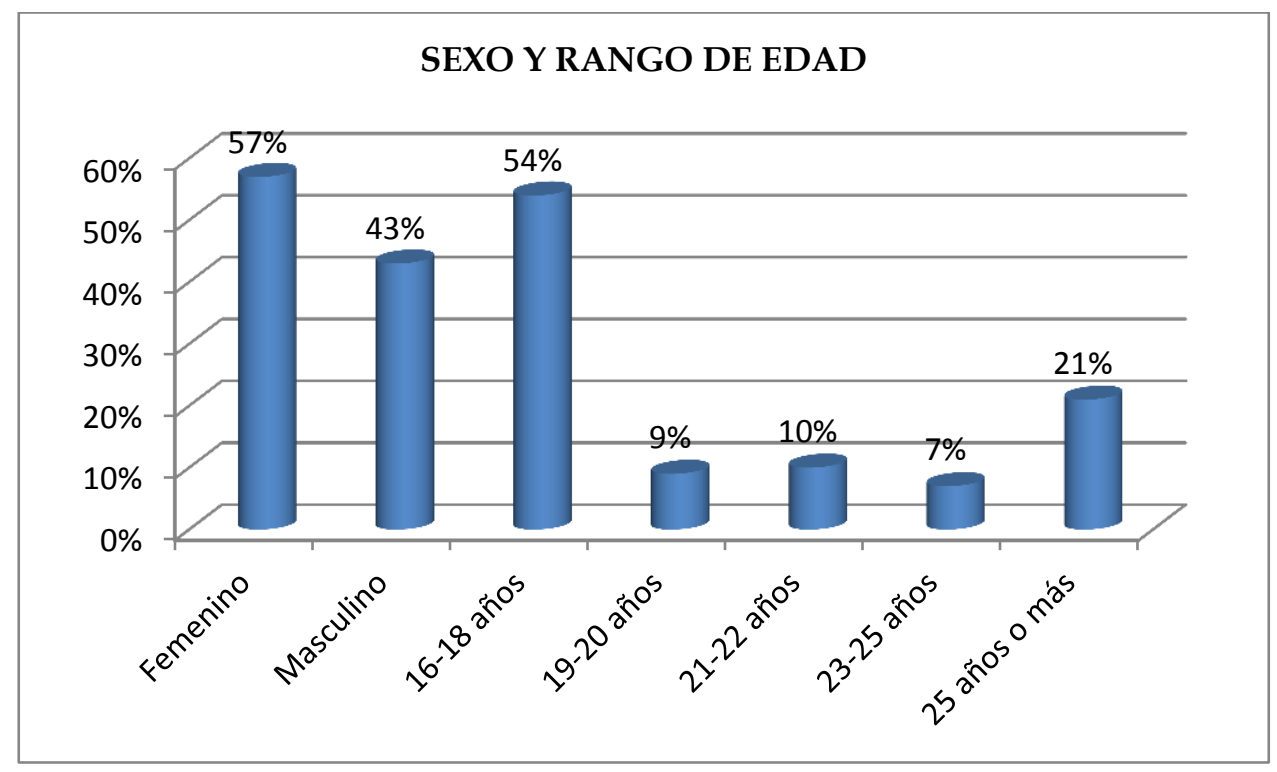

Fuente: cálculos de la investigadora 
Entre los egresados encuestados las mujeres constituyen el $57 \%$ y los hombres el $43 \%$, es decir, conservan la misma tendencia observada en los aprendices; en relación con los rangos de edad el mayor porcentaje lo constituye el grupo etario entre los 16 a 18 años con el 54\%, seguido por los mayores de 25 años con el $21 \%$, con un 9\% los grupos de edad de 19 a 20 años, 21 a 22 años con un 10\% y con un 7\% el grupo de edad entre los 23 a 25 años, es decir el 79\% corresponde amenores de 25 años.

\section{Gráfico No. 12. Municipios de Residencia y Trabajo}

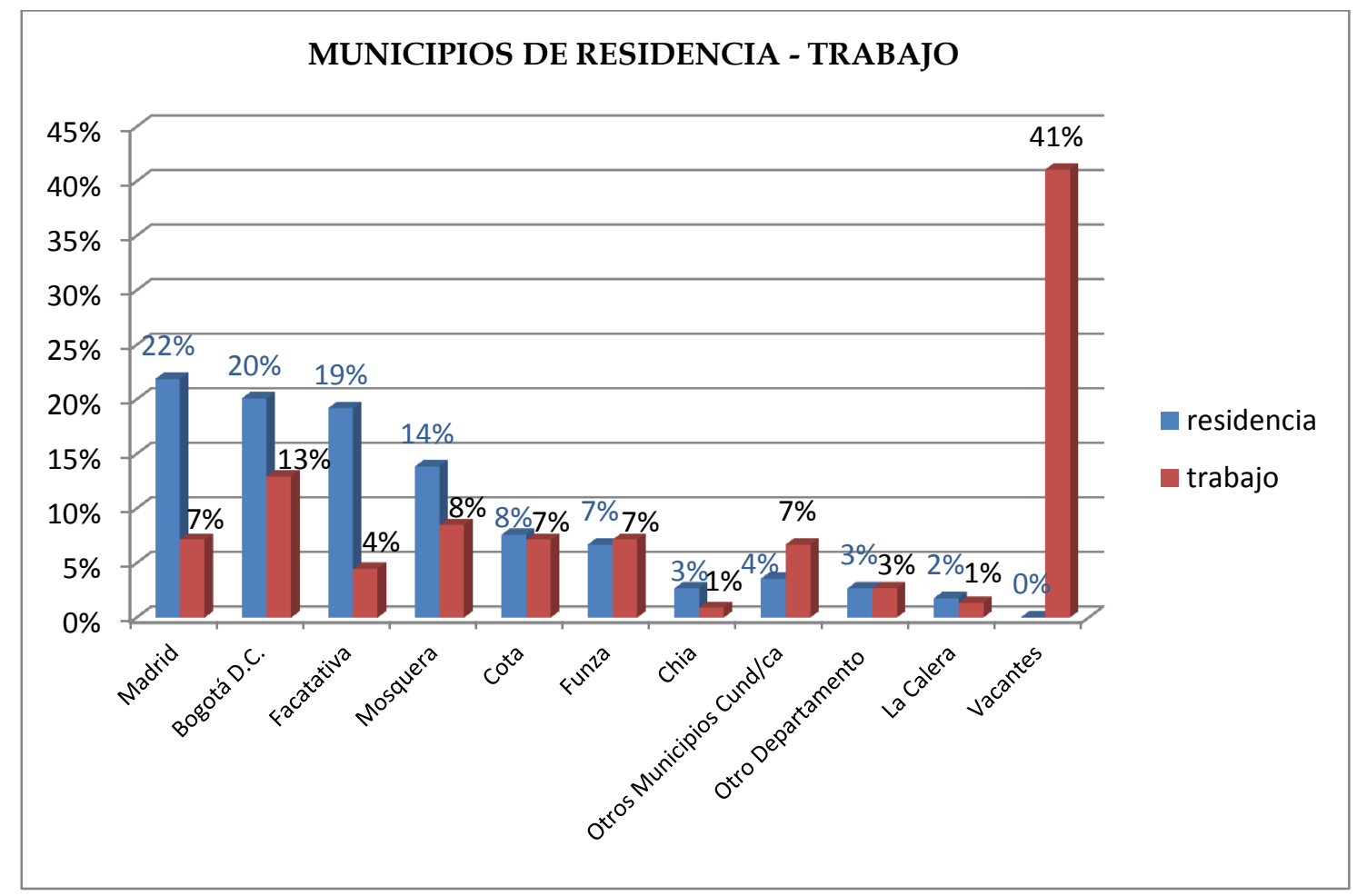

Fuente: cálculos de la investigadora

En el presente gráfico se observa los egresados que están vacantes o desempleados y constituyen el $41 \%$ y por ende los que tienen un desempeño ocupacional corresponden al 59\%. 
Así mismo, está incluido el lugar de residencia y de trabajo de los egresados, en Madrid vive el 22\% y trabaja el 7\%, en Bogotá vive el 20\% y trabaja 18\%, en Facatativá vive el 19\% y trabaja un 4\%, en Mosquera reside el $14 \%$ y trabaja el $8 \%$, en Cota vive el $8 \%$ y trabaja el $7 \%$, en Funza vive y trabaja el $7 \%$, en Chía vive el 3\% y trabaja el 1\%, en La Calera vive el $2 \%$ y trabaja el $1 \%$, Cota tiene $8 \%$ de residentes y un $7 \%$ vinculados laboralmente, en otros municipios de Cundinamarca viven el $4 \%$ y trabaja el $7 \%$ y en otros departamentos vive y trabaja el 3\%.

Por consiguiente podemos concluir que se presentó una movilidad del lugar de residencia de los egresados en relación al lugar de vivienda de los aprendices, a los municipios que pertenecen al corredor occidental, donde están ubicadas las zonas francas, Bogotá, Mosquera y Funza.

Los municipios que aumentaron su participación en lugar de residencia son Madrid del 15\% al 22\%, Bogotá, la capital del país pasó del $4 \%$ al 20\% con una el mayor porcentaje en la ubicación laboral del 18\%, Mosquera del 12\% al 14\%, Facatativá del 20\% al 19\%, Funza del 17\% al 7\%, La Calera del 15\% al 2\%, los municipios de Subachoque, El Rosal y Tabio están en el grupo de otros municipios del departamento de Cundinamarca con un porcentaje de residencia de egresados del $4 \%$ y tenían un porcentaje del $12 \%$ entre los tres municipios. Chía es un municipio de Cundinamarca pero no de cobertura del SENA Mosquera, presenta un 3\% residencia de los egresados y $1 \%$ con ubicación laboral. 40

${ }^{40}$ En el cálculo de porcentajes, sin decimales y aproximación automática, aparece un total superior al $100 \%$ 


\section{Gráfico No. 13. Vivienda de Egresados}

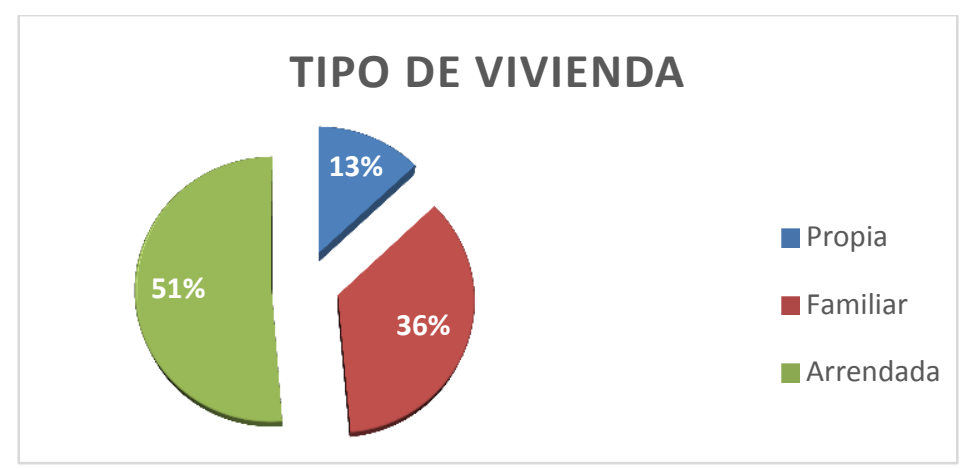

Fuente: cálculos de la investigadora.

Los inmuebles donde habitan los egresados en un 51\% corresponden viviendas en arriendo, un 36\% en bien raíz familiar y un 13\% manifiesta tener propiedad del inmueble de habitación. Se concluye que algunos egresados han iniciado la adquisición de su vivienda propia, sin embargo un $87 \%$ de egresados vive en arriendo y habita con la familia.

\section{Gráfico No 14 Ocupación Laboral}

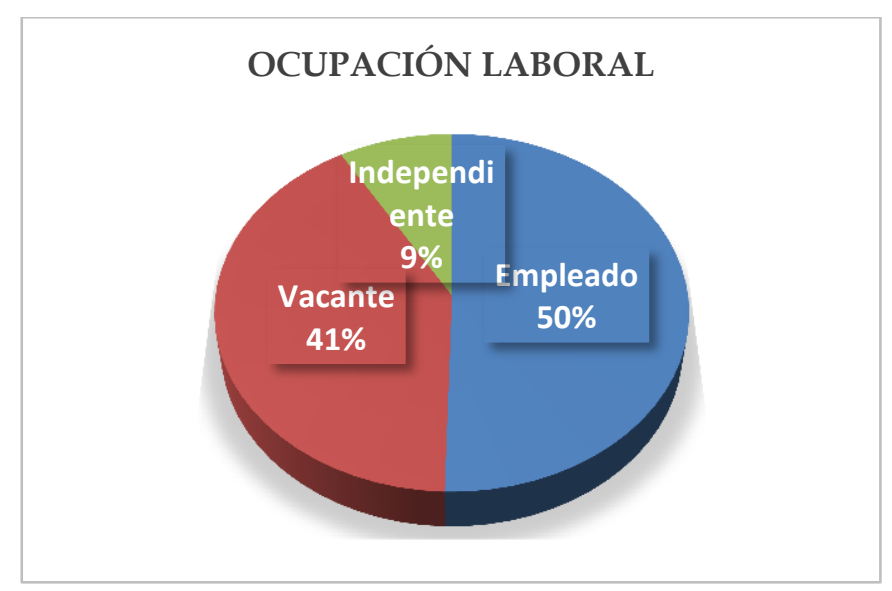

Fuente: cálculos de la investigadora

Entre los egresados que están trabajando constituyen el 59\% y se han ubicado laboralmente como empleados un 50\% y $9 \%$ como independientes y un $41 \%$ están vacantes, no han conseguido un trabajo. 


\section{Gráfico No 15. Desempeño Ocupacional}

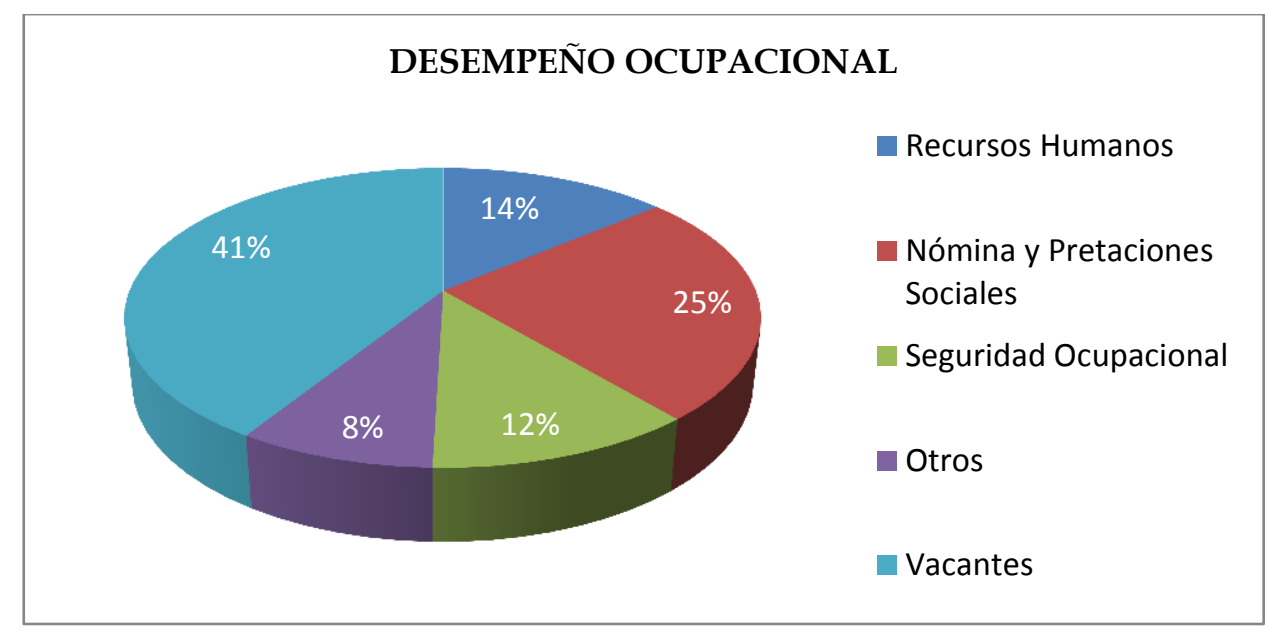

Fuente: cálculos de la investigadora

Los egresados están desempeñándose ocupacionalmente en un $14 \%$ en Recursos Humanos, 25\% en Nómina y Prestaciones Sociales y $12 \%$ en Seguridad Ocupacional, un $8 \%$ en otras actividades y $41 \%$ están vacantes. Es decir el $51 \%$ de los egresados se desempeñan en la formación técnica certificada.

\section{Gráfico No. 16. Visión Ocupacional y Personal}

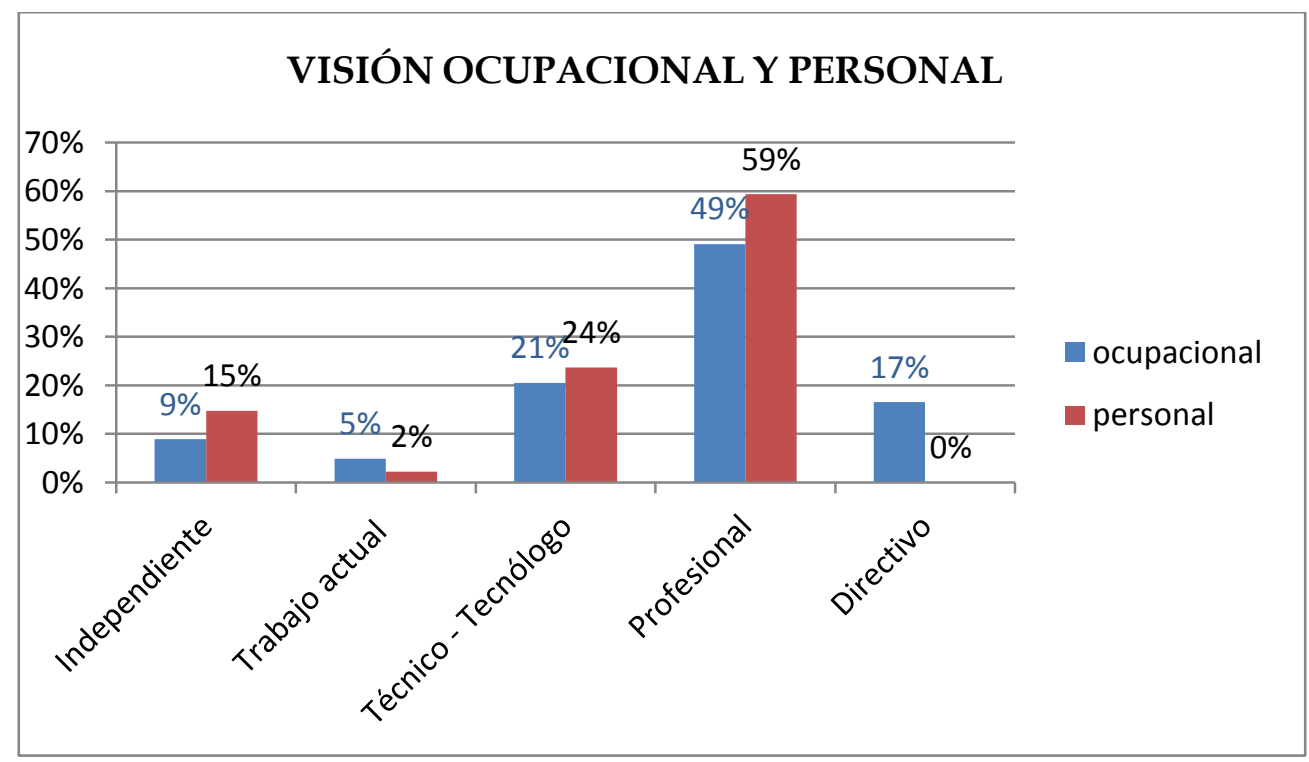

Fuente: cálculos de la investigadora 
Los egresados expresan su visón personal y ocupacional, un 59\% desea ser profesional y un $49 \%$ anhela un desempeño ocupacional como profesional; un $21 \%$ desea ocupar el cargo de técnico y el $24 \%$ anhela continuar con la cadena de formación, seguir como tecnólogo; un 17\% busca un desempeño como directivo sin que esta sea una proyección personal; el ser independiente se constituye una visón ocupacional en un 9\% y es una aspiración de no ser empleado en un $15 \%$; y desea permanecer en el mismo cargo un $5 \%$ y en un futuro conservar el trabajo actual un $2 \%$.

Por consiguiente un $98 \%$ de los egresados tiene una visión personal y el $81 \%$ manifiesta su proyección o a nivel ocupacional.

\section{Gráfico No 17. Afiliación al sistema de salud}

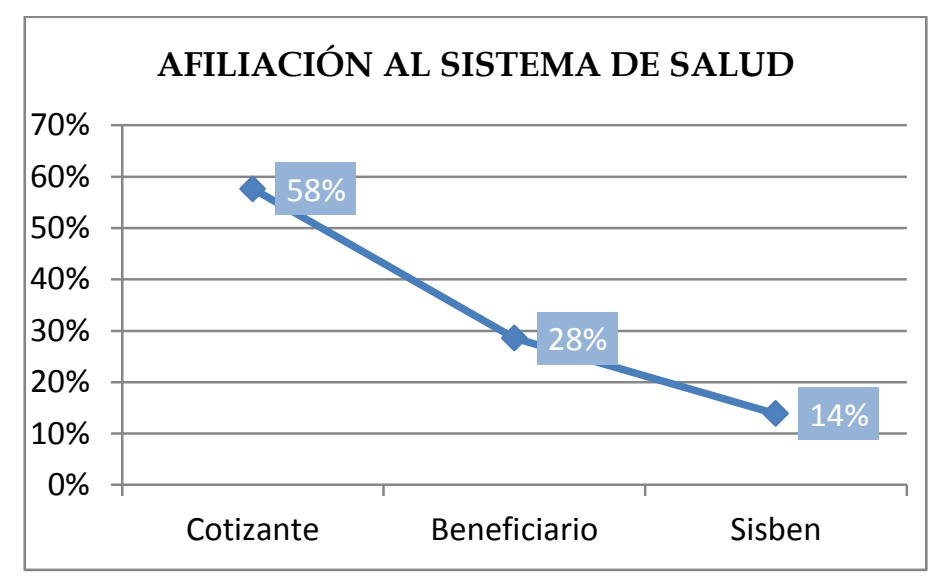

Fuente: cálculos de la investigadora

Los egresados están vinculados al sistema de salud, y un 58\% aportantes al sistema, son beneficiarios el $29 \%$ y subsidiados el $14 \%$. Por la tanto, se observa un cambio de aprendices a egresados en la vinculación al sistema de salud, han pasado del $9 \%$ al $58 \%$ como cotizantes, es decir, muestran un incremento del $49 \%$ y los vinculados al sistema de salud por pagos de terceros corresponden al $42 \%$. 


\section{Gráfico No. 18 Ingresos Mensuales}

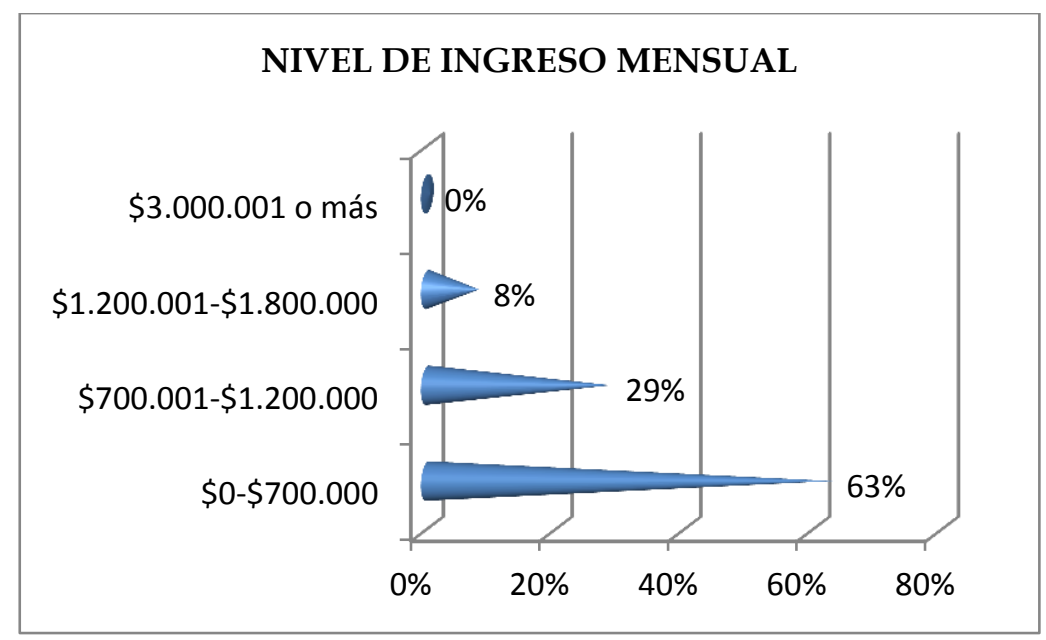

Fuente: cálculos de la investigadora

En el rango de ingresos de $\$ 1.200 .001$ a $\$ 1.800 .000$ son del 8\%, del 29\% para los egresados que perciben entre $\$ 700.001$ a $\$ 1.200 .000$ y un $63 \%$ recibe ingresos hasta los $\$ 700.000$, supera ligeramente al salario mínimo $\$ 689.454$ del 2016.

Gráfico No. 19 Dificultad en el uso de las Competencias

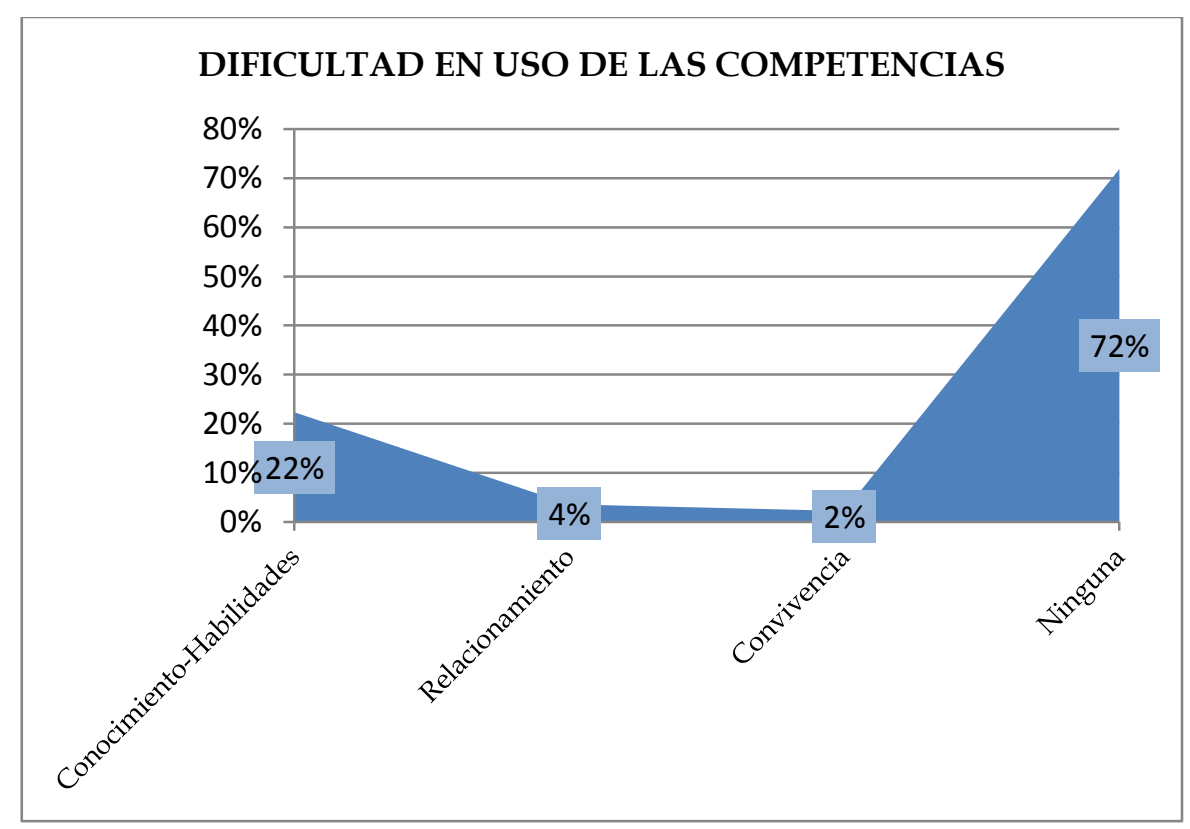

Fuente: cálculos de la investigadora 
Los egresados manifiestan en un $72 \%$ la facilidad en el uso de las competencias adquiridas en la formación técnica, y manifiestan dificultad en el uso de las competencias del conocimiento y el hacer en un $22 \%$; un $4 \%$ en relacionamiento y un $2 \%$ en convivencia; por lo tanto el problema en la aplicación de las competencias de los egresados es del $28 \%$.

\section{Gráfico No. 20. Actividades Extra labórales}

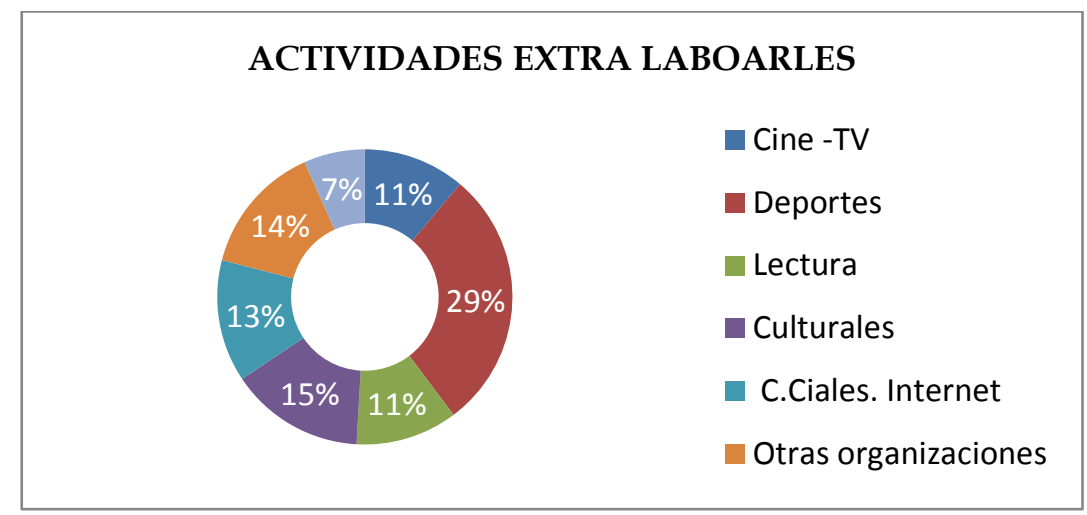

Fuente: cálculos de la investigadora

Los egresados manifiestan la participación en actividades extra laborales, constituidas en el área deportiva, cultural, recreativas o esparcimiento y vinculación en otras organizaciones, en la siguiente forma: $29 \%$ en deportes, $15 \%$ aspectos culturales, $14 \%$ participación en otras organizaciones, $13 \%$ en vista Centros comerciales e internet, $11 \%$ en lectura y con este mismo porcentaje en Cine y TV, un $7 \%$ en brigadas.

La situación de los egresados, expresada en la encuesta, manifiesta que tienen un desempeño ocupacional el 59\%, se han ubicado laboralmente como empleados un $50 \%$ y $9 \%$ como independientes, el $51 \%$ se desempeñan en la formación técnica certificada, un $8 \%$ tiene una ocupación en otras actividades diferentes a la formación recibida y un $41 \%$ de los egresados está vacante, es decir no se ha ubicado en el mundo del trabajo. 
En su desempeño ocupacional manifiestan en un $72 \%$ la facilidad en el uso de las competencias adquiridas en la formación técnica, y tienen dificultad del $28 \%$ en el uso de las competencias. El $98 \%$ de los egresados tiene una visión personal y el 81\% relaciona su visón ocupacional.

Al relacionar la situación de los egresados con el perfil del egresado SENA, planteado el Plan Educativo Institucional, tenemos que la denominación de egresado está dada a toda persona que participe en procesos de Formación Profesional Integral, desarrollando y evidenciando capacidades técnicas, intelectuales, sociales y cívicas que le permitan desempeñarse productivamente en su trabajo; su compromiso de responsabilidad frente a sí mismo, a la comunidad, al trabajo, al respecto los egresados han tomado decisiones, cambiando el sitio de residencia, y tienen una proyección personal y profesional y participan en actividades extra labórales en otras organizaciones y brigadas; sin embargo, el 28\% de los certificados por competencias presentan dificultades en el uso de las competencias en su desempeño ocupacional; es decir, la formación SENA debe ajustarse a la propuesta de la entidad.

Así mismo, es un porcentaje significativo al tener un $41 \%$ de egresados vacantes del 2014 -2015, y provienen de los municipios de cobertura del Centro de Formación, por consiguiente, la oferta laboral presentada no es demandada por el sector productivo de la región.

Es importante mencionar que en el proceso de formación profesional integral del SENA, los aprendices tienen un periodo de lectiva y otro de etapa práctica, que se puede realizar a través del contrato de aprendizaje y en este proceso he observado la dificultad en la ubicación de los aprendices en las 
empresas ${ }^{41}$, porque muchas veces la formación no es pertinente a las necesidades de la región, y hay un pequeño entorno empresarial en los municipios de Cundinamarca, con poca demanda de un recurso humano calificado. Por ende, la etapa práctica de algunos aprendices se desarrolla en las ciudades, como Bogotá.

Así mismo, observo que los aprendices realizan su etapa practica en las empresas, fortalecen las competencias y muchos son vinculados laboralmente con las empresas, sin embargo, los que realizan la etapa practica por proyecto productivo se inclinan al desempeño ocupacional como independientes.

\subsection{Variaciones en la vida de los Aprendices - Egresados}

En la caracterización de los aprendices que se matricularon al SENA Centro de Biotecnología Agropecuaria - Mosquera en la formación técnica de Recursos Humanos, Seguridad Ocupacional y Nómina y Prestaciones Sociales tenemos variables semejantes a las evidenciadas en la encuesta de egresados 2014- 2015 de estas disciplinas.

De la ficha de caracterización de aprendices se evidenciaron las siguientes variables: Sexo y Rango de Edad, Municipios de Residencia y Procedencia, Vivienda, Actividad Permanente, Afiliación a Salud, Población Vulnerable, Problemáticas de los Aprendices, Fuente de Ingresos, Nivel de Ingresos y Pasatiempo de los Aprendices.

En la encuesta de egresados se identificaron las variables a saber: Sexo y Rango de Edad, Municipio de Residencia y lugar de Trabajo, Vivienda, Ocupación Laboral, Área de Desempeño, Visón Ocupacional y Personal,

${ }^{41}$ Clavijo, C.G.. (2015) Diario de Campo 
Afiliación a Salud, Ingreso Mensual, Dificultades en el uso de las Competencias y Actividades Extra laborales.

A continuación observaremos las variables que se relacionan, dado que corresponden a información semejantes de los aprendices obtenida en la ficha de caracterización y de la encuesta de egresados, a saber:

\section{- Afiliación al sistema de salud}

Los aprendices presentan una significativa participación en la afiliación al Sisben del 61\%, en los egresados esta proporción disminuye al 14\% y se incrementa la afiliación por cotización al 58\%, los beneficiarios en salud en aprendices son $30 \%$ y egresados $28 \%$, presentan una ligera variación.

\section{Gráfico No 21 AFILIACIÓN AL SISTEMA DE SALUD}

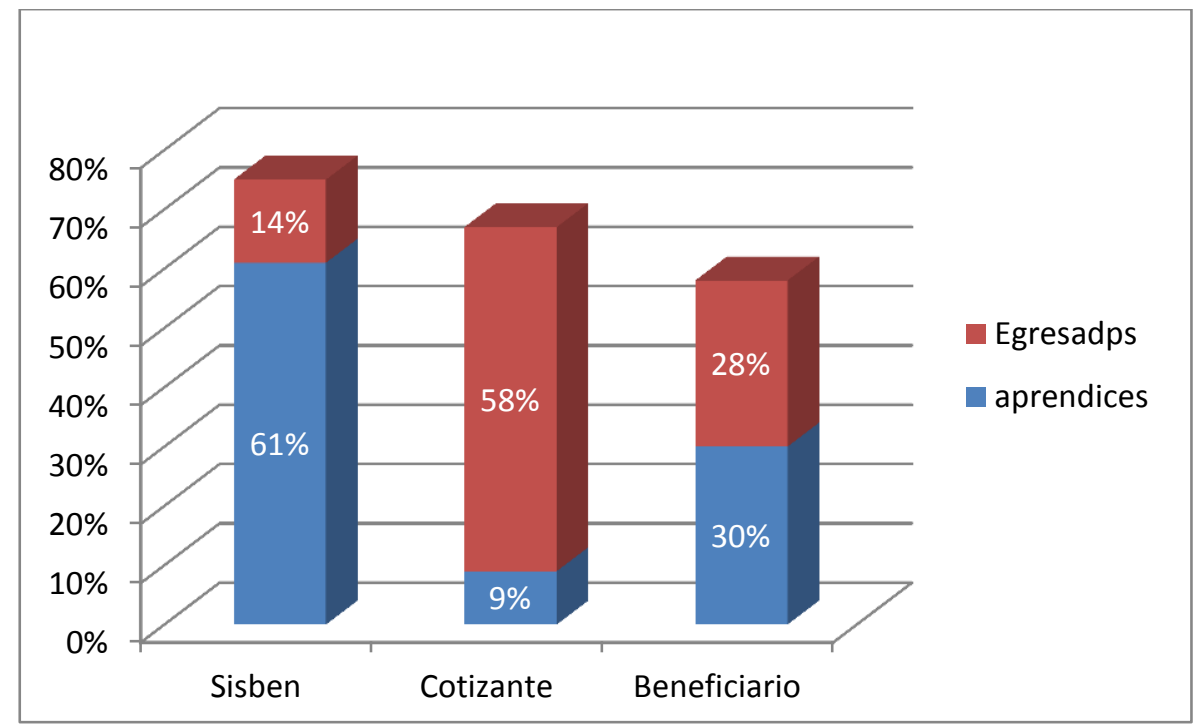

Fuente: cálculos de la investigadora 
Gráfico No. 22. Municipios de Residencia Aprendices y Egresados

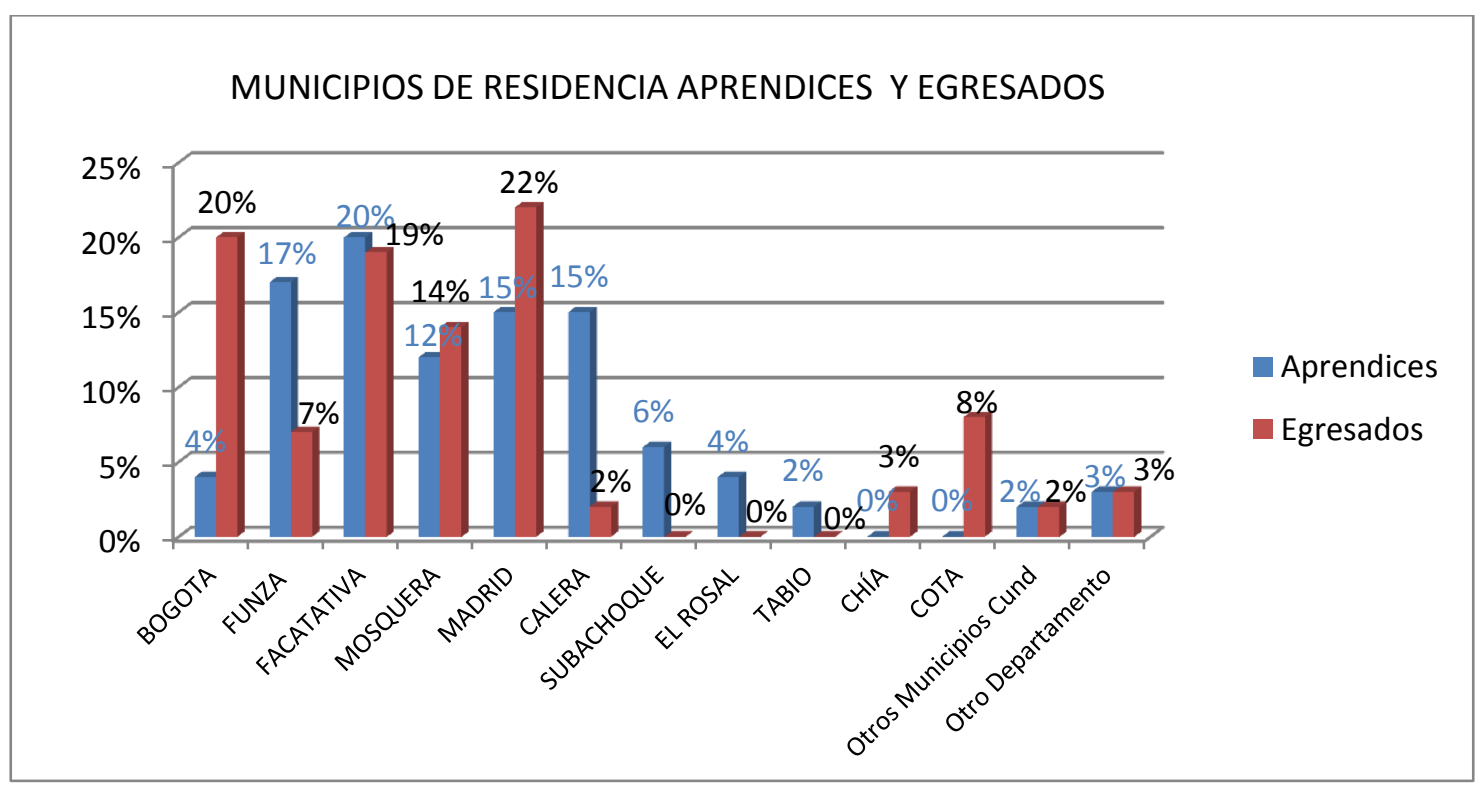

Fuente: cálculos de la investigadora

Se observa gran movilidad del lugar de residencia de los aprendices egresados a los municipios con mayor tejido empresarial del Departamento de Cundinamarca y la capital del país. Los egresados pasaron del $4 \%$ al 20\% a vivir en Bogotá, en Madrid pasaron del 15\% al 22\%, seguido de Mosquera del 125 al a 14\%; los municipios de Cota y Chía que no habían reportado lugar de residencia pasaron a un 3\% y $8 \%$ respectivamente; en los otros municipios del departamento de Cundinamarca se registra una disminución en habitación, Funza del 17\% al 7\%, Facatativá del 20 al 19\%, La Calera del 15\% al 2\%, la mayor disminución se tiene en los municipios de Subachoque con 6\%, El Rosal con $4 \%$, y Tabio con $2 \%$ pasan a un $0 \%$. 


\section{Gráfico No 23 VIVIENDA APRENDICES Y EGRESADOS}

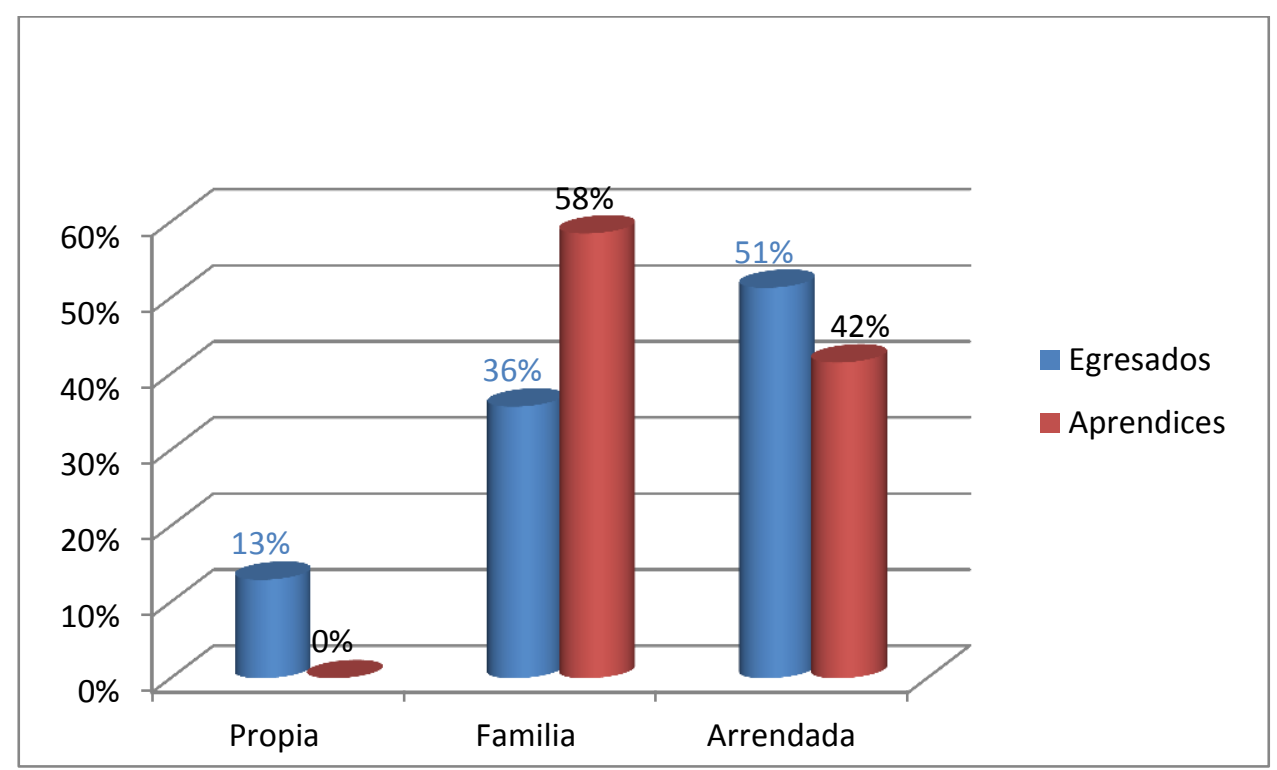

Fuente: cálculos de la investigadora

Hay un cambio sobre los inmuebles donde viven los egresados, un $13 \%$ tienen casa propia, con bien raíz familiar el 36\%, porcentaje que disminuye en relación a los aprendices 58\% que viven con su familia; en la vivienda arrendada los egresados tienen un 51\% y los aprendices un $42 \%$.

\section{Gráfico No 24. Ocupación de Aprendices y Egresados}

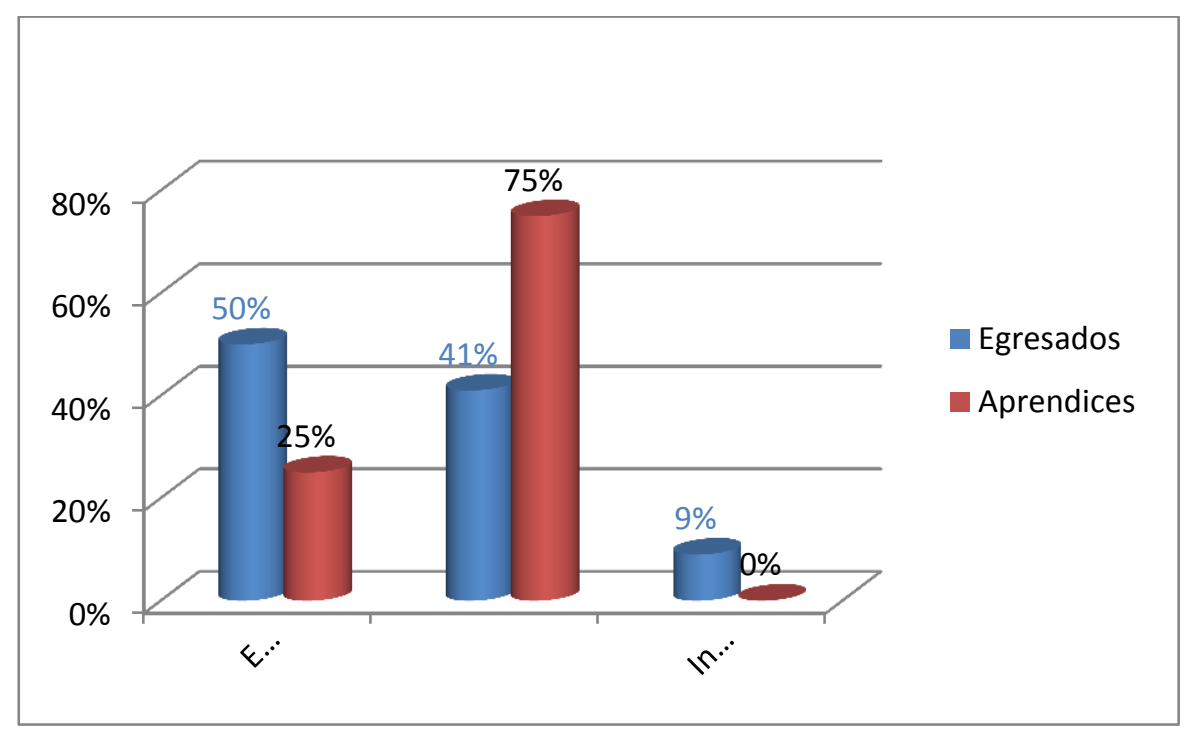

Fuente: cálculos de la investigadora 
En los egresados se presentan cambios en la ocupación, están dados por vacantes en $41 \%$ en contraposición del $75 \%$ dedicados a la formación, 50\% empleados a un $25 \%$ de aprendices y aparece un tercer componente de trabajo independiente con el 9\% en los egresados.

Gráfico No. 25 Nivel de Ingresos de Aprendices y Egresados

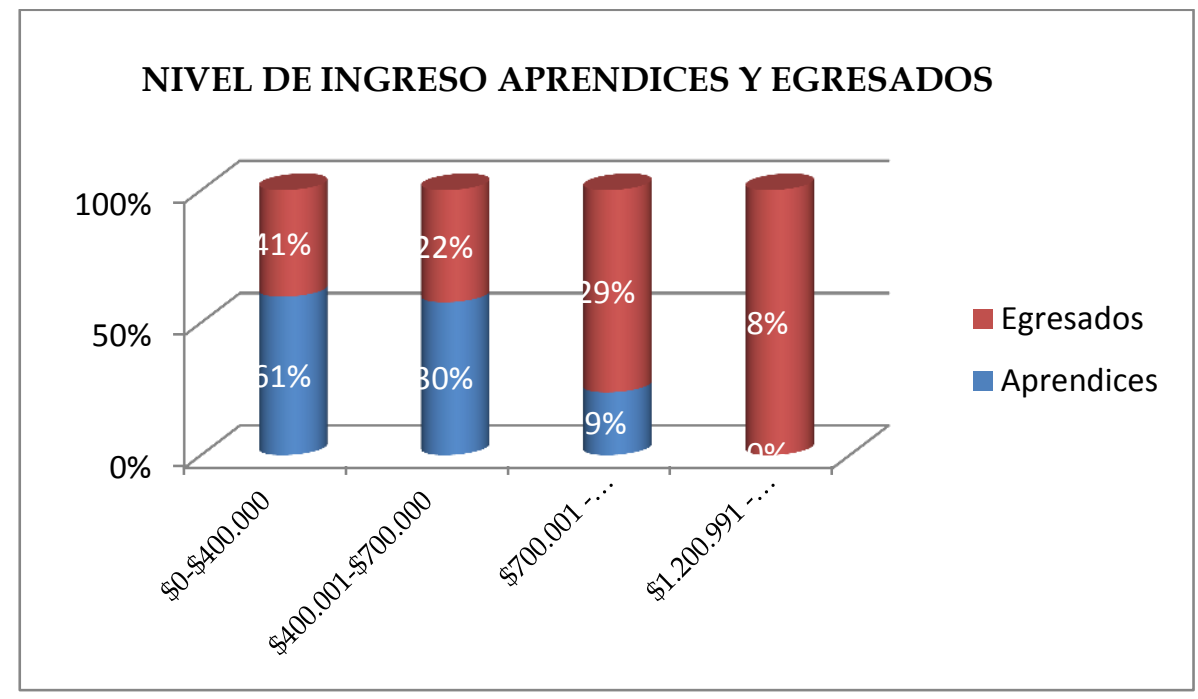

Fuente: cálculos de la investigadora.

En relación a los ingresos, el $41 \%$ de los egresados perciben menos del $\$ 400.000$, al igual que el $61 \%$ de los aprendices; en el rango de $\$ 400.000$ a $\$ 700.000$ los aprendices reciben el 30\% y los egresados el 22\%; en el nivel de ingresos de $\$ 700.000$ a hasta $\$ 1.200 .000$ los egresados se encuentran en un el $29 \%$, mientras que los aprendices en el $9 \%$; solamente el $8 \%$ de los egresados percibe ingresos hasta el $\$ 1.800 .000$. Los ingresos se incrementan en dos últimos parámetros sin sobrepasar el \$3.000.000. 


\section{Gráfico No 26 Actividades Extra Curriculares y Extra Laborales}

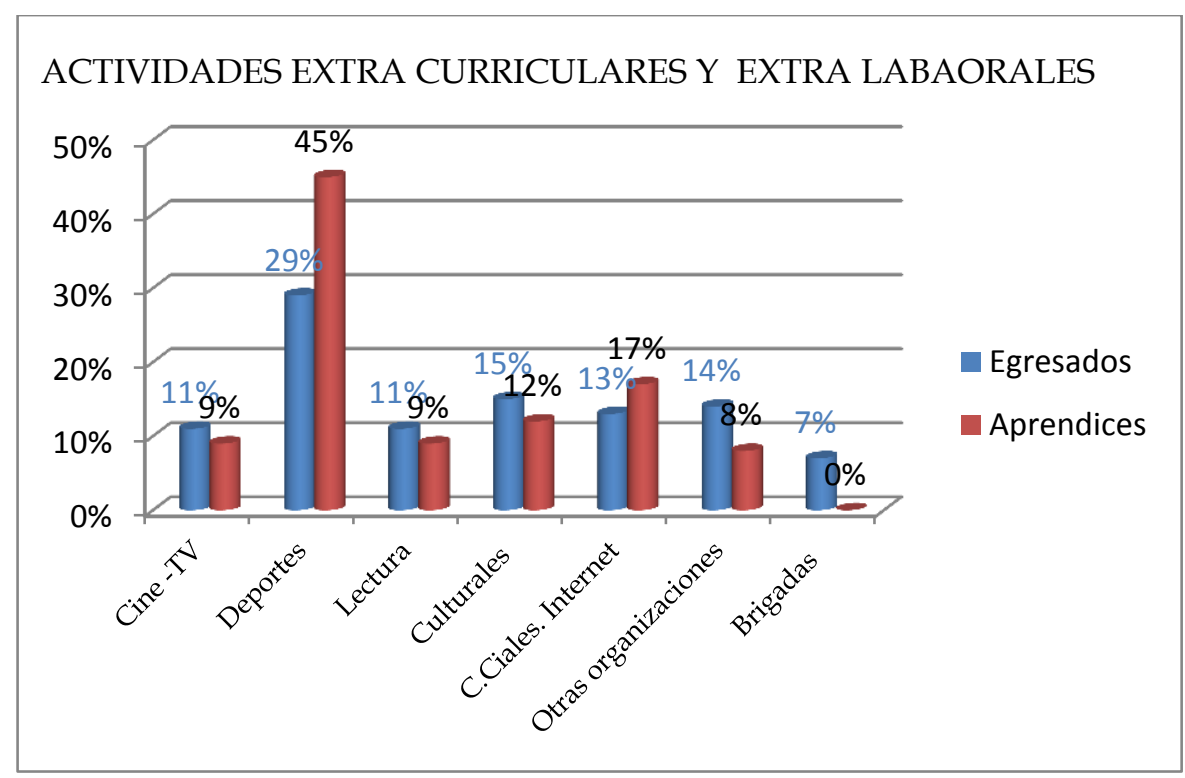

Fuente: cálculos de la investigadora

Tanto los aprendices como los egresados participan en actividades deportivas, culturales, recreativas, de esparcimiento y se vinculan en actividades y otras organizaciones. Con relación a los deportes los aprendices participan en $45 \%$ y los egresados en un $29 \%$, en las actividades culturales y recreativas la participación de los egresados es semejante $11 \%$ en Cine -TV. , Lectura, Cultura 15\%, 13\% C.Cilaes -Internet y los aprendices en 9\%, 12\%, 17\% respectivamente; los egresados participan en brigadas en un $7 \%$ y $14 \%$ en otras organizaciones y los aprendices en un $8 \%$. Los egresados han disminuido sus actividades deportivas cambiándolas por la participación en otras organizaciones y en brigadas.

Podemos concluir que los egresados han tomado decisiones de movilidad, cambiando el municipio de residencia del lugar de residencia de los egresados en relación al lugar de vivienda de los aprendices, a los municipios que pertenecen al corredor occidental, donde están ubicadas las zonas francas, Bogotá, Mosquera y Funza, en busca de para buscar oportunidades laborales, 
el $20 \%$ se trasladó a la capital; los ingresos son superiores al \$400.000 en un $59 \%$, presentan un incremento; un 13\% tienen vivienda propia; la vinculación al sistema de salud como aportante está es de un 58\%; un 50\% son empleados y $9 \%$ independientes. 


\section{CONCLUSIONES}

A continuación se presentan las conclusiones obtenidas en el recorrido del presente trabajo:

De acuerdo a la apreciación de Urbina Criado, el capital humano y el crecimiento de la economía se miran desde las perspectivas de la educación y el conocimiento, estas se relacionan directamente sobre las habilidades desarrolladas por el individuo.

Según los aportes de los autores Becker y Lev, se puede concluir que el capital humano en la nueva economía es el motor del desarrollo organizacional, constituyendo la principal ventaja de las compañías para desenvolverse en sus entornos.

El capital humano, está dado en las personas que han adquirido conocimientos y avanzado en sus capacidades, para un desempeño laboral, a través de procesos de educación y formación, logrado por la inversiones realizadas por los individuos, familia, gobierno en educación y formación, salud y el entorno cultural, y obtenido una acreditación o certificación que les permite presentarse, para una vinculación al mundo del trabajo.

Amartya Sen, concibe el desarrollo como una expansión de la libertad humana mediante la capacidad para llevar la vida que cada uno tenga razones de elegir y según la libertad como capacidad, la educación sirve para aumentar las capacidades de vivir una vida valiosa.

Córdoba expresa: las capacidades tienen varios cometidos en el desarrollo humano: ser el objetivo mismo de tal desarrollo, promover el progreso social que conduce a él $y$, finalmente, influir indirectamente en el aumento de la producción económica.

Mahbub ul Haq. ..."la verdadera riqueza de una nación está en su gente. Sin lugar a dudas, el objetivo básico del desarrollo es aumentar las libertades humanas en un 
proceso que puede expandir las capacidades personales toda vez que amplía las alternativas disponibles para que la gente viva una vida plena y creativa"... (P.N.U.D., 2004, 127).

La consideración del desarrollo humano integral: como el proceso de expandir las opciones de las personas y el objetivo es aumentar las libertades humanas, en el transcurso se pude expandir las capacidades personales, ampliando las alternativas para que las personas tengan una vida plena y creativa.

La Formación Profesional Integral del SENA es un proceso de formación del recurso humano que genera capital humano, con recursos del estado e inversiones de las familias y de las personas; donde los individuos adquieren y desarrollan conocimientos, destrezas y aptitudes, identifican, generan y asumen valores y actitudes, para que participen en el mundo del trabajo y tomen decisiones con un sentido de vida propio; es decir, desarrollan sus capacidades y definen su proyectos de vida.

La propuesta SENA busca del Desarrollo Humano Integral a través del proceso de Formación Profesional Integral del recurso humano que genera capital humano, se basa en el despliegue de las capacidades del aprendiz que le permitan al egresado actuar en forma crítica y proyectarse en su vida, de acuerdo a su visón.

La situación de los egresados presentan un desempeño ocupacional el $59 \%$, se han ubicado laboralmente como empleados un 50\% y $9 \%$ como independientes, el $51 \%$ se desempeñan en la formación técnica certificada, un $8 \%$ tiene una ocupación en otras actividades diferentes a la formación recibida; el $98 \%$ de los egresados tiene una visión personal y el $81 \%$ relaciona su visón ocupacional. 
Es un porcentaje significativo del $41 \%$ de egresados vacantes del 2014 2015, y provienen de los municipios de cobertura del Centro de Formación, por consiguiente, la oferta laboral presentada no es demandada por el sector productivo de la región.

El $28 \%$ de los certificados presentan dificultades en el uso de las competencias en su desempeño ocupacional; es decir, la formación SENA debe ajustarse a la propuesta de la entidad.

Un $9 \%$ de desempeña como independiente y un $15 \%$ se proyecta como emprendedores.

Así mismo, es un porcentaje significativo al tener un $41 \%$ de egresados vacantes del 2014 -2015, y provienen de los municipios de cobertura del Centro de Formación, por consiguiente, la oferta laboral presentada no es demandada por el sector productivo de la región.

Los niveles de ingreso de los egresados han mejorado con relación a la etapa de aprendices, pero solamente un $8 \%$ han logrado ingresos en un nivel técnico, un técnico está en el rango de $\$ 1.200 .000$ a $\$ 1.800 .000$, de acuerdo a la circular anual de directrices y lineamientos de la contratación de servicios personales del SENA.

Podemos concluir que los egresados han tomado decisiones de movilidad, cambiando el municipio de residencia del lugar de residencia de los egresados en relación al lugar de vivienda de los aprendices, a los municipios que pertenecen al corredor occidental, donde están ubicadas las zonas francas, Bogotá, Mosquera y Funza, en busca de para buscar oportunidades laborales, el $20 \%$ se trasladó a la capital; los ingresos son superiores al \$400.000 en un $59 \%$, presentan un incremento; un 13\% tienen vivienda propia; la vinculación al sistema de salud como aportante está es de un 58\%; un 50\% son empleados y $9 \%$ independientes. 


\section{RECOMENDACIONES}

- La propuesta del SENA sobre la Formación Profesional Integral es loable, sin embargo, el logro real de las competencias en los egresados debe revisarse y ser más efectivo, para que los técnicos titulados no presenten dificultad en el desarrollo ocupacional en el entorno laboral.

- La formación técnica que está impartiendo el SENA debe ser pertinente a la vocación productiva de los municipios de cobertura del Centro de Formación, porque se está generando un desplazamiento de la población a otros municipios y ciudades para lograr una ocupación en el mundo del trabajo, y la generación de mano de obra calificada y no ocupada.

- Es recomendable hacer el fortalecimiento de las competencias básicas a los aprendices al inicio de la formación con el fin de facilitar el logro de las competencias específicas. 


\section{BIBLIOGRAFIA}

Acevedo., C., Montes., I., Vásquez., J., Villegas., M., \& Brito., T. (2007). Capital Humano: Una mirada desde la educación y experiencia laboral. Cuadernillos de Investigación, 7.

Aronson. P. (2007). El retorno de la teroría del capital humano. Fundamentos de Humanidades, II(16).

Arámburo, S. D. P. M. DESARROLLO HUMANO INTEGRAL. Diversidades, 33, 2013 Universidad de León. España.

AVSI, I. (2013). Monserrate.(2008). AVSI. Recuperado el, 26.

Becker, G. (1993). Gobierno, capital humano y crecimiento económico. Ciencia Política: Revista trimestral para América Latina y España, 32, 154-156.

Becker, G. S. (1983). El capital humano: un análisis teórico y empírico referido fundamentalmente a la educación. Dialnet.

Bernal, C., \& Mantilla, S. (2011). Aspectos generales del concepto Capital Humano. Criterio libre, 9(14), 203.

Bourdieu, P. (1987). Los tres estados del capital cultural. Sociológica, 2(5), 11-17.

Bueno, E., Salmador, M. P., \& Merino, C. (2008). Génesis, concepto y desarrollo del capital intelectual en la economía del conocimiento: Una reflexión sobre el Modelo Intellectus y sus aplicaciones. Estudios de economía aplicada, 26(2), 43-63.

Castro Castro, L. M. (2012). Informe de sostenibilidad del servicio Nacional de Aprendizaje Sena.

Cejudo Córdoba, R. (2007). Capacidades y libertad: una aproximación a la teoría de Amartya Sen. Revista española de pedagogía,

Clavijo, C.G.. (2015) Diario de Campo.

Córdoba, R. (2010). Desarrollo humano y capacidades. . Documento.

de Urbina Criado, M., \& López, J. (2002). El capital intelectual en la empresa: análisis de criterios y clasificación multidimensional. Economía Industrial, 163-172.

Devore, J. L. (2015). Probability and Statistics for Engineering and the Sciences. Cengage Learning.

Díaz., C. (2009). Documento nucleo documental de Posgrado. (U. N. Rodríguez", Recopilador) Caracas, Venezuela. 
Díaz Pérez, M., de Liz Contreras, Y., \& Rivero Amador, S. (2009). El factor humano como elemento dinamizador del proceso empresarial en la gestión de la información y conocimiento. Acimed, 20(5), 42-55.

de Maldonado, I. P., Pérez, M. M., \& Uzcátegui, S. B. (2015). Clima organizacional y gerencia: inductores del cambio organizacional. Investigación y postgrado, 21(2), 231-248.

Edvinsson, L., \& Malone, M. (1999). El capital intelectual. Gestión 2000.

Estrada, C. G. (2009). Una mirada histórica a los procesos educativos y formativos del Servicio Nacional de Aprendizaje, SENA. EDUCACION Y HUMANISMO, 11(17).

Ferro, J. (2000). Visión de la universidad ante el siglo XXI. Ediciones Uninorte.

Gaitán Rincón, S. Y. (2009). Lineamientos para la localización de grandes infraestructuras industriales y de actividades logísticas en el corredor occidente de la sabana de Bogotá: caso Funza, Mosquera, Madrid (Master's thesis, Facultad de Arquitectura y Diseño).

García Cruz, A. M. (2016). La capacitación laboral en América Latina como un aporte a la mitigación del desempleo en el siglo XXI. Un análisis de la experiencia del SENA en Colombia (Master's thesis, Universidad Andina Simón Bolívar, Sede Ecuador).

Giménez, G. (2005). La dotación de capital humano de América Latina y el Caribe. Revista de la CEPAL.

Gleizes, J. (2000). El capital Humano. En complementos de multitudes . Recuperado el Febrero de 2016, de http:/ / multitudes.samizdat.net/aricle.php3?idarticle=312

Griffin, K. (2001). Desarrollo humano: origen, evolución e impacto. Ensayos sobre el desarrollo humano, 25-40.

Gross, M. (2010). Conozca 3 tipos de investigación: Descriptiva, Exploratoria y Explicativa. Obtenido de Pensamiento Imaginagtivo: http://manuelgross. bligoo. com.

Herrera, S. (2010). La importancia de la educación en el desarrollo: la Teoría del Capital Humano y el Perfil Edad-Ingresos por Nivel Educativo en Viedma y Carmen de Patagones, Argentina. Revista Pilquen, (13), 00-00.

Kendrick, J. (1961). Some Aspects of Capital Measurement. The American Eonomic Review, 51(1), 102-111.

Laroche, M., Merette, M., \& Ruggeri, G. (1999). On the concept and dimensiones of human capital in a knowledge-based econommy context. Canadian Public Policy, 87-100.

Las ciencias sociales. (2010). capital-humano. Recuperado el Agosto de 2014, de http://definición.mx/capital-humano/ixzz3G3OoVLIQ 
Manual para Diseñar Estructuras Curriculares y Módulos de Formación para el Desarrollo de Competencias, SENA 2002

Martínez Miguélez, M. (2009). Dimensiones básicas de un desarrollo humano integral. Polis (Santiago), 8(23), 119-138.

Mireille Laroche and Marcel Mérette Department of Finance G.C. RUGGERI University of New Brunswick. On the Concept and Dimensions of Human Capital in a KnowledgeBased Economy Context. Canadian public policy - analyse de politiques, vol. xxv, no. 1199.

Ministerio de Educación. (2013). Documento de trabajo, MEN, Bogotá.

Ministerio de Industria y Comercio. (s.f.). Recuperado el 7 de Octubre de 2015, de http://www.mincit.gov.co/publicaciones.php?id=10

Nussbaum, MC (1997). Capacidades y derechos humanos. Fordham L. Rev. , 66 , 273.

Observatorio Laboral para la Educación. (2012). Capital Humano para el avance Colombiano. Bogotá: Ministerio de Educación Nacional.

Plan Estratégico SENA 2015- 2018

Piketty, T. (2014). El capital en el siglo XXI. Fondo de Cultura Económica.

Pons, S. C. (Ed.). (2004). Inmigración, contexto familiar y educación: Procesos y experiencias de la población marroquí, ecuatoriana, china y senegambiana. Institut de ciències de l'educació, Universitat autònoma de Barcelona.

Proyecto Educativo Institucional SENA 2013 ajustado - 2015

PNUD. (2015). Objetivos de desarrollo del Milenio. Bogotá: PNUD.

Schultz, T. W. (1961). Investment in human capital. The American economic review, 1-17.).

Sen, A. K. (1998). Las teorías del desarrollo a principios del siglo XXI. Cuadernos de economía, 17(29), 73-100.

Sen, A. (1999). Desarrollo y Libertad. Barcelona: Planeta S.A.

Sen, A. (2000). El desarrollo como libertad. Gaceta Ecológica, (55), 14-20.

Sen, A. (2003). Inclusion and Achievement. En T. Guardian (Ed.), Discurso ante la 15 Conferencia de Ministros de Educación de la Conmmowealth celebrado en Edimburgo. Edimburgo.

Sen, A. K. (2010). Capital humano y capacidad humana. Cuadernos de economía, 17(29), 67-72.

SENA. (2013). Informe Final. Bogotá.

SENA Proyecto Educativo Institucional 2013. 
SENA Clasificación Nacional de Ocupaciones C.N.O. 2013. http://www.sena.edu.co/esco/trabajo/Documents/instructivo_2016.pdf

SENA Plan Estratégico 2015-2018

Smith, A. (1994). Riqueza de las naciones (1776). Madrid: Alianza, 37. Cuadernos de economía, 17(29), 67-72.

Sunkel, O., \& Paz, P. (1999). El subdesarrollo latinoamericano y la teoría del desarrollo. Siglo xxi.

Torres, C. A. B. (2006). Metodología de la investigación: para administración, economía, humanidades y ciencias sociales. Pearson educación.

Varela, R., Arturo, B., \& Lucia, O. (2006). Modelo conceptual de desarrollo empresarial basado en competencias. Estudios Gerenciales, 22(100), 21-47

Villalobos. C., \& Pedroza. R. (2009). Perspectiva de la teroría del capital humano acerca de la relación entre edcucación y desarrollo económico. Tiempo de Educar. 
ANEXO 1

\begin{tabular}{|c|c|c|c|}
\hline \multicolumn{4}{|c|}{ Aprendices Certificados en Formación Titulada } \\
\hline \multicolumn{2}{|c|}{ Fecha Inicial: 1/1/2014 Fecha Final: 31/12/2014 } & \multirow[b]{2}{*}{$\begin{array}{c}\text { Lugar de } \\
\text { Residencia }\end{array}$} & \multirow{2}{*}{$\begin{array}{c}\text { Programa: Seguridad ocupacional } \\
\text { Correo Electrónico }\end{array}$} \\
\hline $\begin{array}{c}\text { Número } \\
\text { Documento }\end{array}$ & Nombre Aprendiz & & \\
\hline 98022261479 & ANDREA CATALINA ROCHA CHAMORRO & LA CALERA & aprendiz.calera@gmail.com \\
\hline 97051507014 & CAMILA LEON CARRANZA & LA CALERA & camila9705@hotmail.com \\
\hline 98060450692 & MARITZA TRUJILLO GARCIA & LA CALERA & sisa.04@hotmail.com \\
\hline 1071168876 & DERSON FABIAN BARAHONA CORTES & LA CALERA & dersonghot@hotmail.com \\
\hline 98051803710 & LAURA TATIANA CRUZ AVELLANEDA & LA CALERA & ta-tuli@hotmail.com \\
\hline 1071168858 & ANGGIE MAYURY GOMEZ JIMENEZ & LA CALERA & anmagoji@hotmail.com \\
\hline 97091300250 & SANDRA LILIANA AYALA SASTOQUE & LA CALERA & sandraj1920@ hotmail.com \\
\hline 97051906652 & LAURA JIMENA VASQUEZ RAMIREZ & LA CALERA & jimenavr1997@gmail.com \\
\hline 1010025203 & JOISS ESNEIDA RODRIGUEZ RODRIGUEZ & LA CALERA & yoyiz.r1896@gmail.com \\
\hline 98051458028 & JUAN PABLO QUITIAN QUITIAN & LA CALERA & juanpabloq11@hotmail.com \\
\hline 1071167966 & PEDRO PABLO PERDIGON JIMENEZ & LA CALERA & aprendiz.calera@gmail.com \\
\hline 97050212657 & LEIDY LORENA CADENA SOTO & LA CALERA & leidylorena00@hotmail.com \\
\hline 98051562437 & LAURA DEL PILAR ESCOBAR ESCOBAR & BOGOTÁ & laura981515@hotmail.com \\
\hline 98050366014 & DERLY MARITZA RODRIGUEZ MORA & LA CALERA & dermy66014@ hotmail.com \\
\hline 1071169640 & DIEGO HERNAN RODRIGUEZ PULIDO & LA CALERA & diego201086@hotmail.com \\
\hline 1071169718 & DEVY JULIANA GALVIS & LA CALERA & devy2375@hotmail.com \\
\hline 97102000572 & MARIA DEL PILAR CORTES FLOREZ & LA CALERA & pilaricacrozy@ hotmail.com \\
\hline 98022864939 & LISETH NATALIA CUBILLOS CIFUENTES & LA CALERA & lisethcubillos@gmail.com \\
\hline 98012450974 & LEIDY YAMILE PEÑA ARIAS & LA CALERA & yamipa1998@hotmail.com \\
\hline 97012209073 & NATALIA GERALDIN MATEUS SASTOQUE & LA CALERA & nataliatkm_977@hotmail.com \\
\hline 97050712714 & INGRID LORENA ANDRADE PIÑEROS & LA CALERA & i.lorenita123@hotmail.com \\
\hline 98010965675 & MARÍA ISABEL VALBUENA ROZO & LA CALERA & chavelita871@hotmail.com \\
\hline 98031065658 & LAURA CAMILA CIFUENTES MARTINEZ & LA CALERA & camicifu10@hotmail.com \\
\hline 1071168952 & VICTOR ALFONSO AREVALO RAMIREZ & LA CALERA & victoralf95@hotmail.es \\
\hline 98031160065 & FABIAN YUSBANY VEGA ALAYON & LA CALERA & yuyus_vega@hotmail.com \\
\hline 97082300299 & NATALIA PERDIGON GARCIA & LA CALERA & nata2318@hotmail.com \\
\hline 1071169230 & DANNA ISABELLA CARDOZO AVILA & LA CALERA & danna.cardozo@hotmail.com \\
\hline 1003578935 & CINDY NATALIA TRUJILLO ESCOBAR & IBARRA & cindytruji@hotmail.com \\
\hline 1019060237 & GERMAN EDUARDO ORTEGA SANCHEZ & BOGOTÁ & edwardhousemd@gmail.com \\
\hline 1069304010 & JOHANA MILENA VELASQUEZ PRIETO & GUASCA & johanamvp@hotmail.com \\
\hline 1071168565 & LADY VIVIANA RINCON ARREDONDO & LA CALERA & viviana_rincon1995@hotmail.com \\
\hline 97061000317 & LAURA KATHERINE PULIDO MARTINEZ & LA CALERA & lkpm_10@hotmail.com \\
\hline 35221921 & ANDREA JULIETH JIMENEZ GARCIA & LA CALERA & andriw_28@yahoo.es \\
\hline 1121910321 & LUZ DANELLY LONDOÑO SALAMANCA & BOGOTÁ & danniny66@hotmail.com \\
\hline 1020804216 & ZHARA VIVIANA ARIAS BELTRAN & BOGOTÁ & zharavivi@yahoo.com \\
\hline 1071168440 & FREDY ALEXANDER RODRIGUEZ MARTINEZ & LA CALERA & fredy_alexander21@hotmail.com \\
\hline 11233614 & OSCAR JAVIER GONZALEZ RUEDA & LA CALERA & karitoz.jg@hotmail.com \\
\hline 1073168563 & YONATHAN DAVID ACOSTA PEÑA & MADRID & jonadava22@hotmail.com \\
\hline 1016043269 & ANGIE ESTEFANIA CRUZ LINARES & BOGOTÁ & angie_estefania16@hotmail.com \\
\hline 35353359 & INGRID NILLYRETH PASCAGAZA VELANDIA & MADRID & ingridnillyreth05@live.com \\
\hline
\end{tabular}




\begin{tabular}{|c|c|c|c|}
\hline 1104129034 & $\begin{array}{l}\text { JORGE LEONARDO CARRASQUILLA } \\
\text { HERRERA } \\
\end{array}$ & FACATATIVÁ & leoch1990@hotmail.com \\
\hline 20739997 & CIELO ALEXANDRA CRUZ & MADRID & ciealexa@gmail.com \\
\hline 1073168893 & EDNA ROCIO MONTAÑEZ ABRIL & MADRID & ednarociomont@misena.edu.co \\
\hline 96081900075 & THALIA MARITZA MURILLO LOZADA & MADRID & tmmurillo@misena.edu.co \\
\hline 1073171949 & ALIX YULITZA CUBIDES CEIJA & $\begin{array}{c}\text { SAN } \\
\text { ANTONIO DE } \\
\text { TENA }\end{array}$ & yulitzakubids@gmail.com \\
\hline 65717644 & NELFI CASAS CASAS & BOGOTÁ & nelficasas75@hotmail.com \\
\hline 1007157843 & DIEGO ALEJANDRO PAVA NOVOA & SOACHA & alejo_eivar19@hotmail.com \\
\hline 1073517395 & INGRID GINETH MORENO ARDILA & MOSQUERA & ingrid_14_08@hotmail.es \\
\hline 1073154754 & ANA FABIOLA AMADO CEPEDA & MADRID & ukaneo@hotmail.com \\
\hline 1073165331 & JINA PAOLA RODRIGUEZ LARROTA & MADRID & hinnita24-6@hotmail.com \\
\hline 1073517870 & LINDA LUCIA PAEZ SANCHEZ & FUNZA & lindalucia123@hotmail.com \\
\hline 1073170568 & MAGALY STEFANNY FIERRO ARDILA & MADRID & sfamagaly@ hotmail.com \\
\hline 1016076977 & ANGIE LICETH AGUJA ROMERO & BOGOTÁ & anguie_aguja@hotmail.com \\
\hline 1073157991 & SANDRA MILENA MORALES MORALES & MADRID & niyisa2224@hotmail.com \\
\hline 1072650263 & TANIA SOLANGY TORRES LOPEZ & CHIA & taky16@hotmail.com \\
\hline 1119585483 & OMAIRA JHAJANDRA GUATAPI ARROYO & MADRID & alejandraarroyo2010@hotmail.com \\
\hline 24228661 & CLAUDIA PATRICIA CEIJA AYALA & $\begin{array}{c}\text { SAN } \\
\text { ANTONIO DE } \\
\text { TENA }\end{array}$ & patriciaceija@gmail.com \\
\hline 1073167803 & ALEJANDRO GARZON PARRA & MADRID & alejogp56@hotmail.com \\
\hline 1073516904 & ANGIE TATIANA SANCHEZ ROBLES & FUNZA & tato--sanchez@hotmail.com \\
\hline 1073161308 & LILIANA PAOLA AVENDAÑO BECERRA & MADRID & pa.olita2306@hotmail.com \\
\hline 1073161589 & JESSICA KATHERINE CASTILLO GARCIA & MADRID & jk_2710@hotmail.com \\
\hline 1073244219 & SERGIO ANDRES MENDEZ RAMIREZ & MOSQUERA & millos_checho04@hotmail.com \\
\hline 1098616421 & CINDY LISETH SALLAS ALVARINO & MADRID & lisset28sallas@hotmail.com \\
\hline 53139145 & MAYTER ALEJANDRA LOZANO NIETO & BOGOTÁ & alozano@unigas.com.co \\
\hline 1069743683 & JIMENA ALEXANDRA RAMIREZ RODRIGUEZ & FUSAGASUGÁ & jimenaramirezr@gmail.com \\
\hline 79369089 & VÍCTOR ARMANDO MARTINEZ ACEVEDO & MOSQUERA & vama66@hotmail.es \\
\hline 79687164 & HERNAN RUIZ SUAREZ & BOGOTÁ & hruiz@unigas.com.co \\
\hline 80176953 & WILLIAM ALEXANDER CARDENAS PEREZ & BOGOTÁ & alex_08cardenas@hotmail.com \\
\hline 63516321 & SANDRA MILENA GALVIS MANTILLA & BOGOTÁ & sgalvismantilla@gmail.com \\
\hline 1014278540 & LUISA FERNANDA BETANCUR MONTOYA & BOGOTÁ & fer.betancur@outlook.com \\
\hline 1013610065 & LUIS EDUARDO CORBA MOLINA & BOGOTÁ & lec90@hotmail.com \\
\hline 9527643 & LUIS ANGEL RODRIGUEZ MEDRANO & BOGOTÁ & LUCHOANGEL19@HOTMAIL.COM \\
\hline 1075267501 & JOSE FELIPE PERDOMO MOLINA & NEIVA & jofepemo@hotmail.com \\
\hline
\end{tabular}

\begin{tabular}{|c|c|c|c|}
\hline \multicolumn{4}{|c|}{ Aprendices Certificados en Formación Titulada } \\
\hline \multicolumn{2}{|c|}{ Fecha Inicial: 1/1/2014 Fecha Final: 31/12/2014 } & & Programa: Recursos Humanos \\
\hline $\begin{array}{c}\text { Número } \\
\text { Documento }\end{array}$ & Nombre Aprendiz & $\begin{array}{c}\text { Lugar de } \\
\text { Residencia }\end{array}$ & Correo Electrónico \\
\hline 1074188491 & YURI PAOLA ARANDIA VASQUEZ & EL ROSAL & arandiayuri@gmail.com \\
\hline 96101617650 & LUZ JANETH BUSTOS OLAYA & EL ROSAL & luzjaneth96@gmail.com \\
\hline 96100804791 & LEIDY GONZALEZ CASTRO & EL ROSAL & leidygonzalezcastro@gmail.com \\
\hline 97070616088 & CRISTIAN DANIEL MARTINEZ RODRIGUEZ & MADRID & casitahuaylas@ @otmail.com \\
\hline
\end{tabular}




\begin{tabular}{|c|c|c|c|}
\hline \multicolumn{4}{|c|}{ Aprendices Certificados en Formación Titulada } \\
\hline \multicolumn{2}{|c|}{ Fecha Inicial: 1/1/2014 Fecha Final: 31/12/2014 } & \multirow[b]{2}{*}{$\begin{array}{c}\text { Lugar de } \\
\text { Residencia }\end{array}$} & \multirow{2}{*}{\begin{tabular}{|c|} 
Programa: Recursos Humanos \\
Correo Electrónico
\end{tabular}} \\
\hline $\begin{array}{c}\text { Número } \\
\text { Documento }\end{array}$ & Nombre Aprendiz & & \\
\hline 97052004040 & YOJAN HELDER RIVEROS QUEVEDO & MADRID & yojan_river.que@hotmail.com \\
\hline 98022406795 & INGRID DAYANA AGUDELO CASTRO & MADRID & ingridagudelo2@gmail.com \\
\hline 97080712662 & JEFFERSON CAMILO ALVAREZ HIGUERA & MADRID & hicaje@gmail.com \\
\hline 98102350197 & LINA PAOLA BERNAL BETANCOURTH & MADRID & bernallinap700@ hotmail.com \\
\hline 98062002522 & ANDRES GIOVANNY BORJA SUAREZ & MADRID & gioborja88idbz@hotmail.com \\
\hline 97070217795 & LEIDY ALEJANDRA BURAI BETANCOURT & MADRID & leidy_5885@hotmail.com \\
\hline 97121412687 & JULIAN DAVID BUSTOS MOJICA & MADRID & david-julian97@ hotmail.com \\
\hline 98021512761 & BRANDON STIVEN CASTRO CARDENAS & MADRID & brandon.castro22@ hotmail.com \\
\hline 1073171532 & LAURA DANIELA GONZALEZ CASTAÑEDA & MADRID & laladanielag@hotmail.com \\
\hline 97050106571 & LEIDY VIVIANA GUTIERREZ GUERRERO & MADRID & leydidi93@hotmail.com \\
\hline 97120509601 & JUAN MANUEL LAMPREA SIERRA & MADRID & jumalasi@hotmail.com \\
\hline 98032860834 & CHARIT MELISSA QUINTERO MORALES & MADRID & melissaquintero2803@hotmail.com \\
\hline 98022253379 & CAROLINE DANIELA SANABRIA LUGO & MADRID & dans1998@hotmail.es \\
\hline 1073172580 & YENNY PAOLA PINZON LOPEZ & MADRID & paolapinzonlopez@gmail.com \\
\hline 98081757038 & LAURA SOFIA SARMIENTO MEDINA & MADRID & laurita.sar98@gmail.com \\
\hline 1073170401 & JEFFERSON GONZALEZ HUERTAS & MADRID & jeffersongonzalez25@gmail.com \\
\hline 1073171488 & DENNIS DAJANA AGUIRRE RIAÑO & MADRID & dayis141@hotmail.com \\
\hline 98031864577 & LADY NATALIA NAVAS BALLEN & MADRID & leidyn1998@gmail.com \\
\hline 97120914204 & FABIAN STIVEN ORTEGA PATIÑO & MADRID & ortegaf31@gmail.com \\
\hline 97022014777 & LORENA RUIZ DIAZ & MADRID & lorenitha_309@hotmail.com \\
\hline 97072103118 & LAURA JULIETH PRIETO CRUZ & MADRID & laurajpc@gmail.com \\
\hline 97120608847 & CARLOS ANDRES TIBAVIZCO LARA & MADRID & carlitoslara_1997@hotmail.com \\
\hline 97091911284 & JOHAN SEBASTIAN ABRIL CRUZ & MADRID & johan.cruz@hotmail.com \\
\hline 97090801353 & ANGIE MARIA JURADO CEPEDA & MOSQUERA & gotik0811@hotmail.com \\
\hline 99040100870 & YORMARY SMITH MORENO VARGAS & MOSQUERA & yormary.smith@hotmail.com \\
\hline 98100450011 & MICHEL NOVOA RIVAS & MOSQUERA & michelin-f@hotmail.com \\
\hline 97090708990 & DIANA CAROLINA PACHON ALAYON & MOSQUERA & diana-alayo@hotmail.com \\
\hline 98072055535 & MARIA FERNANDA RUBIANO CUASPUD & MOSQUERA & mafe-55535@hotmail.com \\
\hline 98032453333 & GERALDIN SANCHEZ VALLECILLA & MOSQUERA & geral-42lalinda@hotmail.com \\
\hline 98092159078 & LAURA CAMILA CAMPOS QUINTERO & BOGOTÁ & lauracquintero@ outlook.com \\
\hline 1073245726 & SANDRA MARCELA VARGAS PADILLA & MOSQUERA & samy_2306@outlook.es \\
\hline 97060407545 & FRANCISCO JAVIER DEVIA GOMEZ & MOSQUERA & francisco.j.dg@hotmail.com \\
\hline 98052256437 & MARIA DEL PILAR AMAYA ALVARADO & MOSQUERA & maria-amaya@live.com \\
\hline 97050604490 & DANIELA ANGULO DONCEL & MOSQUERA & dannydoncel.3@ hotmail.com \\
\hline 1073244763 & LORENA PAOLA BENAVIDES RUIZ & MOSQUERA & lorenitha041995@hotmail.es \\
\hline 98061059105 & JUAN PABLO CHAVARRO SANCHEZ & FUNZA & chavar.ro_98@hotmail.com \\
\hline 98073169852 & ALLISON NICOLLE RAMIREZ CONTRERAS & MOSQUERA & baby-446@hotmail.com \\
\hline 98051555597 & JEIMMY ALEXANDRA RIVERA AROCA & MOSQUERA & yeimi.arok17@gmail.com \\
\hline 1073245275 & LEYDY YOHANA HERNANDEZ HERNANDEZ & MOSQUERA & osiley@hotmail.com \\
\hline 97032304897 & INGRID YURLEY MACHETA LUNA & FUNZA & ingrid.luna230397@hotmail.com \\
\hline 98062760001 & JULIAN STEVEEN TORRES ROMERO & MOSQUERA & juliantorres553@gmail.com \\
\hline 98041259213 & DANIELA PUENTES ESPINOSA & MOSQUERA & daniela.puentesespinosa@hotmail.com \\
\hline 97030410711 & MONICA BIBIANA SALCEDO ALVARADO & FUNZA & ibis97@hotmail.com \\
\hline 97101718771 & AMY YIDNEY SANDOVAL AGUILAR & MOSQUERA & jeos17@hotmail.com \\
\hline 1073243898 & ADRIANA TORRES PERALTA & MOSQUERA & adri.9sister@hotmail.com \\
\hline 97090219832 & LAURA CAMILA ESCOBAR ALDANA & MOSQUERA & 1kamila_02@hotmail.com \\
\hline 97050716990 & LUISA FERNANDA ARANDIA OLIVAREZ & MOSQUERA & maffe_1997@hotmail.com \\
\hline 97100614395 & LAURA ISABEL FRANCO CHITIVA & MOSQUERA & laisfra_3@hotmail.com \\
\hline 98021864250 & DANYELA LISETH TRIANA GOMEZ & MOSQUERA & chiky.1998@hotmail.com \\
\hline 97122607538 & SHARRON STHEPHANY VISBAL ECHEVERRI & MOSQUERA & luisafdae@hotmail.com \\
\hline 1073224771 & NURY SIRLEY BENAVIDES RUIZ & MOSQUERA & nurysirley_1995@hotmail.com \\
\hline
\end{tabular}




\begin{tabular}{|c|c|c|c|}
\hline \multicolumn{4}{|c|}{ Aprendices Certificados en Formación Titulada } \\
\hline \multicolumn{2}{|c|}{ Fecha Inicial: 1/1/2014 Fecha Final: 31/12/2014 } & \multirow[b]{2}{*}{$\begin{array}{l}\text { Lugar de } \\
\text { Residencia }\end{array}$} & \multirow{2}{*}{$\begin{array}{c}\text { Programa: Recursos Humanos } \\
\text { Correo Electrónico }\end{array}$} \\
\hline $\begin{array}{l}\text { Número } \\
\text { Documento }\end{array}$ & Nombre Aprendiz & & \\
\hline 1070943705 & DIANA MILENA RUIZ RIAÑO & FACATATIVÁ & dmruiz50@misena.edu.co \\
\hline 1070944972 & EDISSON HERNAN RIVERA MOLINA & FACATATIVÁ & molina1011@hotmail.com \\
\hline 1070965148 & ANA MARIA MONTAÑO DELGADO & FACATATIVÁ & anamaria3634@gmail.com \\
\hline 1070964988 & PAULA KATHERINE AREVALO JIMENEZ & FACATATIVÁ & yeico527e@ hotmail.com \\
\hline 35526339 & ANGELICA SORAIDA URDANETA GONZALEZ & FACATATIVÁ & anguie_08@hotmail.com \\
\hline 1070974341 & CAROL JINNETHE HERNANDEZ GUTIERREZ & FACATATIVÁ & karitojinn.116@gmail.com \\
\hline 1077035392 & LUISA FERNANDA FORERO CORTES & FACATATIVÁ & lforero67@gmail.com \\
\hline 1070971803 & JENNY CAROLINA SALGADO QUINEME & FACATATIVÁ & jsalgadoqui@gmail.com \\
\hline 35531292 & ALBA YANETH RODRIGUEZ AREVALO & FACATATIVÁ & ayra-1978@ hotmail.com \\
\hline 1070962801 & ELSY VIVIANA BURITICA MACIAS & FACATATIVÁ & evburitica@misena.edu.co \\
\hline 1070959084 & VICTOR ALFONSO MEJIA ORDOÑEZ & FACATATIVÁ & vamejia48@misena.edu.co \\
\hline 52662519 & SANDRA SHIRLEY FUENTES COTRINA & MOSQUERA & sfuentescotrina@gmail.com \\
\hline 1022394993 & PEDRO ALEJANDRO SOTO GARZON & FUNZA & alejo55sg@hotmail.com \\
\hline 1073519071 & SANDRA YANETH CAÑON GARCIA & MOSQUERA & sandra37_@misena.edu.co \\
\hline 52663865 & LUZ ANGELA AMADO REYES & MOSQUERA & luzangelaamado@hotmail.com \\
\hline 52664776 & YEIMMY ALEJANDRA CASTILLO GALINDO & FUNZA & alejacastillo2613@hotmail.com \\
\hline 1073245156 & YESSIKA TATIANA VANEGAS POVEDA & MOSQUERA & tatianavanegas1996@gmail.com \\
\hline 1073168477 & ALMILKAR PEÑUELA VARGAS & MADRID & superp1965@hotmail.com \\
\hline 35394610 & SONIA ROCIO DUQUE GOMEZ & MOSQUERA & guimel456@hotmail.com \\
\hline 1113635562 & KAREN MUÑOZ VILLADA & FUNZA & karyto_14@hotmail.es \\
\hline 1073509554 & SANDRA MILENA MONTENEGRO SILVA & FUNZA & samimosi@gmail.com \\
\hline 1073170829 & JINETH KATHERINE RAMIREZ CONTRERAS & MADRID & jineth-34@hotmail.com \\
\hline 52664198 & SANDRA MILENA MORENO SANABRIA & MOSQUERA & sami-04@live.com \\
\hline 1073231934 & FREDY FERNANDO CASTILLO CADENA & FUNZA & fredcas77@hotmail.com \\
\hline 52984715 & MARICEL MUÑOZ CARDENAS & FUNZA & marym2605@hotmail.com \\
\hline 1032359712 & LILIANA FERNANDA LOPEZ GARIBELLO & MOSQUERA & liliana.lopez18@hotmail.com \\
\hline 1016067552 & CINDY GISELL AMAYA MONCADA & FUNZA & ciindyamayam@hc \\
\hline 1073515970 & $\begin{array}{l}\text { NERILLETH AYLIN CASTAÑEDA } \\
\text { HERNANDEZ }\end{array}$ & FUNZA & neryhernandez_1919_@hotmail.com \\
\hline 1090456298 & HENRY DANILO SEPULVEDA CORONEL & FUNZA & danilo.1492@hotmail.com \\
\hline 52730377 & ZULY ROCÍO DÍAZ DUARTE & MADRID & zulydi@gmail.com \\
\hline 1024462654 & LEIDY ALEXANDRA GOMEZ RICARDO & FUNZA & leialexa86@yahoo.es \\
\hline 1074131389 & CLAUDIA MILENA CRUZ HERNANDEZ & CAQUEZA & claumile0910@ @otmail.com \\
\hline 35394288 & MARYLUZ ORTEGA JIMENEZ & MOSQUERA & abrilde2001@yahoo.es \\
\hline 1007412078 & LUISA FERNANDA CUARTAS & MADRID & luisafer01@live.com \\
\hline 1073162950 & $\begin{array}{l}\text { YESSICA ALEXANDRA CRISTANCHO } \\
\text { HERNANDEZ }\end{array}$ & MADRID & ALEX01118@OUTLOOK.COM \\
\hline 1070960203 & YERALDIN PALACIOS RIAÑO & EL ROSAL & taniayerald192428@hotmail.com \\
\hline 1074186858 & LINDA CATHERINE CASTILLO PINZON & EL ROSAL & lindita100724@hotmail.com \\
\hline 1074186716 & LEIDY CAROLINA OSORIO & EL ROSAL & mijova2812@gmail.com \\
\hline 35536611 & YENNIS PAOLA RACINES CONRADO & EL ROSAL & stefany.0815@hotmail.com \\
\hline 1077035390 & DANIELA ALEJANDRA RODRIGUEZ MARIN & $\begin{array}{l}\text { SUBACHOQU } \\
\text { E }\end{array}$ & alejandra962011@hotmail.com \\
\hline 39545166 & DORA JANETH ALVAREZ RODRIGUEZ & BOGOTÁ & janethe68@hotmail.com \\
\hline 20959217 & CLAUDIA MILENA ALGARRA HERNANDEZ & $\begin{array}{l}\text { SUBACHOQU } \\
\text { E }\end{array}$ & algarraclaudiam17@hotmail.com \\
\hline 1077032713 & RUTH EMILSEN SCARPETA PULIDO & $\begin{array}{l}\text { SUBACHOQU } \\
\text { E }\end{array}$ & emilsens1088@hotmail.com \\
\hline 1077033686 & LUISA FERNANDA VELA BARACALDO & $\begin{array}{l}\text { SUBACHOQU } \\
\text { E }\end{array}$ & lfvelab@gmail.com \\
\hline 3086605 & NELSON MAURICIO CIFUENTES MORA & FACATATIVÁ & nemacimo123@hotmail.com \\
\hline 35519793 & ANA ISABEL JIMENEZ MORA & FACATATIVÁ & isajimenezmora@yahoo.es \\
\hline 177461 & JESUS ANTONIO CUERVO BARRERA & FACATATIVÁ & jesuscuervo@hotmail.es \\
\hline
\end{tabular}




\begin{tabular}{|c|c|c|c|}
\hline \multicolumn{4}{|c|}{ Aprendices Certificados en Formación Titulada } \\
\hline \multicolumn{2}{|c|}{ Fecha Inicial: 1/1/2014 Fecha Final: 31/12/2014 } & Programa: Recursos Humanos \\
\hline $\begin{array}{c}\text { Número } \\
\text { Documento }\end{array}$ & Nombre Aprendiz & $\begin{array}{c}\text { Lugar de } \\
\text { Residencia }\end{array}$ & Correo Electrónico \\
\hline 79755005 & CESAR ANDRES SUAREZ HERNANDEZ & LA DORADA & cesarandres.suarez@inpec.gov.co \\
\hline 1030603224 & MAYERLY MUNAR PEÑA & $\begin{array}{c}\text { AGUA DE } \\
\text { DIOS }\end{array}$ & maye.munar@gmail.com \\
\hline 13512407 & EDGAR AUGUSTO VILLAMIZAR CALA & BOGOTÁ & yoanarquia13@ hotmail.com \\
\hline 1070704542 & YENIFER CAROLINA ESPINOZA GONZALEZ & FACATATIVÁ & jeka1287@ hotmail.com \\
\hline 79134259 & JULIO CESAR SANCHEZ ZUÑIGA & FACATATIVÁ & juanmartinezc98@ gmail.com \\
\hline 11441349 & ALEXANDER GOMEZ BARRAGAN & FACATATIVÁ & alexgomezb11@ hotmail.com \\
\hline 11439689 & NELSON AUGUSTO LEÓN BAQUERO & FACATATIVÁ & juanmartinezc98@misena.edu.co \\
\hline 52662823 & SOFÍA ALEJANDRA CAMARGO BAQUERO & FACATATIVÁ & sac8181@hotmail.com \\
\hline 1069872014 & EDWIN ALEJANDRO ZARATE ROJAS & FACATATIVÁ & alexandrozarate10@hotmail.com \\
\hline
\end{tabular}

\begin{tabular}{|c|c|c|c|}
\hline \multicolumn{4}{|c|}{ Aprendices Certificados en Formación Titulada } \\
\hline \multicolumn{2}{|c|}{ Fecha Inicial: 1/1/2014 Fecha Final: 31/12/2014 } & \multirow[b]{2}{*}{$\begin{array}{c}\text { Lugar de } \\
\text { Residencia }\end{array}$} & \multirow{2}{*}{\begin{tabular}{|c|} 
Programa: Nomina y Pres Sociales \\
Correo Electrónico
\end{tabular}} \\
\hline $\begin{array}{c}\text { Número } \\
\text { Documento }\end{array}$ & Nombre Aprendiz & & \\
\hline 1073161792 & WILSON SNEIDER SEGURA CHISCO & MADRID & wilsonsegurach@hotmail.com \\
\hline 1014255119 & GINA KATERINE GOMEZ ACEVEDO & MADRID & katerine2105@hotmail.com \\
\hline 1070916943 & DEISY PAOLA ARIAS & COTA & paolirris88@gmail.com \\
\hline 1193133842 & CLAUDIA KATHERIN MARTINEZ CAMELO & FACATATIVÁ & kathe_kmelo@hotmail.com \\
\hline 1073235862 & CAROLINA LINEROS GARZON & BOGOTÁ & carolitolineros@hotmail.com \\
\hline 1073167103 & LILI MAYERLY FONSECA ALARCON & MADRID & lmfonsecaa@misena.edu.co \\
\hline 52664882 & JENNIFER PAOLA BUITRAGO ARIAS & FUNZA & paola_58mora@yahoo.es \\
\hline 1070968081 & NATHALIA CARRILLO & FACATATIVÁ & heavennathalia@hotmail.com \\
\hline 1121823025 & YULI ANDREA MACIAS & MOSQUERA & andreitamacias22@hotmail.com \\
\hline 1073164650 & LAURA ANDREA SANCHEZ GARCIA & MADRID & lauritahimura@hotmail.com \\
\hline 1070955817 & $\begin{array}{l}\text { LEIDY CONSTANZA MONROY RODRIGUEZ } \\
\end{array}$ & FACATATIVÁ & lady-2089@hotmail.com \\
\hline 20971482 & MARIBEL ORJUELA FORERO & FUNZA & mys2414@hotmail.com \\
\hline 96110904972 & THALIA SILVA RODRIGUEZ & FUNZA & thalia1910@hotmail.es \\
\hline 1057582481 & LAURA VANESSA VASQUEZ RODRIGUEZ & FUNZA & jaivane_89@hotmail.com \\
\hline 1070967502 & CAROL YINETH RODRIGUEZ PARRA & FACATATIVÁ & yinethr_16@hotmail.com \\
\hline 1030620524 & BRENDA STEPHANIA GARCIA BARRERO & BOGOTÁ & bsgarcia4@misena.edu.co \\
\hline 30406710 & NANCY LUCIA ARIAS CARDONA & MOSQUERA & arias-nancy@ hotmail.com \\
\hline 1073516995 & JOANA ROJAS BELTRAN & MOSQUERA & johana_6@misena.edu.co \\
\hline 1110086751 & ADRIANA ROCIO NIÑO OCAMPO & MADRID & rochimar1110@hotmail.com \\
\hline 53054836 & LEYDI TATIANA CASTIBLANCO RAMIREZ & MOSQUERA & tata836@gmail.com \\
\hline 1070978864 & ANNGYE PATRICIA RUSINQUE CUELLAR & FACATATIVÁ & rusinque390@gmail.com \\
\hline 97081812520 & BRAYAN STEVEN SEVILLA GUERRERO & FACATATIVÁ & stevensevilla1101@hotmail.com \\
\hline 1070978045 & WENDY YURANY SUAREZ MERCHAN & FACATATIVÁ & yurany199688@hotmail.com \\
\hline 1061793505 & ANGIE LILIANA VALLEJO COLLAZOS & FACATATIVÁ & VALLEJOANGIE10@ gmail.com \\
\hline 99051511901 & DANNY ALEXANDER VALLEJO COLLAZOS & FACATATIVÁ & VALLEJODANNY10@gmail.com \\
\hline 97093010713 & ERIKA TATIANA VIVAS PARADA & FACATATIVÁ & kikavivas@hotmail.com \\
\hline 1070975849 & FERNEY SEBASTIAN MOLANO RIAÑO & FACATATIVÁ & iluyherrera@gmail.com \\
\hline 1070977727 & CARLOS JULIO AREVALO AREVALO & FACATATIVÁ & cjarevaloa@misena.edu.co \\
\hline 1070970145 & EDGAR ANDRES CALIZ & FACATATIVÁ & andrescaliz2013@hotmail.com \\
\hline 1070969418 & DIEGO FERNANDO CHAVEZ RODRIGUEZ & FACATATIVÁ & diegoyk.do@gmail.com \\
\hline 1003689143 & CRISTIAN CAMILO CARDONA & FACATATIVÁ & cardonadj111@ @otmail.com \\
\hline 98091962411 & NICOLLE DANIELA MOLINA MARTINEZ & FACATATIVÁ & dani199838@ hotmail.com \\
\hline 1070976963 & BRIAN LEONARDO NUÑEZ GALLEGO & FACATATIVÁ & brian9952010@hotmail.com \\
\hline 98070552817 & PAULA ANDREA OSSO PUENTES & FACATATIVÁ & paula_andrea050719@hotmail.com \\
\hline 99010413270 & KAREN DANIELA PINZON HERNANDEZ & FACATATIVÁ & karen-99.ph@ hotmail.com \\
\hline 98101515907 & DANIEL ALBERTO ACUÑA FORERO & FACATATIVÁ & danie1981511@ hotmail.com \\
\hline 98070358824 & JHON ALEXANDER ALFONSO VARGAS & FACATATIVÁ & alfonso.jhon.10@gmail.com \\
\hline 98070156709 & ANDRES FELIPE CHAPARRO ORTIZ & FACATATIVÁ & pipelous1998@hotmail.com \\
\hline
\end{tabular}




\begin{tabular}{|c|c|c|c|}
\hline \multicolumn{4}{|c|}{ Aprendices Certificados en Formación Titulada } \\
\hline \multicolumn{2}{|c|}{ Fecha Inicial: 1/1/2014 Fecha Final: 31/12/2014 } & & Programa: Nomina y Pres Sociales \\
\hline $\begin{array}{c}\text { Número } \\
\text { Documento }\end{array}$ & Nombre Aprendiz & $\begin{array}{l}\text { Lugar de } \\
\text { Residencia }\end{array}$ & Correo Electrónico \\
\hline 97081214984 & CRISTIAN CAMILO CORREDOR GALLEGO & FACATATIVÁ & corredon1230@hotmail.com \\
\hline 97121823016 & DEISI CATERINE FONSECA PRIETO & FACATATIVÁ & fonseca.deisy.10@hotmail.com \\
\hline 1070974432 & BRIGITTE NEEFHER HENAO CHAVARRO & FACATATIVÁ & neferth12@hotmail.com \\
\hline 97122109821 & DIEGO HERNANDEZ HERNANDEZ & FACATATIVÁ & diego972013@hotmail.com \\
\hline 1070977040 & MICHAEL ALEXANDER MAHECHA MICAN & FACATATIVÁ & mahecha.maicol.10@gmail.com \\
\hline 97061823410 & JESICA MAYERLI MOLANO RIAÑO & FACATATIVÁ & yesikamolano@outlook.es \\
\hline 1070975389 & DIANA PAOLA PUENTES CARRERO & FACATATIVÁ & diana.5898@hotmail.com \\
\hline 52746401 & YULY PAOLA MARTINEZ RINCON & MOSQUERA & mpmartinezr@hotmail.com \\
\hline 1070975080 & YAMILE ANDREA ALFONSO BERNAL & FACATATIVÁ & andreitha_2001@hotmail.com \\
\hline 1073230651 & AIXA HERSILIA SANDOVAL NUÑEZ & MOSQUERA & aixa1226@hotmail.com \\
\hline 1010160792 & LADY JOHANNA ALVAREZ & BOGOTÁ & lajoalvarez@hotmail.com \\
\hline 1073515115 & LINA MARCELA RAMIREZ GONZALEZ & FUNZA & lina-marcela1551@hotmail.com \\
\hline 1012339704 & ALEXIS ROA SANABRIA & MOSQUERA & alexis.roa@hotmail.com \\
\hline 1073517418 & NANCY SEPULVEDA HORTUA & FUNZA & BONIS_FLAQUIS@HOTMAIL.COM \\
\hline 52663847 & SANDRA MILENA AFANADOR & FUNZA & sandramil.83@hotmail.com \\
\hline 1073244544 & OSCAR FERNANDO VARGAS RODRIGUEZ & MOSQUERA & millos.oscar01@yahoo.com.co \\
\hline 1073517617 & DEISY JOHANNA OROZCO JIMENEZ & FUNZA & deis_y2022@hotmail.com \\
\hline 1073508412 & MARIA ISABEL RIVERA GONZALEZ & FUNZA & mary_260628@hotmail.com \\
\hline 1073517615 & CINDY LORENA SALCEDO VELEZ & FUNZA & haz.by@hotmail.com \\
\hline 1070962060 & LUIS EDUARDO MACIAS NIÑO & MOSQUERA & luisnio2030@ hotmail.com \\
\hline 52770128 & NANCY LOPEZ CARDONA & BOGOTÁ & danjeis@ hotmail.com \\
\hline 1070974452 & CLAUDIA CAROLINA MONROY RODRIGUEZ & FACATATIVÁ & krola_0801@hotmail.com \\
\hline 1070963592 & OSCAR IVAN VELASQUEZ CASTRO & FACATATIVÁ & OSCARBLASQUEZ@HOTMAIL.COM \\
\hline 1066177162 & BRIYITH BANQUEZ RAMOS & MOSQUERA & briyiban94@hotmail.com \\
\hline 52663594 & MARIA ANGELICA JIMENEZ BARBOSA & FUNZA & angelica0329@hotmail.es \\
\hline 1026282415 & MAIRA LIZETH VEGA MARTINEZ & FUNZA & mairalin18@hotmail.com \\
\hline 1073235213 & TANIA MILENA BARAJAS PARRADO & MOSQUERA & tania_0077@yahoo.com \\
\hline 1073239810 & ERIKA YINETH SERRATO TRIANA & MOSQUERA & eri200510@hotmail.com \\
\hline 1073156740 & DUVAL ALBERTO TORRES OSPINO & FUNZA & datorres047@misena.edu.co \\
\hline 1073510288 & YENY LORENA ARROYO CELIS & FUNZA & arroyolorena91@gmail.com \\
\hline 1073517196 & MABEL ANGELICA RODRIGUEZ PENAGOS & FUNZA & mabe19594@hotmail.com \\
\hline 1073515397 & SHARON LISETETH RINCON QUINTANA & FUNZA & sharonrincon.1006@gmail.com \\
\hline 1073239752 & GISELL ANDREA CASTIBLANCO CASTAÑEDA & MOSQUERA & andreita-2911@hotmail.com \\
\hline 1053771110 & ERIKA YOHANA MARTINEZ QUINTERO & FUNZA & erikayohanam@hotmail.com \\
\hline 1073516164 & NIYIRET ASTRID GARCIA CORREDOR & FUNZA & astrid_2614@hotmail.com \\
\hline 1003338887 & LUZ KELY SALGADO CASILLO & $\begin{array}{c}\text { LA } \\
\text { APARTADA }\end{array}$ & luzkelly1108@hotmail.com \\
\hline 1073166590 & DANIEL ERNESTO SANABRIA CRISTANCHO & MADRID & danielernesto2494@hotmail.com \\
\hline 1073169641 & YURY ANDREA TORRES CAMARGO & MADRID & yurytc@misena.edu.co \\
\hline 1073153399 & MAIRA LILIANA NUMPAQUE ESPEJO & MADRID & mairaliliana13@gmail.com \\
\hline 1073168737 & DIANA MAYERLI GARZON SANCHEZ & MADRID & reveille_19@outlook.com \\
\hline 1073159986 & ERIKA CONSTANZA CUERVO VARGAS & MADRID & brain27@misena.edu.co \\
\hline 1073166605 & YESSIKA XIMENA BERNAL LEGUIZAMO & MADRID & ximenita181@hotmail.com \\
\hline 52874816 & ROCIO JOHANNA HERNANDEZ MONTAÑA & MADRID & soher@misena.edu.co \\
\hline 1073169362 & WENDY VIVIANA PATIÑO ROJAS & MADRID & wendyvivianap478@hotmail.com \\
\hline 1070960234 & LUZ ANGELA RUBIANO ARIAS & MADRID & lunadread1@hotmail.com \\
\hline 23823788 & ANA SOFIA CARRILLO HUERTAS & BOGOTÁ & anasofiacarrillo@hotmail.es \\
\hline 1073165504 & DIANA ISABEL ROMERO FANDIÑO & MADRID & dianita1608@hotmail.com \\
\hline 1073170182 & LUISA FERNANDA SANTIAGO HERRERA & MADRID & fernandasantiago15@hotmail.com \\
\hline 1073169620 & KELLY ZULAY PUIN PALMA & MADRID & kellypuin_795@hotmail.es \\
\hline 1073161513 & EDISSON LEONARDO LADINO GUTIERREZ & MADRID & e.llg@hotmail.com \\
\hline 1136909004 & LEIDY ROCIO BORBON HERRERA & FACATATIVÁ & lborbonherrera@yahoo.com.co \\
\hline 51993640 & ALBA VALERIA MORA ROA & FACATATIVÁ & albavaleria_7@ @otmail.com \\
\hline 1070958332 & NIDIA JAZMIN HERNANDEZ HERNADEZ & FACATATIVÁ & pocajontas82@hotmail.com \\
\hline 35534221 & SANDRA PATRICIA MALDONADO JIMENEZ & FACATATIVÁ & patriciamaldonadoj1982@ hotmail.com \\
\hline 1070972073 & ADRIANA MARCELA RUEDA ZABALETA & FACATATIVÁ & armarcelitha252@gmail.com \\
\hline 59650336 & JENNY ELIANA FLOREZ ASCUNTAR & FACATATIVÁ & jeneli_fa@hotmail.com \\
\hline
\end{tabular}




\begin{tabular}{|c|c|c|c|}
\hline \multicolumn{4}{|c|}{ Aprendices Certificados en Formación Titulada } \\
\hline \multicolumn{2}{|c|}{ Fecha Inicial: 1/1/2014 Fecha Final: 31/12/2014 } & & Programa: Nomina y Pres Sociales \\
\hline $\begin{array}{c}\text { Número } \\
\text { Documento }\end{array}$ & Nombre Aprendiz & $\begin{array}{c}\text { Lugar de } \\
\text { Residencia }\end{array}$ & Correo Electrónico \\
\hline 35535890 & LILIANA EMILCE RAMOS ORTEGA & FACATATIVÁ & mariaf200822@ hotmail.com \\
\hline 35353943 & ADRIANA YINETH PENAGOS SILVA & MADRID & adrianayinethpenagos@hotmail.com \\
\hline
\end{tabular}

\begin{tabular}{|c|c|c|c|}
\hline \multicolumn{4}{|c|}{ Aprendices Certificados en Formación Titulada } \\
\hline \multicolumn{2}{|c|}{ Fecha Inicial: 1/1/2015 Fecha Final: 30/9/2015 } & \multirow[b]{2}{*}{$\begin{array}{l}\text { Lugar de } \\
\text { Residencia }\end{array}$} & \multirow{2}{*}{\begin{tabular}{|c|} 
Programa: Seguridad Ocupacional \\
Correo Electrónico \\
\end{tabular}} \\
\hline $\begin{array}{c}\text { Número } \\
\text { Documento }\end{array}$ & Nombre Aprendiz & & \\
\hline 1071167228 & DIANA CRISTINA VENEGAS TOVAR & LA CALERA & leandroydiana09@gmail.com \\
\hline 1071164917 & MIGUEL J PIÑEROS DAZA & LA CALERA & migueljey@ hotmail.com \\
\hline 1073162500 & ANGUIE NATHALY GARAY ACOSTA & MADRID & nathalyacosta-29@hotmail.com \\
\hline 1073171064 & ANGIE ANGELICA YEPES CUERVO & EL ROSAL & angelicayepes14@hotmail.com \\
\hline 35355467 & FANNY JOHANA CALDERON OLARTE & MADRID & pulgalufer4@gmail.com \\
\hline 20739385 & DORA CECILIA ROJAS CESPEDES & MADRID & cecirojas2@hotmail.com \\
\hline 1078752095 & NIXA YULIETH PEÑA CABRERA & MADRID & nixajc93@hotmail.com \\
\hline 1073161173 & JULIETH ESTEFANY MOYA MORA & MADRID & Julieth-1991@ hotmail.com \\
\hline 1073161129 & CEYDE JANETH SANABRIA MARTINEZ & MADRID & sebbastian_kardona@hotmail.com \\
\hline 52558042 & BETTY VELOZA MORA & BOGOTÁ & bveloza@unigas.com.co \\
\hline 1070949300 & ANGELICA ASTRID CUBILLOS JIMENEZ & FACATATIVÁ & astridcaj_25@hotmail.com \\
\hline 1070952338 & YENNI ALEXANDRA RIAÑO VIRGUEZ & FACATATIVÁ & aleza6@yahoo.com.co \\
\hline 1070979143 & SAMARY YAMILE BELTRAN BAUTISTA & FACATATIVÁ & samarybeltran@gmail.com \\
\hline 1070978342 & DANIELA DEL PILAR ROA MARTINEZ & FACATATIVÁ & danielaroamartinez@hotmail.com \\
\hline 52815135 & NUBIA ELIZABETH VARGAS DURAN & FACATATIVÁ & nubiezita@yahoo.com \\
\hline 1070960379 & LEIDY KATHERINE TRIANA GONZALES & FACATATIVÁ & JUANLOZADA1991@HOTMAIL.COM \\
\hline 1070965487 & DAVID STEVEN FUENTES BAUTISTA & FACATATIVÁ & david.1793@hotmail.com \\
\hline 1070957579 & $\begin{array}{l}\text { KATHERINE MARCELA FERNANDEZ } \\
\text { PARRA } \\
\end{array}$ & FACATATIVÁ & kmfernandez97@misena.edu.co \\
\hline 1070978720 & ISMAEL ANDRES CASTAÑEDA CARDENAS & FACATATIVÁ & and_cng@hotmail.com \\
\hline 1070967911 & IVETH PAOLA RODRIGUEZ ENCISO & FACATATIVÁ & ivethenci@hotmail.com \\
\hline 1070966924 & JONATHAN DUVAN AGUDELO GIL & FACATATIVÁ & jonathan.agudelogil@gmail.com \\
\hline 1070981366 & DIEGO ANDRES BELTRAN VIVAS & FACATATIVÁ & diegoandresbeltranvivas@gmail.com \\
\hline 1073172878 & ANGIE LORENA HERNANDEZ ACOSTA & MADRID & lorenita2304@ hotmail.com \\
\hline 1070967682 & WENDY NIYIRETH CORTES & FACATATIVÁ & wencortes08@gmail.com \\
\hline 1026254734 & CLAUDIA LILIANA LONDOÑO OSORNO & FACATATIVÁ & claudialiliana1026@hotmail.com \\
\hline 1070976001 & ASTRID XIOMARA MACIAS SERRATO & FACATATIVÁ & xiomy_1296@hotmail.com \\
\hline 1074187516 & CARLOS ALBERTO PINEDA GARCIA & MADRID & pinedaDC_31@ @otmail.com \\
\hline 1070962880 & WENDY ROCIO QUIROGA CASTILLO & FACATATIVÁ & wquiroga20@hotmail.com \\
\hline 1070977237 & MARIA ALEJANDRA AGUILAR MORALES & FACATATIVÁ & maleja132009@hotmail.com \\
\hline 37392210 & SILVYA YULIETH CARDENAS PALENCIA & FUNZA & yulieth753@gmail.com \\
\hline 1073246157 & LAURA VANESA DUEÑAS PRIETO & MOSQUERA & lauravanesadue@outlook.com \\
\hline 1016012221 & EDICSON GIOVANNY BURGOS RAMIREZ & BOGOTÁ & edibmx22@gmail.com \\
\hline 1073509314 & LEIDY PAOLA RUIZ MONTOYA & MOSQUERA & lepao18@hotmail.com \\
\hline 1072895552 & JENNY KATHERINE GUTIERREZ GARCIA & MOSQUERA & jenngutierres1993@hotmail.es \\
\hline 1073514648 & LUISA FERNANDA MOSCOSO CUERVO & FUNZA & luu.0104@hotmail.com \\
\hline 1073243186 & $\begin{array}{l}\text { DIANA CAROLINA RODRIGUEZ } \\
\text { CONTRERAS }\end{array}$ & MOSQUERA & carito-995@hotmail.com \\
\hline 80657807 & HALVER ALEXANDER MURCIA PEÑA & FUNZA & black2090@ hotmail.com \\
\hline 1024508801 & JARED OSPINA NAVARRO & SOACHA & kamilajd_22@hotmail.com \\
\hline 1026566688 & LINA PAOLA MUÑOZ GRAJALES & MOSQUERA & 1pmunoz886@misena.edu.co \\
\hline 11366956 & CESAR ARLEY RAMIREZ GOMEZ & MADRID & diluna15@gmail.com \\
\hline 1016085039 & JULIETH DANIELA GONZALEZ PEÑA & BOGOTÁ & juli.dape16@hotmail.com \\
\hline 1085260046 & NANCY LISET MONCAYO HERNANDEZ & MOSQUERA & nancitanena01@ hotmail.com \\
\hline 1073235246 & JUANITA ALEJANDRA SOPO POSADA & FUNZA & juanitaalejandra1203@hotmail.com \\
\hline
\end{tabular}




\begin{tabular}{|c|c|c|c|}
\hline \multicolumn{4}{|c|}{ Aprendices Certificados en Formación Titulada } \\
\hline \multicolumn{2}{|c|}{ Fecha Inicial: 1/1/2015 Fecha Final: 30/9/2015 } & \multirow[b]{2}{*}{$\begin{array}{c}\text { Lugar de } \\
\text { Residencia }\end{array}$} & \multirow{2}{*}{$\begin{array}{c}\text { Programa: Seguridad Ocupacional } \\
\text { Correo Electrónico }\end{array}$} \\
\hline $\begin{array}{c}\text { Número } \\
\text { Documento }\end{array}$ & Nombre Aprendiz & & \\
\hline 1016066238 & LURY YIBEL SANTOS LOPEZ & MADRID & lurylopez.22@hotmail.com \\
\hline 1016088937 & KAREN LORENA OSPINA QUIROGA & BOGOTÁ & kareno-20@hotmail.com \\
\hline 1073519558 & ANGIE LORENA DAZA CASTILLO & BOGOTÁ & angielore-96@ hotmail.com \\
\hline 1073237074 & JESSICA PAOLA HUERFANO BETANCOURT & MOSQUERA & jeessikaa15@hotmail.com \\
\hline 1073238622 & ANDREA FERNANDA MELO GARCIA & MOSQUERA & meloandrea20@gmail.com \\
\hline 1072660386 & MARÍA XIMENA ARÉVALO RODRÍGUEZ & FUNZA & ximenita_1001@hotmail.com \\
\hline 52663651 & DIANA PILAR FORERO PENAGOS & FUNZA & dianae_8374@hotmail.com \\
\hline 1073236913 & PAULA ANDREA CALDERON PEÑARANDA & MOSQUERA & pkhtz2013@hotmail.com \\
\hline 20739026 & YENNY ALEXANDRA MEDINA MURCIA & MOSQUERA & yealmemu@ hotmail.es \\
\hline 38211763 & DIANA FERNANDA CELEMIN ARANGO & FUNZA & flacacel@hotmail.com \\
\hline 1073170170 & MICHEL XIMENA CHAVEZ HERNANDEZ & MADRID & princes_always@hotmail.com \\
\hline 80208350 & HUGO ANDRES CAMARGO CORREDOR & MADRID & hugokmargo@ hotmail.com \\
\hline 1073516647 & WUINDY JASBLEIDY GUZMAN BOLAÑOS & FUNZA & Wendyguzman1102@hotmail.com \\
\hline 1073167848 & KELY DISNEY BERNAL ORTIZ & MADRID & yeyibernal05@gmail.com \\
\hline 97072908728 & JUAN DIEGO GONGORA RUBIO & FUNZA & jdgongora88@gmail.com \\
\hline 1073245712 & ANGIE DORELLY RODRIGUEZ BARAJAS & MOSQUERA & angiedo1007@outlook.com \\
\hline 1073150197 & YENNY MARCELA GAONA BELTRAN & MADRID & MYJENNY_HELLO@HOTMAIL.COM \\
\hline 1072922059 & YENY ALEJANDRA ALFONSO LEAL & $\begin{array}{c}\text { SAN } \\
\text { FRANCISCO }\end{array}$ & yen-aleja@hotmail.com \\
\hline 1070960693 & ERIKA BEATRIZ JIMÉNEZ NIÑO & FACATATIVÁ & moniguis0491@hotmail.com \\
\hline 1070976542 & LUISA FERNANDA BOLIVAR NIETO & FACATATIVÁ & luisabolivar96@hotmail.com \\
\hline 1071330832 & DEICY YURANNI GOMEZ RODERO & FACATATIVÁ & deicygomezr@hotmail.es \\
\hline 35537824 & MONICA DEL PILAR AREVALO RAMOS & FACATATIVÁ & monik85402@ hotmail.com \\
\hline 1070956090 & LINA PAOLA ALONSO SANABRIA & FACATATIVÁ & linispao26@hotmail.com \\
\hline 1061714162 & YAMILETH ARTUNDUAGA MURCIA & FACATATIVÁ & yamisart@hotmail.com \\
\hline 1070960383 & LEIDY PAOLA ORJUELA CORREA & FACATATIVÁ & p-orj19@hotmail.com \\
\hline 35530034 & $\begin{array}{l}\text { YEIMY ALEXANDRA SCARPETA } \\
\text { RODRIGUEZ } \\
\end{array}$ & FACATATIVÁ & yeialexa23@hotmail.com \\
\hline 1070980838 & ANGIE YERALDIN HERNANDEZ FLOREZ & FACATATIVÁ & anyisitabluer@gmail.com \\
\hline 1070951436 & BRILLY TATIANA VELANDIA PEREZ & FACATATIVÁ & brinkytatu02@hotmail.com \\
\hline 1073165949 & MARCO TULIO ROMERO RUIZ & MADRID & yuni256@outlook.es \\
\hline 35530220 & FLORA CHAVISTA GONZALEZ & FACATATIVÁ & flordeiry_c08@hotmail.com \\
\hline 1070974633 & SIRLEY VANESSA PAEZ RUIZ & FACATATIVÁ & kiragis12@hotmail.com \\
\hline 1070953819 & YOLY DARIANA VANEGAS MARTINEZ & FACATATIVÁ & yolyvanegas89@hotmail.com \\
\hline 1070975779 & LAURA VALENTINA MANCIPE BARRERA & FACATATIVÁ & lauramancipe220810@hotmail.com \\
\hline 1081396771 & LUZ DEICY GRIJALBA TORO & FACATATIVÁ & nena-linda_87@hotmail.com \\
\hline 35529861 & NORMA CONSTANZA MAYORGA BECERRA & FACATATIVÁ & normacmayorga@hotmail.com \\
\hline 1070969154 & ANNIE LISETTE VELANDIA PEREZ & FACATATIVÁ & annie.v994@gmail.com \\
\hline 1073507890 & JAVIER ALONSO PACHECO GUZMAN & FUNZA & javier2002_pacheco@hotmail.com \\
\hline 52694625 & SANDY TATIANA LEON GOMEZ & FUNZA & santalego@hotmail.com \\
\hline 52660262 & ANA YANET RAMIREZ PINILLA & FUNZA & any.p.ramirez@hotmail.es \\
\hline 35537420 & SANDRA LILIANA MARTINEZ GUZMAN & MOSQUERA & sandralilianamartinez@outlook.com \\
\hline 79747526 & JOHN ANDERSON RAMIREZ MENDOZA & MADRID & johnander77@yahoo.es \\
\hline 1082215076 & DIANA MARIA ANDRADE MONTAÑEZ & FUNZA & dmandrade67@gmail.com \\
\hline 1073168901 & BRIAN DAVID FARFAN SANCHEZ & MADRID & farfan.1995@hotmail.com \\
\hline 52340652 & ANDREA FABIOLA BARRETO MORENO & BOGOTÁ & andreabarreto677@gmail.com \\
\hline 35537610 & CLAUDIA PATRICIA ROJAS LOPEZ & FUNZA & claudiapatriciahseq@gmail.com \\
\hline 1073164048 & LEIDY PATRICIA USAQUEN PRIETO & MADRID & leidyusaquen@hotmail.com \\
\hline 1073503153 & OSCAR RENE DIAZ MALDONADO & FUNZA & oscar19nov@hotmail.com \\
\hline 1073518837 & MONICA LEONOR VEGA ROMERO & MOSQUERA & monica_1236@ hotmail.com \\
\hline 80734545 & HERMIS ALEXANDER DUARTE PRIETO & FUNZA & alexander_duarte08@yahoo.es \\
\hline 1073168520 & STEFFANY FORERO GUERRERO & MADRID & teffi_1576@hotmail.com \\
\hline 1120578561 & LINA MARCELA LOPEZ OSPINA & FUNZA & lina-mar-182@hotmail.com \\
\hline
\end{tabular}




\begin{tabular}{|c|c|c|c|}
\hline \multicolumn{4}{|c|}{ Aprendices Certificados en Formación Titulada } \\
\hline \multicolumn{2}{|c|}{ Fecha Inicial: 1/1/2015 Fecha Final: 30/9/2015 } & \multirow[b]{2}{*}{$\begin{array}{c}\text { Lugar de } \\
\text { Residencia }\end{array}$} & \multirow{2}{*}{\begin{tabular}{|c|} 
Programa: Seguridad Ocupacional \\
Correo Electrónico
\end{tabular}} \\
\hline $\begin{array}{l}\text { Número } \\
\text { Documento }\end{array}$ & Nombre Aprendiz & & \\
\hline 7177799 & JAIME ALBERTO CASALLAS RUIZ & BOGOTÁ & jamesarmy2011@hotmail.com \\
\hline 76028715 & FREI DAVID MENA & TIMBIO & newtatoo2012@hotmail.com \\
\hline 52161041 & SONIA MILENA OSORIO GARCIA & FACATATIVÁ & sosorio@ citec.ws \\
\hline 1070962993 & LAURA NATHALI SOTO RODRIGUEZ & FACATATIVÁ & launatik111@hotmail.com \\
\hline 1070949931 & YINA PAOLA RIOS RODRIGUEZ & FACATATIVÁ & yiyisp17@hotmail.com \\
\hline 10186674 & CARLOS ALBERTO OSORIO GIRALDO & FACATATIVÁ & carlosalberto-26@hotmail.es \\
\hline 1057544561 & OSCAR SILVESTRE TORRES AVILA & ALMEIDA & oscar.santiago.torres.mateus.1210@hotmail.com \\
\hline 7707431 & JOSE GABRIEL VELASQUEZ RIVERA & FACATATIVÁ & josegaveri78@hotmail.com \\
\hline 80729938 & WILMAR GILBERTO LEON NEIVA & $\begin{array}{l}\text { VILLAGARZÓN } \\
\text { (VILLA } \\
\text { AMAZÓNICA) }\end{array}$ & oscarln1301@ hotmail.com \\
\hline 1022095041 & CARLOS ANDRES IBARRA VILLA & FACATATIVÁ & wizaribarra@hotmail.com \\
\hline 3104409 & DIEGO ARMANDO PERALTA DIAZ & NILO & agosto100485@hotmail.com \\
\hline 5864107 & LESLEY CAMPOS & FACATATIVÁ & Lecampos71@hotmail.com \\
\hline 74379820 & JULIO CESAR ALARCON QUINTERO & PAIPA & capi2304@hotmail.com \\
\hline 10492139 & DONEY BOLIVAR RUDA & FACATATIVÁ & valejoha2810@gmail.com \\
\hline 14695534 & DAVID ANDRES TRIANA MORENO & PALMIRA & davidtriana29@hotmail.com \\
\hline 52345673 & SANDRA PATRICIA ABRIL PATIÑO & FACATATIVÁ & mariarozo@citec.ws \\
\hline 1077035540 & JESSICA LORENA RODRIGUEZ GARCIA & SUBACHOQUE & jessicalo-24@hotmail.com \\
\hline 1077035572 & JOSE DUVAN GONZALEZ CAJICA & SUBACHOQUE & duvangonzaleznegro@ hotmail.com \\
\hline 1075682935 & KAREN SOFIA RODRIGUEZ ORTIZ & ZIPAQUIRÁ & kata_1824@hotmail.com \\
\hline 1076621576 & SINDY NATALIA AMORTEGUI RODRIGUEZ & TABIO & nataamortegui@hotmail.com \\
\hline 1076622120 & LINA MARITZA GIL ALEMAN & TABIO & linamary1990@outlook.com \\
\hline 1073521920 & XILENA LIZETH MACIAS CRUZ & FUNZA & xmaciasc@misena.edu.co \\
\hline 1073245890 & DIANA MARCELA ALDANA CANTOR & FUNZA & dianamaldana@misena.edu.co \\
\hline 52781194 & YENNY JOHANNA MENDEZ GUZMAN & BOGOTÁ & samyen@misena.edu.co \\
\hline 1052972574 & LILIBETH COMAS RIVERA & MOSQUERA & lilicomas_r9101@hotmail.com \\
\hline 1073171468 & JOHANA MARCELA CAICEDO RATIVA & MADRID & temarce@misena.edu.co \\
\hline 52127062 & ELSA ALARCON NUÑEZ & FUNZA & ealarcon26@misena.edu.co \\
\hline 80664309 & JAMES ARBEY VANEGAS VALDERRAMA & COTA & vanegasjames09@gmail.com \\
\hline 1016054131 & MIGUEL ANGEL PEREZ ROMERO & MOSQUERA & maperez131@misena.edu.co \\
\hline 1073235559 & $\begin{array}{l}\text { DIANA CAROLINA CAJAMARCA } \\
\text { CAJAMARCA }\end{array}$ & MOSQUERA & dccajamarca9@misena.edu.co \\
\hline 1122129313 & ESNEIDER ANDREY SUAREZ VARGAS & MADRID & djesnaky@gmail.com \\
\hline 1071168225 & SERGIO FELIPE CRUZ AVILAN & LA CALERA & SERGIOFELIPE_9409@HOTMAIL.COM \\
\hline 1070970917 & KAREM VIVIANA HERNANDEZ DELGADO & FACATATIVÁ & vivixlinda@ hotmail.com \\
\hline 1070978289 & LEIDY JOHANNA RODRIGUEZ PARADA & FACATATIVÁ & leidyrodriguez1822@gmail.com \\
\hline 1057588775 & LUDY YANILE SIERRA FERNANDEZ & FUNZA & lysf0924@hotmail.com \\
\hline 1104405743 & GENRRY ALEJANDRO SANTOS CASTILLO & BOGOTÁ & genrry.santos@gmail.com \\
\hline 1070979234 & ANGIE JIMENA TABLA ROJAS & FACATATIVÁ & ximena.xd@hotmail.com \\
\hline 1077035095 & ANGIE NATALIA MENDEZ GONZALEZ & SUBACHOQUE & anyell-nat.mg@ @otmail.com \\
\hline 1078370367 & ANGELA MARIA ISAZA GUTIERREZ & TABIO & angelami11@hotmail.com \\
\hline 1069098855 & LUZ MAYERLY SABIO FARFAN & TABIO & maysabio.10@hotmail.com \\
\hline 1050945935 & LIZETH PATRICIA GONZALEZ RODRIGUEZ & $\begin{array}{l}\text { MARÍA LA } \\
\text { BAJA }\end{array}$ & lpgonzalez53@misena.edu.co \\
\hline 1073244677 & LUISA JAZMIN ARÉVALO LOZANO & MOSQUERA & lulajazare04@hotmail.com \\
\hline 1073170815 & ANDRY BRIGITTE GARNICA ANGARITA & MADRID & andre.vivis@hotmail.com \\
\hline 1073172955 & DAVID LEONARDO PINILLA RUBIO & MADRID & dapinilla9716@gmail.com \\
\hline 1073165521 & GINA ALEJANDRA AREVALO CRUZ & MADRID & aleja.ac@hotmail.es \\
\hline 20916826 & LUZ NYDIA MOGOLLON CASTRO & MADRID & ositawhitex@yahoo.es \\
\hline 1073159267 & YESIKA LIZBETH RINCON BALLEN & MADRID & yessikota_@hotmail.com \\
\hline 1073165473 & LIZ ANGELICA SIERRA CAMARGO & MADRID & lizsierra93@hotmail.com \\
\hline 1073162640 & HEIDY FERNANDA HERNANDEZ CLAVIJO & MADRID & heidyfer0230@hotmail.com \\
\hline
\end{tabular}




\begin{tabular}{|c|c|c|c|}
\hline \multicolumn{4}{|c|}{ Aprendices Certificados en Formación Titulada } \\
\hline \multicolumn{2}{|c|}{ Fecha Inicial: 1/1/2015 Fecha Final: 30/9/2015 } & & Programa: Seguridad Ocupacional \\
\hline $\begin{array}{c}\text { Número } \\
\text { Documento }\end{array}$ & Nombre Aprendiz & $\begin{array}{c}\text { Lugar de } \\
\text { Residencia }\end{array}$ & Correo Electrónico \\
\hline 1073169623 & MIGUEL ANGEL RONDON DUQUE & MADRID & bekexha2595@gmail.com \\
\hline
\end{tabular}

\begin{tabular}{|c|c|c|c|}
\hline \multicolumn{4}{|c|}{ Aprendices Certificados en Formación Titulada } \\
\hline \multicolumn{2}{|c|}{ Fecha Inicial: 1/1/2015 Fecha Final: 30/9/2015 } & \multirow[b]{2}{*}{$\begin{array}{l}\text { Lugar de } \\
\text { Residencia }\end{array}$} & \multirow{2}{*}{$\begin{array}{c}\text { Programa: Recursos Humanos } \\
\text { Correo Electrónico }\end{array}$} \\
\hline $\begin{array}{c}\text { Número } \\
\text { Documento }\end{array}$ & Nombre Aprendiz & & \\
\hline 1074189461 & LEIDY YOHANNA LOBATON TORRES & EL ROSAL & johanalobatongnr@gmail.com \\
\hline 1073172120 & MARIA FERNANDA ROJAS SUAREZ & MADRID & mariafernanda.rojassuarez@yahoo.com \\
\hline 32763222 & MARIA EUGENIA PINTO BALLESTERO & FACATATIVÁ & gamolina5@misena.edu.co \\
\hline 25221612 & MARY LUZ VELANDIA HIDALGO & FACATATIVÁ & maryluzvelandia@hotmail.com \\
\hline 35536620 & DIANA MILENA HINCAPIE TRIANA & FACATATIVÁ & julianhulk11@ hotmail.com \\
\hline 1105680692 & JULIAN RICARDO RIOS CALDERON & FACATATIVÁ & julianriosrh@gmail.com \\
\hline 1070977251 & ANGIE CAROLINA HOLGUIN PALACIOS & FACATATIVÁ & ANGIELR.11@hotmail.com \\
\hline 1073514469 & JHON ALEXANDER OVALLE CASTAÑEDA & MOSQUERA & jhonalex.2010@hotmail.com \\
\hline 52783754 & NANCY YANETH PEREZ DUARTE & FUNZA & nancyjan28@hotmail.com \\
\hline 52617845 & MONICA MARIA PINEDA VELEZ & FUNZA & pmonicamaria@gmail.com \\
\hline 1073237859 & FRANCY CAROLINA PALACIOS CHEQUE & MOSQUERA & francy_palacios@hotmail.com \\
\hline 1073517194 & JOSE CAMILO TOBAR RODRIGUEZ & FUNZA & kmi9523@hotmail.com \\
\hline 35536566 & GRACE LIZET ROMERO RODRIGUEZ & FUNZA & lunaguato1503@hotmail.com \\
\hline 1073240071 & KATHERIN JOHANNA ACEVEDO PEREZ & MOSQUERA & ktjohana41@hotmail.com \\
\hline 1073520599 & JEISSON ESTEBAN NOVA PRADA & FUNZA & jeisonnova@misena.edu.co \\
\hline 39666610 & SANDRA CASTAÑEDA ZAMBRANO & FUNZA & nanitis69@hotmail.com \\
\hline 1073162075 & ADRIANA CRISTINA FORERO FARFAN & MADRID & metal_acff@hotmail.com \\
\hline 1074188110 & LEIDY PAOLA VELANDIA CORREDOR & EL ROSAL & lehidypahola@hotmail.com \\
\hline 1074188579 & JAIDER ALEXANDER TRIANA ROCHA & EL ROSAL & alexjaider@hotmail.com \\
\hline 1014187497 & FABIAN ARMANDO NEIRA HUERTAS & BOGOTÁ & fabian_neira@hotmail.es \\
\hline 1077035113 & INGRID LIZETH MOLINA MENDEZ & SUBACHOQUE & lizmolina07@hotmail.es \\
\hline 1070957957 & LIZETH JULIETH BARRERA VARGAS & FACATATIVÁ & liz-let0313@hotmail.com \\
\hline 1077035107 & ANGELA PATRICIA PINTO RODRIGUEZ & SUBACHOQUE & angelapinto16@hotmail.com \\
\hline 1077034986 & JEIMY LORENA RODRIGUEZ GONZALEZ & SUBACHOQUE & yeimy.loren@hotmail.com \\
\hline 1018406639 & EDITH SUSANA ALDANA ROBAYO & SUBACHOQUE & sasa_aldana@hotmail.com \\
\hline 1077034362 & SINDY PAOLA SALAMANCA GARCIA & SUBACHOQUE & sindyp162009@hotmail.com \\
\hline 1077035372 & LIDA CRISTINA GONZALEZ GOMEZ & SUBACHOQUE & lidagonzalez17@gmail.com \\
\hline 1070967847 & PAULA ANDREA CRUZ GOMEZ & MOSQUERA & lucilagomezflorido@hotmail.com \\
\hline 52146937 & MARTHA BIBIANA CAÑAS JIMENEZ & FUNZA & marthys73@hotmail.com \\
\hline 1073238224 & JEIMY ALEXANDRA GARZON CIFUENTES & MADRID & alexandra9421@hotmail.com \\
\hline 1073169358 & ANA MARÍA RODRIGUEZ BERNAL & MADRID & maria-ana97@hotmail.com \\
\hline 1031166857 & YENCI FABIANA RINCON DUARTE & MADRID & yenci.fabiana@gmail.com \\
\hline 1117965221 & DIANA MARCELA GIRALDO AGUIRRE & MADRID & diamarga_1989@hotmail.com \\
\hline 1073171578 & JOHN ALEXANDER GOMEZ PEDRAZA & MADRID & alexis9986@hotmail.com \\
\hline
\end{tabular}




\begin{tabular}{|c|c|c|c|}
\hline \multicolumn{4}{|c|}{ Aprendices Certificados en Formación Titulada } \\
\hline \multicolumn{2}{|c|}{ Fecha Inicial: 1/1/2015 Fecha Final: 30/9/2015 } & & Programa: Recursos Humanos \\
\hline $\begin{array}{c}\text { Número } \\
\text { Documento }\end{array}$ & Nombre Aprendiz & $\begin{array}{c}\text { Lugar de } \\
\text { Residencia }\end{array}$ & Correo Electrónico \\
\hline 1016050134 & SULINT YOMARA HUI FERNÁNDEZ & MOSQUERA & shuif@ucentral.edu.co \\
\hline 1073519783 & CINDY VANESA CONTRERAS BAUTISTA & FUNZA & vanesacontrerasmac@gmail.com \\
\hline 1073166546 & CARLOS HUMBERTO PULIDO TORRES & MADRID & kharlox201@hotmail.com \\
\hline 1073518107 & VIVIANA CATHERINE CORTES TORRES & FUNZA & vivi.cortes23@hotmail.es \\
\hline 38288129 & MARIA EUGENIA HINCAPIE LEON & MADRID & mariaehincapiel@gmail.com \\
\hline 1073243459 & JONATHAN SMITH BARON PORTAL & MOSQUERA & jonatanportale@gmail.com \\
\hline 53038618 & ADRIANA MILDRED AMELIA ARGUELLES REY & FUNZA & adrimil.arguellesrey@outlook.es \\
\hline 1073157084 & BRENDA PAOLA GARCIA ESTUPIÑAN & MADRID & paholitagarcia3004@gmail.com \\
\hline 1070967121 & LEIDY PAOLA CARPETA CASTRO & MADRID & leidy78978@hotmail.com \\
\hline 20716142 & ESTHER MILENA MARTINEZ CALDAS & MOSQUERA & stermilena@hotmail.com \\
\hline 52830881 & SANDRA YANETH GORDILLO URQUIJO & MADRID & jeri121728@hotmail.com \\
\hline 1073160268 & ANGIE PAOLA SANABRIA RIAÑO & MADRID & angies1122@hotmail.com \\
\hline 1073517052 & ANGELY VANESSA GARCIA OSUNA & FUNZA & AngelyStrong_12@hotmail.com \\
\hline 1073167839 & PAOLA ANDREA ABRIL MENDIVELSO & MADRID & cerezaframbuesa_15@hotmail.com \\
\hline 1073521536 & DAMAR DAVID MARTINEZ VELANDIA & FUNZA & David.Martinezjah@gmail.com \\
\hline 1073161822 & YERALDIN ISAZA RODRIGUEZ & MADRID & yeral.520@hotmail.com \\
\hline 52664157 & YEINY ANDREA LEON RAMOS & MADRID & natha.0306@hotmail.com \\
\hline 1073511847 & MERY ANDREA SARMIENTO CORTES & MOSQUERA & meryk16_@hotmail.com \\
\hline 35354316 & YEIMMY NATALIA SEGURA MORALES & MADRID & nata.segu@hotmail.com \\
\hline 1075660032 & ANGY XIOMARA SANCHEZ ROJAS & MOSQUERA & angiesan69@gmail.com \\
\hline 1073150560 & OLGA LUCIA BOTIA VILLATE & MADRID & lucy.891@hotmail.com \\
\hline 1070980556 & YULI ALEXANDRA SANCHEZ ORTIZ & FACATATIVÁ & yulialexandra68@gmail.com \\
\hline 1073168140 & FABIAN STIVEN GARCIA HERRERA & MADRID & fabian.nirvana1130@hotmail.com \\
\hline 35355597 & CONSUELO CAMARGO PALOMINO & MADRID & consuelo.1985@hotmail.com \\
\hline 1070979864 & MARIA ALEJANDRA GARZON RIVERA & FACATATIVÁ & alejandragarzonrivera@hotmail.com \\
\hline 1070977190 & CATERINE TATIANA ACOSTA PRADA & FACATATIVÁ & niretak120@hotmail.es \\
\hline 1073167750 & NASLLY DAYAN DIAZ SANTANA & MADRID & dayanalove-894@hotmail.com \\
\hline 1032395113 & ANGELICA MATILDE BULLA MARIN & MADRID & kittenangelik@hotmail.com \\
\hline 1073245318 & ANGELICA MARIA CHAPARRO MELO & MOSQUERA & angelicachaparrom@hotmail.com \\
\hline 1016074119 & TERESA HASBLEIDY LEON ACOSTA & MOSQUERA & teresita.hasbleidy@hotmail.com \\
\hline 1070977980 & DAYANA MAITE OSORIO RINCON & FACATATIVÁ & angiemeliza1605@hotmail.com \\
\hline 1073151279 & DAHIAN RODRIGUEZ CEBALLOS & MADRID & dahian2823@hotmail.com \\
\hline 1070954591 & CLAUDIA MARCELA MARTINEZ HORTUA & FACATATIVÁ & marcelastar17@hotmail.com \\
\hline 1071162731 & EDNA JOHANNA CORTES ESPINEL & LA CALERA & johis860716@hotmail.com \\
\hline 1071162598 & NELLY ESPERANZA FLOREZ SANCHEZ & LA CALERA & nellyflorez23@hotmail.com \\
\hline 1071169642 & DERLY JOHANA CIFUENTES GONZALEZ & LA CALERA & derly_gonzalez.2@hotmail.com \\
\hline 79883600 & DEIBY DANILO VELOZA PINZON & LA CALERA & daniloveloza@hotmail.com \\
\hline 52662201 & SANDRA MILENA RIAÑO ROZO & FUNZA & sandrar27@hotmail.com \\
\hline 1073506742 & $\begin{array}{c}\text { A } \\
\text { NYELA CAROLINA ROBAYO GOMEZ }\end{array}$ & FUNZA & anyela313@hotmail.com \\
\hline 1073514190 & LINA MARCELA NIETO BUITRAGO & FUNZA & liina_marcela_94@hotmail.com \\
\hline
\end{tabular}




\begin{tabular}{|c|c|c|c|}
\hline \multicolumn{4}{|c|}{ Aprendices Certificados en Formación Titulada } \\
\hline \multicolumn{2}{|c|}{ Fecha Inicial: 1/1/2015 Fecha Final: 30/9/2015 } & Programa: Recursos Humanos \\
\hline $\begin{array}{c}\text { Número } \\
\text { Documento }\end{array}$ & Nombre Aprendiz & $\begin{array}{c}\text { Lugar de } \\
\text { Residencia }\end{array}$ & Correo Electrónico \\
\hline 1074189413 & DIEGO FABIAN RODRIGUEZ ROBAYO & EL ROSAL & diegofabia08@gmail.com \\
\hline 1049372886 & LUIS EDUARDO CORDON MEDINA & EL ROSAL & wualdo172@gmail.com \\
\hline 1074189125 & DORA LILIANA CORTES RUBIANO & EL ROSAL & correoinformatica@gmail.com \\
\hline 52662475 & CLAUDIA MARCELA LAGUNA GALEANO & MOSQUERA & marcealanice@ @otmail.com \\
\hline 1073172378 & ANGELA ENITH TRUJILLO VALDERRAMA & MADRID & angelita9679@hotmail.com \\
\hline 1003703993 & YULIED PAOLA SUA CHAPARRO & MOSQUERA & ypsua3@misena.edu.co \\
\hline 1070974858 & ANGIE MARCELA PALACIOS MENDEZ & FACATATIVÁ & marcela-palaciosmendez@ hotmail.com \\
\hline 26478203 & ADIELA COCA MONROY & COLOMBIA & adicm51983@hotmail.com \\
\hline
\end{tabular}

\begin{tabular}{|c|c|c|c|}
\hline \multicolumn{4}{|c|}{ Aprendices Certificados en Formación Titulada } \\
\hline \multicolumn{2}{|c|}{ Fecha Inicial: 1/1/2015 Fecha Final: 30/9/2915 } & \multirow[b]{2}{*}{$\begin{array}{c}\text { Lugar de } \\
\text { Residencia }\end{array}$} & \multirow{2}{*}{\begin{tabular}{|c|} 
Programa: Nomina Pres Sociales \\
Correo Electrónico
\end{tabular}} \\
\hline $\begin{array}{c}\text { Número } \\
\text { Documento }\end{array}$ & Nombre Aprendiz & & \\
\hline 1073507900 & SANDRA MARCELA SEVILLA FAJARDO & FUNZA & sebyjor-1@hotmail.es \\
\hline 20654729 & CAROLINA GUZMAN SABOGAL & MADRID & caguza82@hotmail.com \\
\hline 1073165862 & MARIA HELENA JIMENEZ RINCON & MADRID & maria_jimrin10@hotmail.com \\
\hline 1073169250 & MARIA CAMILA BALLEN MENDEZ & MADRID & kami0694@gmail.com \\
\hline 1070976045 & ANGIE CAROLINA CUTA LARA & FACATATIVÁ & angie.carolina_14@hotmail.com \\
\hline 1070972494 & SINDY KATHERINNE LEON ESCOBAR & FACATATIVÁ & sindy9577@ hotmail.com \\
\hline 1070963375 & YESSICA KATHERINE CHACON VERDUGO & FACATATIVÁ & ye-k-a15@hotmail.com \\
\hline 1070945725 & ALEXANDRA BOTON BARON & FACATATIVÁ & pocahontas8701@ @otmail.com \\
\hline 1070959733 & DIANA PAOLA CADENA PEREZ & FACATATIVÁ & dianis1633@hotmail.com \\
\hline 1074616740 & SHYRLEY DAYANA MOLINA PICHIMATA & ZIPACÓN & shirley_15.12@hotmail.com \\
\hline 1070977086 & CAROL ANDREA SIERRA PINEDA & FACATATIVÁ & andrehitasierra@ hotmail.com \\
\hline 1073162830 & JUDITH GERALDI MORALES MORA & MADRID & fliper175@hotmail.com \\
\hline 1073164439 & LIBARDO SALAMANCA JIMENEZ & MADRID & 1salamanca93@hotmail.com \\
\hline 1073159748 & ADRIANA DIAZ CALDERON & MADRID & adrianadical@ hotmail.com \\
\hline 1073510139 & CRISTINA RIVEROS ACUÑA & MOSQUERA & kristina.122012@hotmail.com \\
\hline 1073507099 & YEIMI YOHANNA ARANDIA GARCIA & MOSQUERA & joisfr@hotmail.com \\
\hline 1073170998 & YEISON FABIAN SANCHEZ HILARION & MOSQUERA & yeisonfabian96@hotmail.com \\
\hline 1073502165 & JULY KATERINE RUBIANO SOPO & MOSQUERA & katerinerubiano03@gmail.com \\
\hline 35394111 & ANGELA DAYANA LANCHEROS SARMIENTO & FUNZA & dayannis@hotmail.com \\
\hline 52664381 & ERIKA MARCELA SIERRA VEGA & MOSQUERA & emsierra1@misena.edu.co \\
\hline 1081402794 & NORBY YUVERICA TRUJILLO TRUJILLO & FUNZA & norby8905@hotmail.com \\
\hline 35521351 & MARTHA LUCIA FANDIÑO LEON & MOSQUERA & marthafo67@hotmail.com \\
\hline 1073503488 & NATALY RINCON RODRIGUEZ & FUNZA & natar_19@hotmail.com \\
\hline 39771145 & FANNY TRIANA MORENO & MADRID & fannyt9473@hotmail.com \\
\hline 1073241667 & GLORIA JULIETH RICO MONTENEGRO & MOSQUERA & gloria.124@ hotmail.com \\
\hline 35220396 & MARTHA NIDIA GUTIERREZ PINZON & LA CALERA & nidiagutierrez78@gmail.com \\
\hline 23964402 & HERMINDA ROJAS CHAVEZ & LA CALERA & daherosan@yahoo.es \\
\hline 35220969 & LUZ ADRIANA VENEGAS TRUJILLO & LA CALERA & luzyaya_1980@hotmail.com \\
\hline 52664446 & MONICA MARIA FRANCO LOPEZ & FUNZA & moni_franco84@hotmail.com \\
\hline 1070950590 & EDGAR JAVIER CASTRO RUIZ & FACATATIVÁ & JAVIERGATO3220@HOTMAIL.COM \\
\hline 1073160871 & MARGARITA ROSA TORRES MORALES & MADRID & margaritarosat.m@hotmail.com \\
\hline
\end{tabular}




\section{ANEXO 2}

\section{Encuesta Social de Caracterización ó Ficha de Caracterización}

\section{Cordial saludo.}

Apreciados aprendices SENA, por medio de este módulo reconoceremos las principales necesidades de los miembros SENA, con el fin de mejorar la relación y entendimiento de los mismos, fortaleciendo la atención oportuna y pertinente a los requerimientos del entorno.

Recordamos que la información registrada será de uso confidencial la cual será trabajada por cada uno de los expertos en el tema de nuestros Centros de Formación y Regionales.

A continuación encontrará la encuesta de caracterización de aprendices matriculados. Por favor diligenciar esta encuesta completa sin dejar espacios en blanco. En las casillas en que deba digitar información, por favor hacerlo en mayúsculas sostenidas, sin puntos ni comas (ejemplo: números de identificación 1123456789).

\section{A. Información Personal}

1. Nombres y Apellidos del aprendiz

Escriba en letras mayúsculas y continuas

2. Tipo de documento

- C.C. Cédula de Ciudadanía

- T.I. Tarjeta de Identidad

- C.E. Cédula de Extranjería

3. Número de Documento

- Número de Documento: Campo que muestra el número de documento de identidad del usuario que se está registrando en SOFIA Plus.

4. Fecha de Nacimiento

\section{$\mathrm{Dd} / \mathrm{mm} / \mathrm{aaaa}$}

5. Lugar de Nacimiento

6. Sexo

- Femenino

- Masculino

7. Correo

8. Teléfono de Contacto

9. Dirección y Nombre del Barrio/Vereda

10. Municipio

11. Departamento

B. Aspectos de vivienda

12. Clase de vivienda

- Propia

- Familiar

- Arrendada

- Albergue

- Pensión (Inquilinato)

13. ¿En qué sector se encuentra ubicado su residencia? 
- Rural

- Urbana

14. ¿Cuál de las siguientes problemáticas afecta al sector en el cual está ubicada su vivienda?

- Venta y consumo de drogas

- Delincuencia común

- Pandillismo

- Prostitución

- Paramilitarismo

- Guerrilla

- Otra

C. Seguridad social

15. ¿Está inscrito en el SISBEN?

- $\mathrm{Si} / \mathrm{No}$

16. ¿Está usted afiliado al régimen contributivo de salud?

- Contributivo

- Subsidiado

- Otros

17. Nombre de la EPS

18. Pertenece a algún programa de gobierno

- Familias en acción

- Jóvenes en acción

- ACR (Agencia Colombiana para la reintegración)

- Restitución de tierras

- Otro. ¿Cuál?

D. Perfil ocupacional

19. Trabaja actualmente

- $\mathrm{Si} / \mathrm{No}$

20. Tipo de contrato

- Jornal o destajo

- Contrato por prestación de servicios

- Contrato laboral

- Informal

- Ninguno

- Fines de semana solamente

21. Teniendo en cuenta el SMMLV (\$689.455), calcule el rango total de ingresos de su hogar.

- $\quad$ Menos de 1 SMMLV

- $\quad$ Entre 1 y 2 SMMLV

- $\quad$ Entre 2 y 4 SMMLV

- $\quad$ Entre 3 y 5 SMMLV

- Más de 5 SMMLV

22. ¿Recibe algún tipo de apoyo por parte del estado o institución?

- Familias en acción

- Subsidio Jóvenes en Acción

- Subsidio de Reinserción

- Pensión Asistencial

- Pensión de Invalidez 
- Subsidio de Tercera Edad

- Subsidio de Desplazados

- Subsidio de Familias en Acción

- Subsidio por Desplazamiento

- Apoyo de sostenimiento

- Otros

E. Habilidades básicas

23. ¿Cuál de las siguientes actividades ocupa su tiempo libre?

- Iglesia

- Deportes

- Televisión, Redes sociales, Navegar en la Web

- Música

- Viajes

- Artes 


\section{ANEXO 3 \\ ENCUESTA DE EGRESADOS}

Por favor, dedique unos minutos a completar esta encuesta. La información que nos proporcione será utilizada para conocer el estado actual de los estudiantes egresados. Sus respuestas serán tratadas de forma confidencial y solo serán utilizadas para ayudarnos a mejorar. Esta encuesta dura aproximadamente 5 minutos.

1. ¿Cuál es su edad?

16-18 años

19-20 años

21-22 años

23-25 años

25 años o más años

2. ¿Cuál es su sexo?

Masculino

Femenino

3. Vinculación actual al sistema de salud

Cotizante

Beneficiario

Sisben

4. Ocupación laboral

Empleado

Independiente

Vacante

5. Nombre de la empresa

6. ¿En qué área desempeña en la empresa?

Recursos Humanos

Nomina y Prestaciones sociales

Seguridad Ocupacional

Otros

7. ¿Cuál es el cargo que desempeña actualmente?

8. ¿A cargo aspira en la empresa?

9. ¿En qué municipio se encuentra laborando? (Elija uno)

Bogotá DC

Municipios de Cundinamarca

Otro Departamento

Ninguna de las anteriores 
10. ¿Cuál es su ubicación residencial? (Elija una)

Bogotá DC

Municipios de Cundinamarca

Otro Departamento

Ninguna de las anteriores

Ninguna de las anteriores

11. Tipo de vivienda

Familiar

Propia

Arrendada

12. ¿Cuál es su ingreso mensual?

$\$ 0-\$ 700000$

$\$ 700001-\$ 1200000$

$\$ 1200001-\$ 1800000$

$\$ 1800001-\$ 3000000$

\$3000001 o más

13. ¿Ha recibido apoyo de la Agencia Pública de Empleo Sena (APE) para su ubicación laboral?

Sí

No

14. ¿Cuál ha sido su mayor dificultad en cuanto a las competencias que desarrolla en el cargo?

Competencias Laborales (Conocimiento- Habilidades)

Competencias Transversales (Comportamiento-Convivencia)

Competencias Sociales (Relacionamiento)

Ninguna

15. ¿Continua en contacto con sus compañeros del SENA?

$\mathrm{Si}$

No

Dentro de su proyección profesional a corto plazo desea:

Continuar la cadena de formación en el SENA

Ser profesional

Ser emprendedor

Otra

16. Participa en alguna actividad diferente al desempeño de su cargo en la empresa donde trabaja:

Cultural

Deportiva

Sindicato

Brigada de emergencia

otro 
17. ¿Desea hacer algún comentario?

Muchas gracias por su opinión.

Si quiere proporcionarnos sus datos personales para realizar un seguimiento de sus respuestas, pueden hacerlo a continuación. No olvide que esto es voluntario.

Autoría de la investigadora. 